

\section{DOCUMENT AVAILABILITY}

Reports produced after January 1, 1996, are generally available free via the U.S. Department of Energy (DOE) Information Bridge.

Web site http://www.osti.gov/bridge

Reports produced before January 1, 1996, may be purchased by members of the public from the following source.

National Technical Information Service

5285 Port Royal Road

Springfield, VA 22161

Telephone 703-605-6000 (1-800-553-6847)

TDD 703-487-4639

Fax 703-605-6900

E-mail info@ntis.gov

Web site http://www.ntis.gov/support/ordernowabout.htm

Reports are available to DOE employees, DOE contractors, Energy Technology Data Exchange (ETDE) representatives, and International Nuclear Information System (INIS) representatives from the following source.

Office of Scientific and Technical Information

P.O. Box 62

Oak Ridge, TN 37831

Telephone 865-576-8401

Fax 865-576-5728

E-mail reports@osti.gov

Web site http://www.osti.gov/contact.html

This report was prepared as an account of work sponsored by an agency of the United States Government. Neither the United States Government nor any agency thereof, nor any of their employees, makes any warranty, express or implied, or assumes any legal liability or responsibility for the accuracy, completeness, or usefulness of any information, apparatus, product, or process disclosed, or represents that its use would not infringe privately owned rights. Reference herein to any specific commercial product, process, or service by trade name, trademark, manufacturer, or otherwise, does not necessarily constitute or imply its endorsement, recommendation, or favoring by the United States Government or any agency thereof. The views and opinions of authors expressed herein do not necessarily state or reflect those of the United States Government or any agency thereof. 
Energy and Transportation Science Division

\title{
Making Homes Part of the Climate Solution: Policy Options to Promote Energy Efficiency
}

\author{
Marilyn A. Brown, * Georgia Institute of Technology \\ Jess Chandler, Georgia Institute of Technology \\ Melissa V. Lapsa, Oak Ridge National Laboratory \\ Moonis Ally, Oak Ridge National Laboratory
}

June 2009

\author{
Prepared by \\ OAK RIDGE NATIONAL LABORATORY \\ Oak Ridge, Tennessee 37831-6283 \\ managed by \\ UT-BATTELLE, LLC \\ for the \\ U.S. DEPARTMENT OF ENERGY \\ under contract DE-AC05-00OR22725
}

*Corresponding author:

Dr. Marilyn A. Brown

Professor, School of Public Policy

Georgia Institute of Technology

DM Smith Building

685 Cherry Street, Room 312

Atlanta, GA 30332-0345

email: marilyn.brown@pubpolicy.gatech.edu

Phone: 404-385-0303 



\section{Table of Contents}

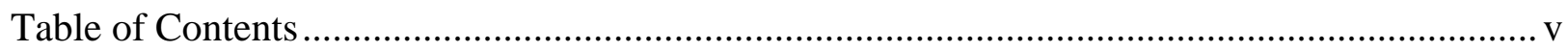

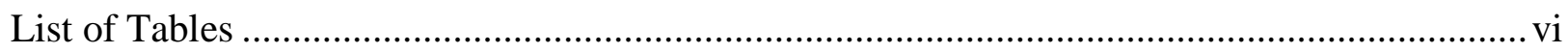

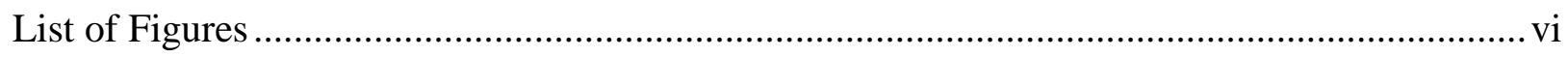

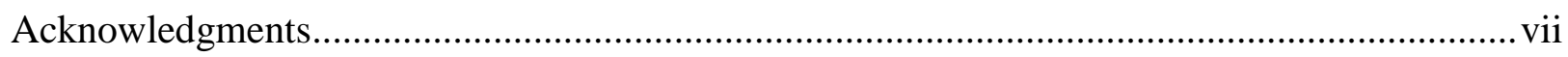

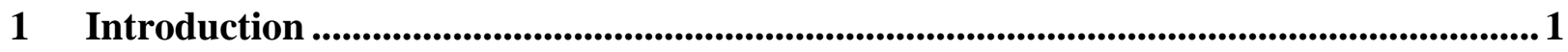

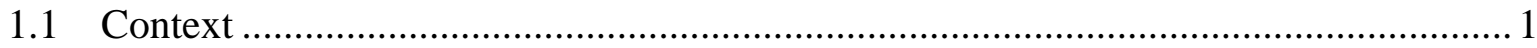

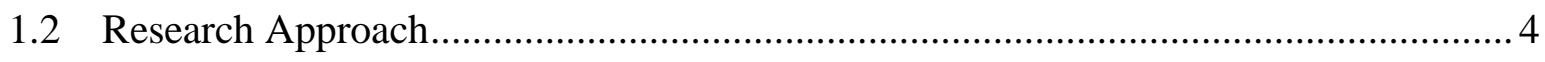

2 Policy Options to Promote Energy Efficient Residential Construction ...........................9

2.1 Advancing and Enforcing State Building Energy Codes ....................................... 10

2.2 Expanded Use of Home Energy Performance Ratings .......................................... 21

3 Policy Options to Promote Energy-Efficient Improvements to Existing Residences ................................................................................................331

3.1 Mandated Disclosure of Energy Performance Information .................................... 32

3.2 On-Bill Financing of Energy-Efficiency Improvements ...................................... 49

4 Utility-Based Policy Options to Promote Energy-Efficient Residential Buildings....... 63

4.1 Performance Specifications for Smart Meters and Expanded Demand Response ...... 64

4.2 Alignment of Utility Financial Incentives with Customer Energy Efficiency ........... 76

4.3 National Energy Efficiency Resource Standard (EERS) ...................................... 82

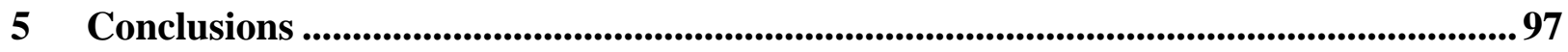

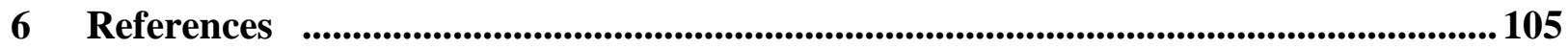




\section{List of Figures}

1.1 Projected Change in Carbon Dioxide Emissions by Sector, 2009-2030 .......................2

1.2 Federal Policies to Reduce GHGs in Buildings, by Type of Policy and Measure............. 3

2.1 Status of Residential and Commercial State Energy Codes as of February 2009 .......... 12

2.2 Costs and Savings in New Residential and Commercial Construction, 2010-2030 ........ 18

3.1 Energy Rating Form in use in Denmark .......................................................... 36

3.2 Progress Energy Example Energy Analysis Graph: "Most Recent 12 Months

Compared to Previous 12 Months ............................................................................ 46

3.3 Conceptual Organization of an "On-Bill Financing" Program .................................... 50

Fannie Mae Energy Loan Process............................................................................. 52

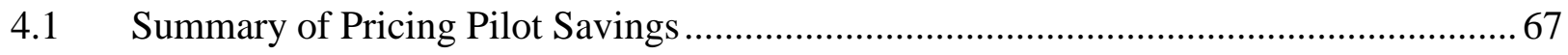

4.2 Supply and Demand Curves in (A) Normal Markets vs. (B) Capacity-Constrained

Markets with Perfectly Inelastic Demand ......................................................... 70

4.3 Example of Flow Chart of How to Measure Societal Benefits..................................... 72

4.4 Comparison of Estimated Range of Benefits and Costs of

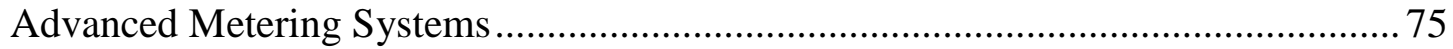

4.5 Status of Decoupling Requirements Across States in 2008 ...................................... 81

4.6 Energy Efficiency Resource Standards in the States .......................................... 83

5.1 Timeline of Anticipated Energy Savings from Alternative Policy Targets ................... 97

\section{List Tables}

1.1 Markets Addressed by the Seven Policy Options ................................................. 6

2.1 Incremental Cost Estimates for Residential Energy Code Compliance.......................... 19

2.2 Existing Occupied Housing Units by Census Region, 2005-2007 ..............................26

$2.3 \quad$ What does the HERS Number Mean? ................................................................. 27

2.4 Energy Savings required to Recover the Cost of Rating ..........................................29

3.1 Existing Occupied Housing Units and Home Sales by Census Region, 2005-2007 ....... 41

3.2 Vintage of Occupied Housing Units in the United States, 2007................................. 43

3.3 Estimated Utility Bill Savings after Switching to ENERGY STAR or

Best Available Technology ................................................................................. 44

4.1 Estimates of U.S. Efficiency Potential as a Percent of End-Year

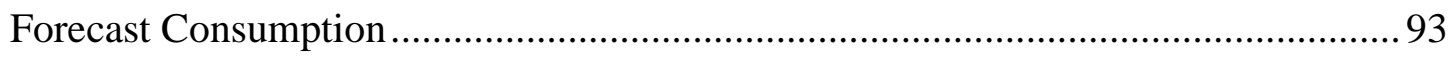

5.1 Summary Assessment of Policy Options ............................................................... 98

5.2 Complementariness of the Seven Policy Options ................................................. 102 


\section{ACKNOWLEDGMENTS}

This report was sponsored by the U.S. Climate Change Technology Program (CCTP). We wish to acknowledge Dr. Robert Marlay, Director of the U.S. Department of Energy's Office of Science and Technology Policy and Deputy Director of CCTP, who saw the value in funding this study and who contributed to its design and execution. Similarly, we thank Lindsay Roland who was an important contributor to the report's scope and content, and helped navigate through multiple revisions.

Several colleagues took the time to review this study, and their insights and feedback are greatly appreciated:

- Jean Boulin (DOE Building Technology Program)

- Jerry Dion (DOE Building Technology Program)

- Patrick Hughes (Oak Ridge National Laboratory)

- Larry Mansuetti (DOE Office of Electricity)

- Andrew Nicholls (Pacific Northwest National Laboratory)

- Paul Stern (National Academies)

- Ed Vine (California Institute for Energy and Environment)

This report would not have been possible without the involvement of the behavioral workshop participants who provided valuable background on non-technical explanations for the existence of an energy efficiency gap. In addition to most of the experts listed above, the workshop participants included the following individuals:

- Karen Ehrhardt-Martinez (American Council for an Energy-Efficient Economy)

- Mark Freidrichs (DOE Climate Change Technology Program)

- Jeff Harris (Alliance to Save Energy)

- Kathryn Janda (Oxford University)

- Skip Laitner (American Council for an Energy-Efficient Economy)

- Loren Lutzenhiser (Portland State University)

- Sean McDonald (Pacific Northwest National Laboratory)

- Christopher Payne (Lawrence Berkeley National Laboratory)

- Graham Pugh (DOE Climate Change Technology Program)

- Linda Schuck (California Institute for Energy and Environment)

In addition, Joan Pellegrino and Matt Antes from Energetics Incorporated helped to facilitate the workshop and to summarize its findings. Elise Logan (Federal Energy Regulatory Commission) and Nilgun Atamturk (California Public Utilities Commission) also merit acknowledgment. They were both graduate research assistants at the Georgia Institute of Technology in 2008, and they both contributed significantly to this project.

Finally, we wish to thank Charlotte Franchuk for assistance with the report's references and formatting. Her attention to the details of manuscript production was invaluable. 
June 2009 


\section{INTRODUCTION}

In the area of energy efficiency, advanced technologies combined with best practices appear to afford not only large, but also cost-effective options to conserve energy and reduce greenhouse gas emissions (McKinsey \& Company, 2007). In practice, however, the realization of this potential has often proven difficult. Progress appears to require large numbers of individuals to act knowledgeably, and each individual must often act with enabling assistance from others. Even when consumer education is effective and social norms are supportive, the actions of individuals and businesses can be impeded by a broad range of barriers, many of which are nontechnical in nature.

Title XVI of the Energy Policy Act of 2005 included a mandate to examine barriers to progress and make recommendations in this regard. A detailed report on barriers as well as the National strategy for overcoming barriers met this requirement (Brown et al, 2008; CCCSTI, 2009). Following up on this mandate, the U.S. Climate Change Technology Program (CCTP) chose to focus next on the development of policy options to improve energy efficiency in residential buildings, with supporting analysis of pros and cons, informed in part by behavioral research. While this work is sponsored by CCTP, it has been undertaken in coordination with DOE's Building Technologies Program and Office of Electricity Delivery and Energy Reliability.

\subsection{Context}

Residential buildings account for about 21 percent of U.S. energy use and energy-related $\mathrm{CO}_{2}$ emissions (EIA, 2009, Tables A2 and A18). Over the long term, buildings are expected to continue to be a significant component of increasing energy demand and, both directly and indirectly, a major source of $\mathrm{CO}_{2}$ emissions (Figure 1.1). This is driven in large part by the continuing trends of population increase, economic recovery and growth, urbanization, and rising standards of living. In the U.S. the need for energy efficiency is made both more urgent and intractable by the longevity of building stocks. 


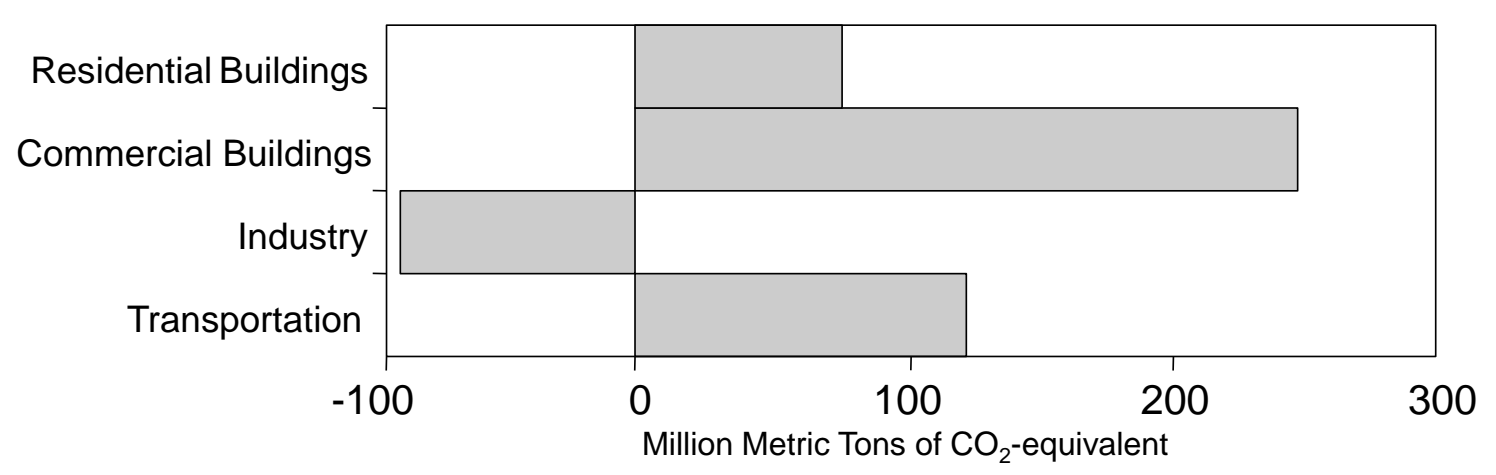

Figure 1.1 Projected Change in Carbon Dioxide Emissions by Sector, 2009-2030

(Source: EIA, 2009)

As the U.S. population grows, a substantial amount of new housing will be added - perhaps as many as 20 to 30 million new units are expected to be built between 2005 and 2030. In addition, much building equipment and many structural features of the existing housing stock will be upgraded over the next several decades. It would seem wise to design, build, and refurbish this infrastructure with exemplary energy performance and supporting behavioral accommodations, lest opportunities for efficiency improvements are lost (Dirks et al., 2008).

A total of 124 Federal policies, programs, and measures are currently in place to encourage more efficient use of energy in buildings. ${ }^{1}$ Most prominent among these Federal deployment activities are a range of labeling and information dissemination programs. There are also 20 or more Federal activities targeting GHG reductions in buildings that involve coalitions and partnerships; tax policy and other financial incentives; education, training, and workforce development; and market conditioning. Relevant Federal policies also include power rates offered by the Bonneville Power Administration, Tennessee Valley Authority and other federal power producers that typically do not pass along real-time power prices to residential consumers. In addition the federal government influences mortgage interest tax deductions that encourage increased home sizes, and highway construction programs that promote sprawl at the expense of mixed-use transit oriented development. State and local policies also have wide-ranging influences on residential markets, sometimes promoting climate-smart development patterns and building practices, but often favoring low-density, energy-intensive land use development.

\footnotetext{
${ }^{1}$ Source: CCTP/Energetics Deployment Inventory Database dated June 5, 2009. For a description of these deployment activities, see CCCSTI (2009).
} 


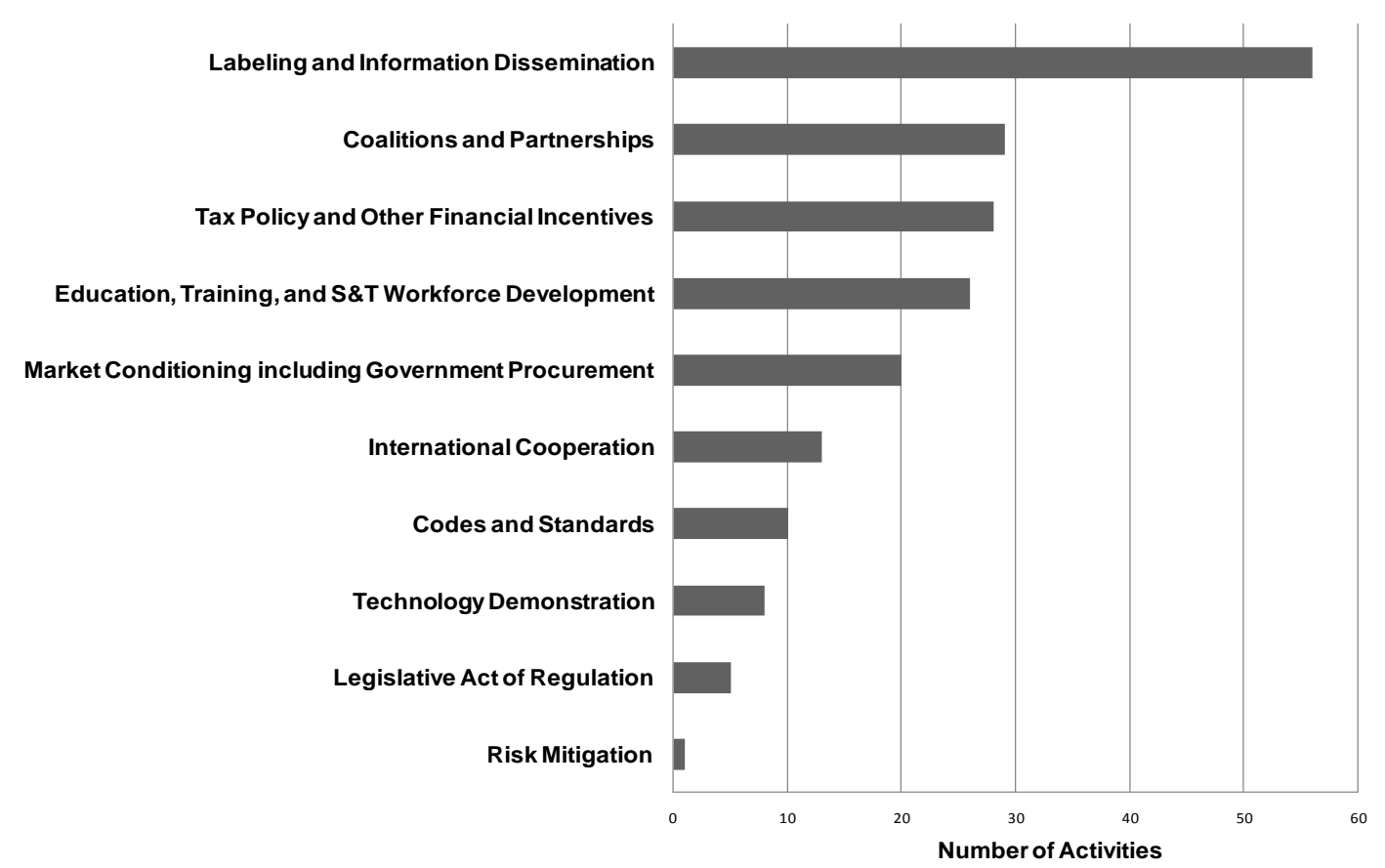

Source: CCTP/Energetics Deployment Inventory Database dated June 5, 2009.

Note: Some activities fit into more than one category, so the total count exceeds the total number of

\section{Figure 1.2 Federal Policies to Reduce GHGs in Buildings, by Type of Policy and Measure}

These activities can facilitate significant potential savings when the products of Federal research and development efforts are picked up in the marketplace. For example, an analysis of the 2005 DOE Building Technologies program budget estimated savings in the residential sector of 560 TBtu by 2030 (Scott et al, 2008). ${ }^{2}$ However, there are still many opportunities for improving efficiency that are not being explored. One recent National estimate of energy savings in residential buildings found the techno-economic potential to be 30 percent for electricity and 28 percent for natural gas over "business-as-usual" in 2030 (Brown, R. et al., 2008). New policies may be needed to address effectively non-technical and behavioral barriers that continue to thwart the more rapid diffusion and greater adoption of cost-competitive, low-carbon buildings technologies in the residential sector.

Consumers have been found to be largely unaware of the relationships between their lifestyles, energy consumption, and the environment (Garrett and Koontz, 2008). Behavioral-related studies have shown that individuals do not know how much energy appliances or their homes use, do not know where energy comes from, assume new appliances are efficient, do not consider energy when they make purchasing decisions, and focus on up-front costs (Lutzenhiser, 2009; DEFRA, 2007; McKeown, 2007).

\footnotetext{
${ }^{2}$ This estimate is based on two DOE residential programs: Building America and Building Energy Codes
} 
Research on residential energy consumption suggests the following general lessons according to Stern (2008a, b):

- "The influences on behavior are quite varied and do not fall in the domain of any one discipline (economics, psychology, etc.)

- The pattern of influences on behavior can vary greatly with the behavior

- The strongest influences on behavior are often contextual (building structure, available technology, home ownership, legal and regulatory requirements, material costs and rewards, convenience, etc.)

- The more a behavior is shaped by context, the weaker the effect of personal factors

- Behaviors are often not chosen; many are habitual

- When choices are made, they are not often carefully considered

- The most productive approach to understanding these behaviors is multidisciplinary"

The purposes of this effort are to (1) revisit the overall situation in light of a growing body of recent social and behavioral research and to (2) examine a series of proposed remedies in the form of policy options and supporting analysis. This work is motivated, in part, by an increased sense of urgency regarding the need to improve energy efficiency, lower consumer energy expenditures, moderate pressures for new energy supply, and reduce greenhouse gas emissions and their associated environmental effects.

\subsection{Research Approach}

This research project began with a literature review and assessment of barriers to the deployment of greenhouse gas mitigation technologies (Brown et al., 2008). The review built on a foundation of similar efforts, including the Office of Technology Assessment's 1992 report on Buildings Energy Efficiency; DOE Office of Policy's 1996 report, "Policies and Measures for Reducing Related GHG Emissions: Lessons from Recent Literature," and the ACEEE Buildings Summer Study Proceedings from 2008. A review article on behavioral issues in energy-efficient buildings was also commissioned from Paul Stern of the National Academies (Stern, 2008a).

This literature review, in turn, helped inform the design of a "Buildings Workshop on Behavioral Research and Energy Use" that was held in February 2008 in Washington, DC. The purpose of the workshop was to obtain a broad understanding of socio-economic aspects of energy consumption in buildings as a basis for more informed greenhouse gas mitigation policy recommendations by CCTP. After various presentations and brainstorming sessions, the workshop's 15 expert participants were asked to identify potentially effective policies for further 
consideration. Follow-on discussions with several workshop participants and others helped identify a dozen policy options for further consideration. The selection and design of these policy options was informed by past research on the human dimension of energy use - a domain ignored by most policies that seek only to incrementally change particular end-uses in the techno-economic arena (Parnell and Larson, 2005; Kempton and Niemann, 1987).

In order to evaluate and narrow the set of the candidate policy options, the following seven criteria were applied.

1) Appropriateness of the Federal role. Many of the more effective policy options and measures in this area require State or local action, as the jurisdictional responsibilities reside most strongly at this level of governance. However, State and local action may be encouraged by supportive Federal policy options and measures. Clarity must be provided with respect to specificity and appropriateness of the Federal role.

2) Broad Applicability. Since the number of proposed policy options and measures to be analyzed is small, but their impact is derived to be large, the options selected for analysis should have broad applicability across the National scene, encouraging action at a fairly comprehensive scale.

3) Significant Potential Benefits. Policy options and measures with significant and early quantitative benefits are to be favored over those with later and fewer benefits.

4) Solutions not Dependent on Future R\&D. The policy options and measures selected should address barriers and/or risks of mainly an institutional, policy, or non-technical nature. The answers to some non-technical barriers, such as lack of enablers, may reside in the technological arena, but the barrier itself should not be seen primarily as a technology R\&D limitation.

5) Cost Effectiveness. In the analysis, both costs and benefits must be weighed. In the selection of policy options to study, consideration should be limited to those that would be expected to have reasonable costs, a strong social benefit, and a relatively high benefit-to-cost ratio.

6) Administrative Practicability. For policy options to be implemented, they need to be capable of being fairly easily established and, if necessary, managed and/or enforced. Some may require special training or expertise, broadly applied across the nation. Some approaches can be focused on a limited set of players in the delivery system. Such implementation factors are considered here.

7) Additionality. The collection of selected policy options should be diverse, such that each option represents a somewhat different approach to a barrier or to different market segments. Thus, each policy option is evaluated in terms of the independent contribution it could make above and beyond the influences of existing policies.

Brief assessments of the 12 policy options were prepared covering these seven criteria. A short list of seven policies resulted, which are described in this report (Table 1.1). As the following table shows, these policies address various parts of the residential building market, especially 
existing homes. In addition, several of these policies could be helpful in promoting energy efficiency economy-wide. A national energy efficiency resource standard, in particular, could have far-ranging impacts in commercial and industrial markets as well as in the housing market.

Table 1.1 Markets Addressed by the Seven Policy Options

\begin{tabular}{|c|c|c|c|c|c|}
\hline & $\begin{array}{c}\text { New } \\
\text { Residential } \\
\text { Construction }\end{array}$ & $\begin{array}{c}\text { Existing } \\
\text { Homes }\end{array}$ & $\begin{array}{c}\text { Gas \& } \\
\text { Electric } \\
\text { Utilities }\end{array}$ & $\begin{array}{c}\text { Commercial } \\
\text { Buildings }\end{array}$ & $\begin{array}{c}\text { Industrial } \\
\text { Facilities }\end{array}$ \\
\hline \multicolumn{6}{|c|}{ Policy Options to Promote Energy Efficient Residential Construction } \\
\hline $\begin{array}{l}\text { Advancing and } \\
\text { Enforcing State Building } \\
\text { Energy Codes }\end{array}$ & & & & & \\
\hline $\begin{array}{l}\text { Expanded Use of Home } \\
\text { Energy Performance } \\
\text { Ratings }\end{array}$ & 0 & & 0 & & \\
\hline \multicolumn{6}{|c|}{ Policy Options to Promote Energy-Efficient Improvements to Existing Residences } \\
\hline $\begin{array}{l}\text { Mandated Disclosure of } \\
\text { Energy Performance } \\
\text { Information }\end{array}$ & $\bigcirc$ & & & 0 & \\
\hline $\begin{array}{l}\text { On-Bill Financing of } \\
\text { Energy-Efficiency } \\
\text { Improvements }\end{array}$ & & & & & \\
\hline \multicolumn{6}{|c|}{ Utility-Based Policy Options to Promote Energy-Efficient Residential Buildings } \\
\hline $\begin{array}{l}\text { Performance } \\
\text { Specifications for Smart } \\
\text { Meters and Expanded } \\
\text { Demand Response }\end{array}$ & $\bigcirc$ & 0 & & & 0 \\
\hline $\begin{array}{l}\text { Alignment of Utility } \\
\text { Incentives with } \\
\text { Customer Energy } \\
\text { Efficiency }\end{array}$ & $\bigcirc$ & & & & 0 \\
\hline $\begin{array}{l}\text { National Energy } \\
\text { Efficiency Resource } \\
\text { Standard (EERS) }\end{array}$ & & & & & \\
\hline
\end{tabular}

= Primary market; $\bigcirc$ = Secondary market

No policy option is free of issues or sensitivities. There are typically pros and cons; benefits and costs. There will be segments of society and the economy that may gain, others may not, and dislocations may occur. In the process of debating the merits of policy options, these cross 
currents of concern will manifest themselves in vigorous policy debates from all sides. In considering policy options, a priori, these issues and sensitivities should be made clear to those considering them, before they go forward into full-scale public view, whether in the form a rulemaking, proposed legislation, or even as administrative actions. The format of this policy options report is intended to allow these issues to be made visible, illustrated by analysis, and clearly understood.

The savings from a combination of these policies will be complementary (slightly overlapping in cases), but necessarily so as sets of policies work together to enable and then transform the market by reaching many actors and helping overcome their barriers. Four conditions are assumed to be necessary to enable a particular energy saving option (such as installing additional insulation or purchasing more efficient windows): the option must be available; adopters must have sufficient knowledge about the option (unless the option is required by law); restrictions or barriers to adoption must be removed; and adopters must be motivated to invest in the option (Boonekamp, 2006). A combination of policy instruments - including information, economic measures, and enabling administrative and technology changes would be useful to foster energy efficient behavior (Linden, Carlsson-Kanyama, and Eriksson, 2006). To make sufficient headway, individual householder self-interest, energy knowledge, and cognitive capacity should be considered in the design of energy conservation policies (Parnell and Larsen, 2005).

Establishing a National Energy Efficiency Resource Standard (EERS) will have an economywide impact, and a percentage of savings will be applied to the residential sector. In the presence of an EERS, other policies to reduce consumption in the residential buildings sector would likely add up to meet and/or exceed the target. Home energy performance ratings, mandatory disclosure of home energy performance, and smart meters can reduce information barriers and help consumers make a more conscious approach to energy consumption; these policies can increase consumer knowledge about energy without over-taxing their cognitive skills. However, changes will be limited by financial and market barriers - consumers face relatively low aggregate energy prices, and both consumers and providers face risky returns for investing in more efficient technology if it is not the norm. Policies to improve building code compliance can ease market barriers and establish a ceiling for future home energy performance. Dynamic pricing structures can provide incentives to consumers to make it in their self-interest to change their consumption behavior while on-bill financing can relieve stress on consumers from high first costs, high discount rates, and lack of access to capital. Policies to remove utility disincentives to investing in customer energy efficiency can encourage greater utility involvement in a transition to a more efficient energy economy.

Further understanding of interactions can be achieved through ongoing monitoring and evaluation of policies in the field. Because products, practices and prices all change over time, the policies in place to move the market will have to be resilient and adaptive. 


\section{Policies to Promote Energy Efficient Residential Construction}

During the design and construction of homes and apartment complexes, opportunities for energy efficiency exist that become prohibitively expensive and technically infeasible once the structure is complete (Dirks et al., 2008). This suggests that a premium should be placed on energyefficient residential construction. In reality, newly constructed homes often do not benefit from "best practices," as represented by the technologies and design features embodied in the code recommendations of the International Energy Conservation Code (Lowe and Oreszczyn, 2008). These "lost opportunities" result from a range of complex barriers including industry fragmentation, misplaced incentives, incomplete and asymmetric information, and lack of a knowledgeable workforce (Brown et al., 2008).

The construction industry is large, diverse, and fragmented with numerous players whose interests often do not align. Nearly 500,000 homebuilders operate each year; the five largest of these account for less than seven percent of new homes, while the top 100 account for just another seven percent (DOE/EERE, 2003). Besides builders, decision-makers influencing the construction industry also include investors, owners, occupants, tradesmen, architects, equipment manufacturers, suppliers, lenders, insurers, codes and standards setters, zoning officials, realtors, and so forth. This means that a large number of firms and individuals need to be influenced to have a significant collective impact because those engaged in building design and construction generally have little interaction with each other. The result is lack of information awareness among builders, consumers, and specialists in the building process (Alliance to Save Energy, 2005; Loper et al., 2005).

The numerous participants in the decision-making process have distinct interests, they impact the process at different points in design, construction and use, and they often act as decision-making intermediaries who do not represent the long-term interests of building owners and occupants (CCCSTI, 2009; Brown et al., 2009). In the case of new buildings, developers and speculative builders emphasize the need to limit construction costs and disregard the need to constrain operating costs, since their financial interests end with the sale of the building. This is a classic example of misplaced incentives, or the principal-agent problem. These decision criteria hinder investments in energy-efficient designs and technologies that require a greater up-front investment to achieve lower life-cycle operating costs. Energy-efficient building technologies are most affordable when installed during the construction phase; achieving post-construction energy savings can be comparatively expensive and technically challenging.

Many green building technologies are cost effective on a life cycle basis but are often not adopted because builders and consumers do not know if higher up front expenditures in improved building design will translate to increased value or equity in the property later. The 
public is generally accepting/supportive of improved home energy efficiency, but their understanding of policies and technologies is limited (Raven et al., in press). Thus, speculative builders invest in houses with the hope of attracting homebuyers; higher up-front costs associated with "green" features may not be valued by home buyers due to complexities associated with decisions such as home purchases and the inability to "warrant" efficiency levels. Builders who adopt more efficient technologies face greater market risks because their costs are higher and they do not know whether the market will clear these higher costs. Greater understanding of non-energy benefits and market dynamics could drive adoptions of more efficient building practices (Jakob, 2006). Similarly, widespread compliance can simultaneously reduce market risks and incremental costs.

In the buildings industry, there is also a workforce training gap. Few builders or tradespeople have access to sufficient training in new technologies, new standards, new regulations, and best practices. Lowe and Oreszczyn (2008) describe this lack of knowledge as a remnant of the shift of the construction industry from one of apprenticeship to one of labor, and they offer that the industry will need to become a producer of human capital in order to support a new generation of residential buildings. Local government authorities tend to face this difficulty as well with building code officials working without skills necessary to evaluate compliance with building energy codes.

The result of these market barriers and obstacles is a large reservoir of lost opportunities for improving the energy efficiency of U.S. housing. The following policy options would help address barriers to energy efficiency in residential construction practices.

\subsection{Advancing and Enforcing State Building Energy Codes}

Policy Option: Expand technical assistance to States to accelerate their adoption of advanced building energy codes. Subject to available funds, provide financial assistance to establish and expand training and certification programs focused on third-party verification of building energy code compliance.

\subsubsection{Synopsis of Policy Option}

A vigorous Federal effort is required to accelerate the promulgation of flexible and advanced State building energy codes and to ensure that compliance is thorough. A two-pronged Federal approach is proposed here.

Expand technical assistance to States to accelerate their adoption of advanced building energy codes. Providing technical assistance to ensure that advanced energy codes are adopted across the country brings the industry of professionals who are designing, supervising, and constructing 
buildings into a consistent framework that recognizes the need for region- and climate-specific energy solutions while at the same time ensuring economics of regulation. Uniform adoption and enforcement of codes also reduces market risks, ensuring that no one builder takes on all the first-of-a-kind costs while others reap the benefits; over time, improved building construction practices can reduce technical risks as builders and users "learn-by-doing." DOE could support accelerated building code adoption by States by expanding the technical assistance activities of its Building Codes Assistance Program.

Provide technical and financial assistance (subject to available funds) to establish and expand training and certification programs focused on third-party verification of building energy code compliance. Strong compliance efforts can reduce the ability of building owners to avoid meeting strict building energy code guidelines in order to keep their costs down; this is especially a concern when the initial owner or builder will not bear the future energy costs over the years the building remains in use. Third-party verification (also called assessment or inspection) is required for the National Green Building Standard, recently developed under the ANSI process and approved by ANSI. ${ }^{3}$ Federal technical and financial assistance could support development of a third-party verification industry as well as liaisons to work with the third-party verifiers, the construction industry, and local officials charged with building permitting. Compliance training will be an essential part of this policy, at least in its infancy. The effectiveness of this training could be greatly enhanced by the provision of (1) technical assistance to train the trainers and develop common training modules, and (2) financial assistance to offset some of the costs of providing and taking the training.

Recognizing the need to upgrade and enforce building energy codes, the American Recovery and Reinvestment Act (ARRA) requires governors who want a share of State energy assistance grants to certify their State will adopt an energy code for one- and two-family homes, townhouses and low-rise, multiple-family buildings that meets or exceeds provisions in the 2009 IECC for residential construction, and the ANSI/ASHRAE/IESNA Standard 90.1-2007, as referenced in the 2009 IECC for commercial buildings. DOE is currently in the process of determining whether or not adoption of the 2009 IECC for commercial buildings is sufficient to meet this requirement, as there are differences between the 2009 IECC and Standard 90.1-2007 for commercial buildings. The ARRA also requires governors to certify that they will put in place a plan to achieve compliance with their certified energy codes within eight years in at least 90 percent of new and renovated residential and commercial building space. The required plan is also to include training and enforcement programs. ${ }^{4}$

\footnotetext{
${ }^{3}$ http://www.energycodes.gov/news/items/022409 ansi.stm

4 http://www.energycodes.gov/news/items/022409_stimulus.stm
} 


\subsubsection{Policy Experience}

Despite the continuous upgrading of residential and commercial energy building codes in many States across the nation, there is considerable room for improvement. As of February 2009, only 22 States have residential codes that meet or exceed the 2006 International Energy Conservation Code (IECC). In fact, 15 States either have no residential energy codes or their codes precede the 1998 IECC. ${ }^{5}$ Similarly, only 25 States have commercial codes that meet or exceed the ASHRAE 90.1-2004 code, and 14 States either have no commercial energy codes or their codes precede ASHRAE 90.1-1999. ${ }^{6}$ As Figure 2.1 shows, most of the States along the eastern and western seaboard have modern codes, while there is a cluster of Mountain, Upper Midwestern, and Southeastern States with outdated codes.

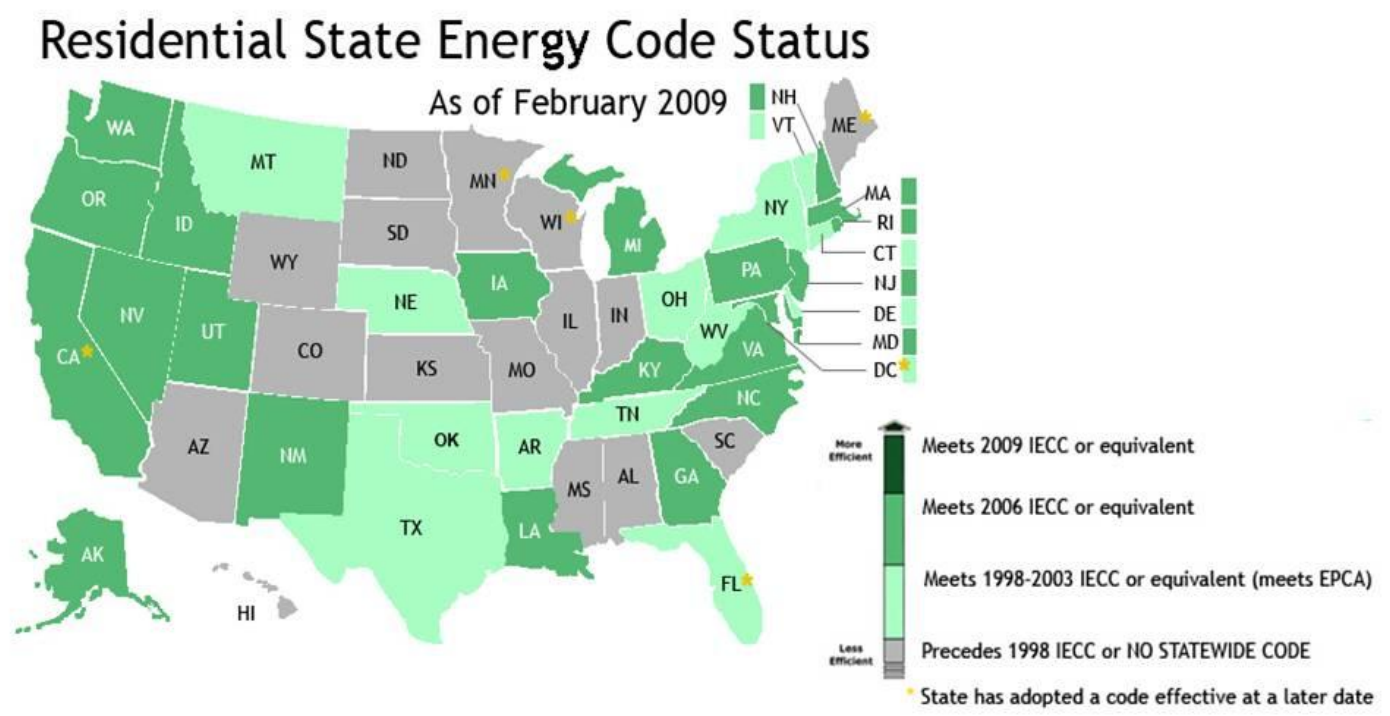

Figure 2.1 Status of Residential State Energy Codes as of February 2009

(Source: DOE EERE Building Energy codes Program: http://www.energycodes.gov/implement/state_codes/index.stm)

One of the reasons that States have not adopted the most current energy code might be that DOE may not be completing its determination fast enough to push states to adopt new codes. ${ }^{7}$

\footnotetext{
${ }^{5}$ The energy Code that applies to most residential building is the IECC, which supersedes the Model Energy Code. The 2000 IECC is the most recent version for which DOE has issued a positive determination. The Federal Energy Conservation and Production ACT (ECPA) was amended in 1992 to require states to review and adopt the MEC (and its successor, the IECC), or submit to the Secretary of Energy its reasons for not doing so.

${ }^{6}$ Most commercial building energy codes are based on ASHRAE/IESNA Standard 90.1, jointly developed by ASHRAE and the Illuminating Engineering Society (IES). ECPA requires states to adopt the most recent version of ASHRAE Standard 90.1 for which DOE has made a positive determination for energy savings, currently 90.1-1999. By referencing Standard 90.1 for commercial buildings, IECC offers designers alternate compliance paths.

${ }^{7}$ The Energy Policy and Conservation Act (EPCA, Public Law 94-163), as amended by the Energy Policy Act of 1992 (EPACT, Public Law 102-486), establishes a role for DOE to determine whether revisions to energy conservation codes would lead to energy savings; if DOE makes a positive determination, states must consider adopting the code in their state and provide a
} 
Nevertheless, many States are surpassing these older codes, but their code compliance is often limited. The continuous updating of existing codes, adoption of new codes, and expansion of code programs to improve compliance and achieve real energy and financial savings appear to be difficult for many States because they lack consistent code enforcement and support programs.

Several State, Federal initiatives, and regional non-governmental organizations (NGOs) focus on modernizing State building code practices.

- The Building Codes Assistance Program (BCAP) established in 1994, is a joint initiative of the Alliance to Save Energy, the American Council for an Energy-Efficient Economy (ACEEE), and the Natural Resources Defense Council and partly funded by DOE. BCAP provides custom-tailored assistance on building energy code adoption and implementation to assist State and local regulatory and legislative bodies and help coordinate others representing environmental interests, consumers, labor, and industry. BCAP provides States with code advocacy assistance, and coordinates with DOE to provide technical assistance.

- DOE has provided financial assistance to selected States to support their implementation of model building codes. For example, in September 2008, DOE announced awards for six State-led projects (Florida, Georgia, Massachusetts, Nebraska, North Carolina, and Washington) valued at \$2.6 million (DOE Share) to develop advanced building codes. Grants will assist States in developing and implementing plans that will achieve model building codes representing a 30 percent improvement over ASHRAE 90.1-2004 and/or the 2006 IECC. The DOE investment in advanced codes will leverage a project cost share of $\$ 2.3$ million. $^{8}$

- DOE's Building Energy Codes Program provides compliance tools for residential (REScheck) and commercial (COMcheck) buildings. DOE's website provides many ways to verify that construction meets the requirements of codes, including the REScheck and COMcheck programs that are both downloadable and web-based.

- The Whole Building Design Guide (WBDG) has introduced an Applied Research section to serve as a clearinghouse of government sponsored research findings to improve performance of federal facilities by sharing expert resources, knowledge, practices and strategies. The goal of WBDG is to create a successful high-performance building by applying the integrated design approach and the integrated team approach to the project during the planning and programming phases (http://www.wbdg.org/).

- Recognizing that building energy codes set a floor on the energy efficiency of buildings, the Southwest Energy Efficiency Project (SWEEP) has developed the Going Beyond code guide to assist State and local governments achieve even higher standards of energy efficiency. Beyond code efficiency can be seen mostly in Western States where the percentage of new construction meeting ENERGY STAR ${ }^{\circledR}$ guidelines is higher than the

response. The last positive determination for residential building energy codes was in 2001 for the 1998 and 2000 versions of the International Energy Conservation Code; for commercial buildings it was in 2002 for the ASHRAE Standard 90.1-1999.(source: http://www.energycodes.gov/implement/determination_process.stm)

${ }^{8}$ BCAP Newsletter, October 2008 edition. http://www.bcapenergy.org/files/BCAP_Newsletter_October_2008_Edition.pdf 
rest of the country; Nevada had a 71 percent ENERGY STAR residential penetration rate in 2006, leading the nation (ENERGY STAR, 2008).

- Regional NGOs such as Northeast Energy Efficiency Partnership (NEEP), Northwest Energy Efficiency Alliance (NEEA), Midwest Energy Efficiency Alliance (MEEA), and more recently Southeast Energy Efficiency Alliance (SEEA) have strong initiatives in the codes area.

Building standards can be distortionary, in spite of their numerous positive influences. Because codes and standards take a long time to adopt and modify, the best performing materials and technologies are not readily deployed, thereby inhibiting innovation and encouraging obsolete technology. Consider the REScheck tool for assisting building code implementation. This tool incorporates tradeoffs between technologies to meet the code requirements of the state or local code, in the jurisdiction permitting its use; in some cases, these tradeoffs lead to distortions when credits are allowed for practices which have become common from the trade-off incentives offered, inhibiting further improvements in efficiency. For example, in the Upper Midwest there is upwards of 80 percent penetration of condensing gas furnaces. The tradeoffs to meet the code allow savings from this now common high efficiency furnace to be used to offset poor envelopes. As a result, this code specification is no longer promoting improved building practices because it has not adapted to technology advances (Brown and Chandler, 2008). Codes that are outdated or fail to adapt to changing available technologies can represent lost opportunities to improve energy efficiency.

Perhaps a more current example of a technology barrier is the long retention of the center of glass U-factor criteria rather than the whole window U-factor criteria. The lack of building infiltration criteria, solar heat gain coefficient (SHGC) criteria, and duct testing requirements are also barriers to technological innovation and progress in new construction (Boulin, 2009).

Smith and McCullough (2001) document various State efforts to meet compliance and enforcement needs with a limited staff and complex performance based codes, suggesting the need for third-party verification. A survey in 2007 found an estimated compliance rate of 80 percent for commercial energy codes among those respondents who provided an estimate - most either did not know or were unwilling to respond (Zing Communications, 2007). However, the same survey showed widespread lack of inspection and verification; "[a]s a weighted average of all respondents, about one in 10 reports that compliance inspections do not occur in their jurisdictions" (Zing Communications, 2007, p.23). The degree of compliance with residential building energy codes is generally unknown, and is likely to remain so, without a verification system. Evidence provided by Yang (2005) suggests a considerable code enforcement and compliance shortfall. The study, which reviewed the existing energy code evaluation studies of 16 States, showed that in general, the Pacific/Western States exhibited higher code compliance rates than the rest of the country. Some of the study's additional findings were that improvements in energy efficiency were offset by increases in the size of homes, HVAC 
equipment was excessively oversized, compact fluorescent lamp (CFL) penetration was low, and there was a need for better builder and consumer education.

\subsubsection{Policy Rationale}

One of the most important barriers to the deployment of energy-efficient building designs and technologies is institutional: the decision-making process is complex and fragmented by numerous players, including investors, owners, occupants, builders, tradesmen, architects, equipment manufacturers, suppliers, lenders, insurers, codes and standards setters, realtors, and so forth. Each of these participants in the decision-making process has distinct interests and impacts the process at different points in design, construction and use (CCCSTI, 2009; Brown et al., 2009).

As a result of this fragmentation, the buildings industry is replete with decision-making intermediaries that do not represent the long-term interests of building owners and occupants. In the case of new buildings, developers and speculative builders emphasize the need to limit construction costs and disregard the need to constrain operating costs, since their financial interests end with the sale of the building. Federal action that accelerates State adoption of advanced building energy codes and promotes greater code compliance through third-party verification would directly address this barrier and could reduce lost opportunities for energy efficiency.

\subsubsection{Stakeholders and Constituencies}

Modern and better enforced residential building energy codes would protect the interests of consumers and would reduce the consumption of fossil energy, thereby mitigating greenhouse gas emissions and the release of other pollutants. States with out-dated building practices will be challenged to learn and implement more advanced building practices, which may be an unpopular requirement among some builders, architects, equipment manufacturers, suppliers, and perhaps code officials, who will have to deviate from "business-as-usual." However, with technical and financial assistance from the Federal government, this transition should be feasible.

\subsubsection{Policy Evaluation}

Appropriateness of the Federal Role. The Federal government uses the BCAP network to train code officials, liaisons, construction professionals, and third-party verifiers. Training and providing assistance to State and local jurisdictions has precedence. Many organizations already exist at the grassroots level within communities and cities such as Green Corps (http://www.greencorps.org/). 
Recent action in the U.S. Congress shows some motivation to aid the enforcement of building codes. For example H.R. 4461 "Community Building Code Administration Grant Act (CBCAG)" passed the House of Representatives on July 9, 2008; if passed by the senate (S 2458), enacted, and funded, CBCAG Act would authorize a grant program through the U.S. Department of Housing and Urban Development (HUD) to provide competitive matching funds grants to local jurisdictions to build-up their building code administration and enforcement capabilities.

Broad Applicability. Building energy codes prescribe the minimum level of efficiency that must be achieved in new construction, both residential and commercial. In the residential sector, energy codes can impact construction practices in single as well as multifamily homes, and in manufactured housing, as well. In the commercial sector, energy codes can improve construction practices for schools, hospitals, large and small office buildings, warehouses, retail sales and service buildings, and religious as well as government buildings. Codes and code assistance programs can be flexible to meet the specific conditions of each climate zone in the United States and to take into account the demographics, social, cultural and economic development plans, and targets of State and local governments. Federal assistance programs shall allow local and State planners to meet their development and sustainability goals while simultaneously reducing energy costs and mitigating greenhouse gas emissions.

Significant Potential Benefits. The 2009 edition of the IECC - the National model energy code of choice for States, cities and counties - is expected to produce approximately 15 percent in energy efficiency gains compared to the 2006 edition, according to BCAP. ${ }^{9}$ IECC 2006 had little thermal improvement over the IECC 2003 code, but it did simplify the process of compliance. Lucas (2006) estimated annual savings of 16-17 percent in West Virginia by adopting the 2003 IECC (unamended) in place of the 2003 IRC with amendments. The 2003 IECC and 2006 IECC are similar in efficiency requirements as the major changes are in ease of compliance and structure.

If every State adopted the most recent commercial and residential model energy codes, improved compliance levels, and applied model energy codes to manufactured housing, the United States would reduce energy use by about 0.85 quads annually, with cumulative savings through 2020 of about five quads. In 2020, annual consumer energy bill savings would be almost $\$ 7$ billion, and the construction of 32 new 400 megawatt (MW) power plants could be avoided. Prindle et al. (2003) also estimate that upgrading residential building codes could save an "average" State about $\$ 650$ million in homeowner energy bills over a 30-year period.

An estimated 0.15 quads of energy were saved in 1998 and 3.55 MMTC were avoided as a result of energy code upgrades through 1998 (this represents about one percent of the 318 MMTC

\footnotetext{
${ }^{9}$ http://www.iccsafe.org/news/nr/2009/0128_2009IECC.pdf
} 
emitted from the building sector in 2002). Rosenquist and coauthors (2004) estimate the nationwide energy savings potential from upgrading residential and commercial building codes in 2010 and again in 2020. Residential building codes are modeled in terms of improvements to shell measures such as insulation, glazing and infiltration that reduce heating and cooling loads. Commercial building codes are modeled in terms of improved space heating, air conditioning, and commercial sector lighting. The result is an estimated cumulative energy savings of 2.2 quads for residential building codes and 3.0 quads for commercial codes - totaling 5.2 quads over the 20-year period or an annual estimated potential savings of 0.26 quads (Brown and Southworth, 2008)

Assuming that all States have adopted the 2006 IECC by 2009 and subsequently more efficient codes every three years thereafter with a steady improvement in thermal performance, savings of about 1.6 quadrillion Btu, or three percent of projected residential and commercial consumption could be achieved in 2030. About two-thirds of these savings are estimated to come from improvements in residential construction. These estimates were derived by expanding the methodology described in the report Energy Efficiency in Appalachia (Brown et al., 2009) to the entire United States.

In that study, Appalachian States are assumed to adopt the 2006 IECC by 2009 and more efficient codes every three years thereafter. Codes are assumed to become effective the year following adoption. Third-party verification of measures occurs, and an incentive to builders is provided for the period 2010-2020. This results in an 80 percent compliance rate. To illustrate, the 419,000 single and multi-family homes projected to be built from 2013 to 2015 in Appalachia are assumed to conform to the 2009 IECC code and therefore use 18 percent less energy for space heating, space cooling, and water heating than they would have if built to 2005 current practice. Homes built from 2016 to 2019 are assumed to use 30 percent less energy for those end-uses. With $\$ 280$ million in program spending and an additional $\$ 2.1$ billion in customer investments over the 2010-2030 period, the Appalachian Region could see net cumulative savings of 1.0 quads of energy and $\$ 16.3$ billion in energy bills by 2030 (Brown et al., 2009). The comparable savings for the United States are estimated to be almost 1.8 trillion Btu of savings for a combined public and private investment of less than \$2 billion (\$2006) (Figure 2.2). 


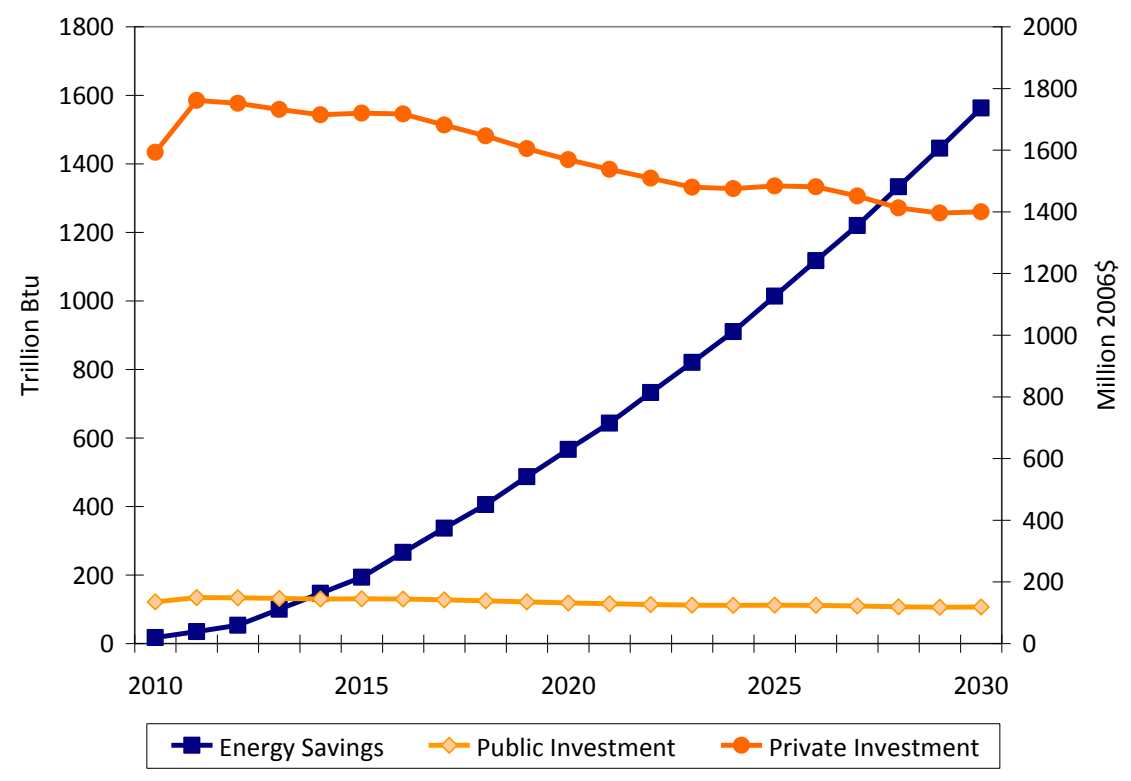

Figure 2.2 Costs and Savings in New Residential and Commercial Construction, 2010-2030

(Calculations by Chandler based on methodology documented in Brown et al., 2009)

While energy efficient building codes do present significant potential benefits, it should be restated that they do also create distortionary effects due to the time required to adopt and modify them. It should also be stated that building energy codes represent an efficiency "floor", while indicators such as ENERGY STAR certifications signify a higher standard in building energy codes.

Solutions not Dependent on Future R\&D. Building energy codes are designed to require the use of current best practices and are not dependent upon future R\&D successes. Because improved materials, technologies, and practices are anticipated in future years, most analysts assume that codes will be strengthened on a regular basis in order to reflect such advances. Indeed, there is a complementary relationship between building codes and R\&D. Often the prospect of more rigorous codes in the future motivate manufacturers to invest in continuous product improvement. By making more efficient building designs and products the norm, efficiency standards can provide assured markets for innovative technologies. Updating building codes on a regular basis as building technologies and design strategies evolve can help expand the knowledge base and maintain a pipeline of new and improved technologies. The complementarity of regulatory approaches and technology innovation has been well documented in the case of the household refrigerator (National Academies, 2001). Recognizing that the building industry is one of the least research-intensive industrial sectors, public investment in R\&D has been a critical source of technology advances that eventually become codified in State building requirements. 
Cost Effectiveness. While the benefits are approximated above based on achieving growing savings, costs are not assumed to rise significantly over time (this assumes some amount of technological improvement and learning). The costs of residential code compliance can be estimated based on a modeled "standard home" in various climate zones, as shown in Table 2.1; however, due to differences in size and use of commercial buildings, offering a per building cost estimate is nonsensical.

Table 2.1. Incremental Cost Estimates for Residential Energy Code Compliance (Brown et al., 2009, Table B-4)

\begin{tabular}{|c|c|c|c|c|}
\hline State & $\begin{array}{c}\text { Code } \\
\text { Studied }\end{array}$ & $\begin{array}{c}\text { Climate } \\
\text { Zone }^{\mathbf{a}}\end{array}$ & $\begin{array}{c}\text { Cost } \\
\text { Estimate } \\
\text { (per home) }\end{array}$ & Reference \\
\hline Illinois & $\begin{array}{c}\text { none to 2006 } \\
\text { IECC }\end{array}$ & 4 & $573-1715$ & Lucas 2007 \\
\hline Illinois & $\begin{array}{c}\text { none to 2006 } \\
\text { IECC }\end{array}$ & 5 & $1173-3062$ & Lucas 2007 \\
\hline Iowa & $\begin{array}{c}1992 \text { MEC to } \\
2003 \text { IECC }\end{array}$ & 5,6 & $0-500$ & Lucas 2003 \\
\hline Kentucky & $\begin{array}{c}1992 \text { MEC to } \\
2000 \text { IECC }\end{array}$ & 4 & $0-300$ & Lucas 2001 \\
\hline West Virginia & $\begin{array}{c}2003 \text { IRC } \\
\text { amended to } \\
2003 \text { IECC }\end{array}$ & 4 & 639 & Lucas 2006 \\
\hline West Virginia & $\begin{array}{c}2003 \text { IRC } \\
\text { amended to } \\
2003 \text { IECC }\end{array}$ & 5 & 659 & Lucas 2006 \\
\hline aatimate zone is the 2006 IECC climate zone. Previous code cycles had more zones.
\end{tabular}

These costs are far less than the costs to bring existing homes to the same code because so much of a home's structure is easiest to change during construction - similarly for commercial buildings.

A recent (2009) study on the 13 States comprising Appalachia, by Brown et al. showed the savings in energy use by private and public investment in residential energy codes for the years, 2010-2030. Public investment is the administrative costs of the program while private investment is the incremental costs of improvement. Figure 2.2 shows the benefits of private and public investments in energy use from this study. 
With cumulative $\$ 220.5$ million in public investment and an additional $\$ 2.2$ billion in private (customer) investments over the 2010-2030 period, the Appalachian region could see net cumulative savings of 802.5 trillion Btu, saving $\$ 13.1$ billion in energy bills by 2030 (Fig. 2.2).

Figure 2.2 shows how energy bill savings might grow from 2010 to 2030 if residential and commercial codes improved over time on a three-year code cycle while costs stayed about even. Further, this figure assumes that public costs include training and liaisons, but not verification costs; private costs include incremental costs (at $\$ 1,000$ per home and $\$ 0.30$ per commercial square foot).

Administrative Practicality. Current code programs and training efforts exist, most notably the BCAP. Such programs offer an existing infrastructure for expanding efforts to advance State policies. The only "new" administrative effort would be enabling third-party verification at the State level. Federal assistance will help these governmental bodies and industry-based verifiers accomplish their goals while providing value to consumers.

Additionality. Building codes improve the energy efficiency of newly constructed dwellings and commercial buildings. Policies that improve information provided to potential building occupants or home buyers could have overlapping benefits as information could drive demand for further improvements.

Utility programs providing support to builders and the green construction industry could also provide complementary and supportive assistance. Utilities in several States offer residential and/or commercial new construction programs, which provide incentives to builders who meet or exceed model energy codes within the utility service area. Utility residential new construction programs have achieved near 100 percent compliance in California, Oregon, and Washington from builders while residences built outside of the program were found to be six percent (or more) less efficient than the current State code (Vine, 1996). An example program is that of Pacific Gas and Electric which provides an incentive of $\$ 400$ or $\$ 500$ to builders per ENERGYSTAR home and additional incentives for outfitting these homes with energy-efficient appliances (PG\&E, 2008). It should be noted that these programs do have a verification component to determine qualification. Similarly, California's Title 24 Field Verification and Testing requires third party verification by Home Energy Rating System (HERS) inspectors that have certification through one of three approved certifying organizations upon installation or maintenance of specific technologies. ${ }^{10}$

\footnotetext{
${ }^{10}$ http://www.energy.ca.gov/2005publications/CEC-400-2005-044/CEC-400-2005-044.PDF
} 


\subsubsection{Summary}

It is recommended that the Federal government expand technical assistance to States to accelerate their adoption of advanced building energy codes and provide financial assistance focused on third-party verification of code compliance. The absence of modern residential energy codes in 15 States in combination with low compliance levels in other States underscores the potential benefits that could result from this proposed Federal initiative. The challenge of establishing third-party verifiers to help enforce building codes is a potential weakness of this policy option that would require monitoring. While many developers, builders, and other stakeholders might oppose the enforcement of modern energy codes, consumers and society would benefit from this policy option in the long run, since many energy-efficient building designs and technologies are only affordable at the point of construction and are lost opportunities to future homeowners.

\subsection{Expanded Use of Home Energy Performance Ratings}

Policy Option: Provide technical and financial assistance to States to develop policies that incorporate home energy performance ratings and ensure a qualified home energy performance rating workforce.

\subsubsection{Synopsis of Policy Option}

Provide technical and financial assistance to States to develop policies that incorporate home energy performance ratings and ensure a qualified home energy performance rating workforce. As part of this effort, the Federal government could develop a common home energy performance reporting method, which will result in uniform data reporting.

In addition, the Federal government could coordinate training of a home energy rating and improvement workforce. Since significant non-governmental capacity already exists for training this workforce, it may be most cost-effective to work within this structure.

Because this policy action directly influences States, State actions cannot be ignored. States will need to follow by developing policies that incorporate home energy performance ratings. These policies could be designed to verify building code compliance, to measure savings achieved by demand reduction efforts, or to help determine where the most need for improvement exists in the existing stock. States may need to take additional action, such as certifying companies that meet their criteria for training home energy performance ratings or developing a method of collecting and storing home energy performance ratings for public use. 


\subsubsection{Policy Experience}

The Department of Energy (DOE) already supports State efforts to create home energy rating systems, and the Environmental Protection Agency (EPA) provides funding support to the Residential Energy Services Network (RESNET) and the National Home Energy Rating Systems Council. ${ }^{11}$ Together they have developed rating guidelines for a particular home energy performance rating system called the Home Energy Rating System (HERS) and rater certification programs.

The HERS Index is a scoring system established by RESNET in which a home built to the specifications of the HERS Reference Home (based on the 2006 International Energy

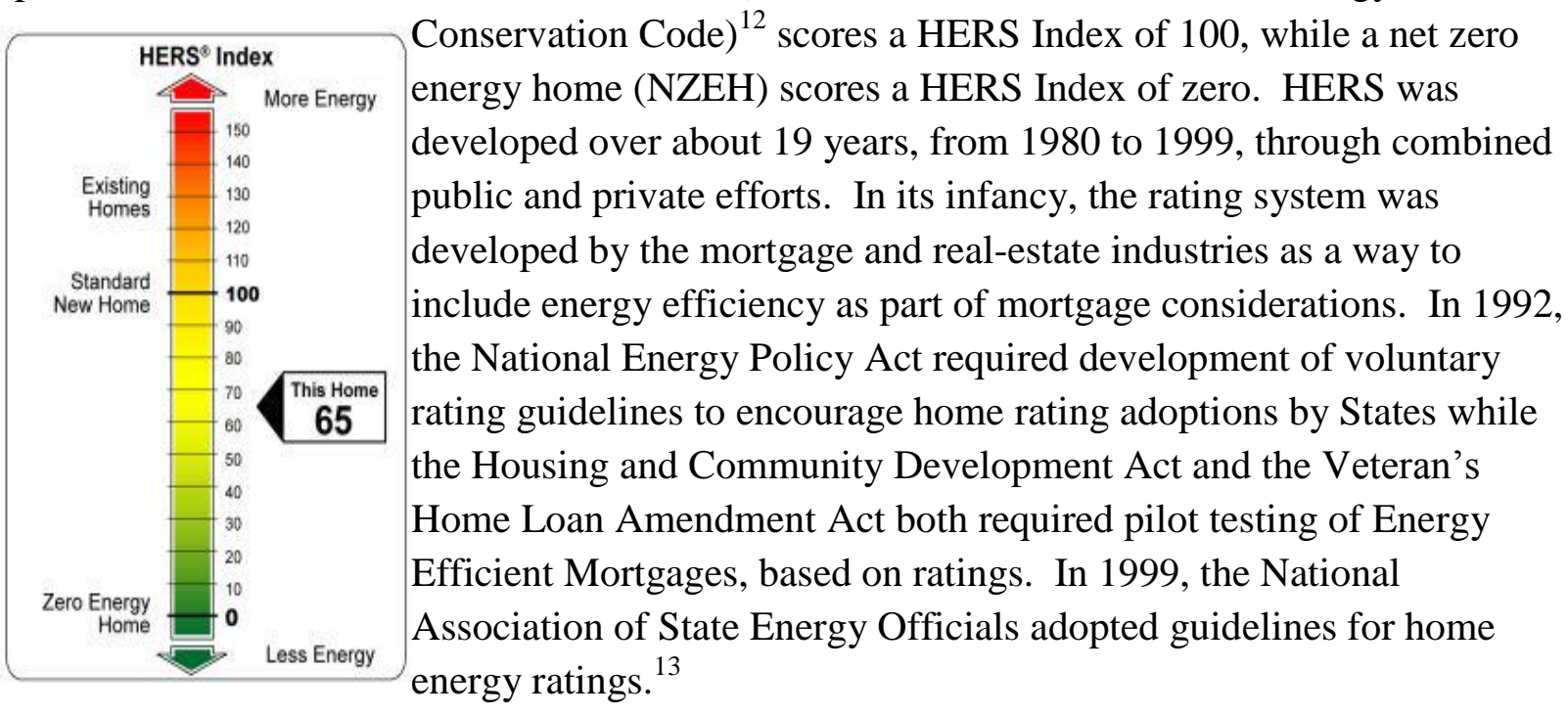

Development and adoption of State and local policies using performance ratings has been mixed. While more than half the States have their own home energy performance rating systems, many are inactive, unproductive, or in a startup phase. Active home energy performance rating systems are in California, Colorado, Florida, Indiana, Utah, Vermont, and Virginia. A handful of States have more experience after being selected for pilot programs in the early 1990's (Alaska, Arkansas, California, Colorado, Vermont, and Virginia). However, programs in some States, like Alaska, Arkansas, and Colorado have lost ground after Federal pilot money ran out; State and local policies must follow that incorporate home energy performance ratings or organizations training and certifying raters will go out of business and their experience will be lost. States with successful home energy performance rating programs have multiple non-profit organizations serving as rating certifiers and coordinators for a network of professional raters and contractors.

\footnotetext{
${ }^{11}$ RESNET is a network of mortgage lenders, utilities, housing and residential energy efficiency professionals

${ }^{12}$ International Energy Conservation Code ${ }^{\circledR}$ (2006) http://www.iccsafe.org/e/prodshow.html?prodid=3800S06

${ }^{13}$ HERS history from : http://www.natresnet.org/ratings/overview/resources/primer/HP02.htm
} 
Federal efforts to expand existing State programs could bring these organizations together to capitalize on decades of experience rather than funding only one organization.

An example of how to use the existing experience can be found in California's Home Energy Rating Systems program where the California Energy Commission approves providers to oversee home energy performance raters providing field verification and diagnostic testing ensure quality supply. Field verification and testing is required by California law for new construction and renovations, which drives demand. Three organizations have been approved to act as providers so far: California Certified Energy Rating \& Testing Services (CalCERTS), California Building Performance Contractors Association (CBPCA), and the California Home Energy Efficiency Rating System (CHEERS). CHEERS has certified more than 500 raters who performed about 20,000 home energy performance ratings in 2008, and it claims that ratings usually cost about $\$ 150$ to $\$ 300 .^{14}$

An example of how pilot programs can fail to work is in Colorado. There, non-profit organizations developed extensive experience training and certifying raters during pilot programs, but State and local policies have not followed to use the home energy performance ratings. Efficiency requirements placed on the States' largest utility, Xcel Energy, led the utility to develop incentives for customers to improve existing home efficiency. Xcel Energy contracted with one of the existing non-profit rater certifying companies, Lightly Treading, to provide steeply discounted home performance audits (added to monthly utility bill) to customers. ${ }^{15}$ If the State had previously created an approved set of rating organizations, the utility may have worked with a consortium rather than one organization; now, the discounted ratings will likely drive consumers to Xcel Energy's program. The discounted ratings are not a problem in themselves, but they may lead to a loss of the collective knowledge embodied in raters and certifiers not associated with the program.

There is recent international experience for home energy performance rating as well. Following the European Union Performance in Buildings Directive (EPBD), all member countries are required to establish standard energy performance audits for existing homes. Directive 2002/91/EC of the European Parliament and of the Council of 16 December 2002 on the energy performance of buildings required European member States to develop common rating schemes and put them into place by 2006 with a grace period for implementation until 2009. ${ }^{16}$ This grace period is expected to be necessary to train inspectors (Wouters and van Dijk, 2007). The most popular form of compliance with the directive is the Energy Performance Assessment of Existing Dwellings (EPA-ED). EPA-ED is standardized to the point that assessors can follow a set of steps for data collection and then utilize EPA-ED software to provide location specific

\footnotetext{
${ }^{14} \mathrm{http}: / /$ www.cheers.org/default.htm

$15 \mathrm{http}: / /$ evstudio.info/2009/01/28/home-energy-audits-from-lightly-treading-and-xcel-energy/

16 http://europa.eu/scadplus/leg/en/lvb/127042.htm
} 
performance assessments; much freedom is allowed for local policy, technical specifications, and climate (Poel, van Cruchten, and Balaras, 2007).

\subsubsection{Policy Rationale}

Federal action could increase the use of home energy performance ratings, develop a common home energy performance reporting method, and coordinate training of a home energy rating and improvement workforce. Providing a standard method of measuring acts as an enabler; policies could be developed going forward with the idea that energy performance of homes is a known value. While it seems simple, this is a transformational piece of information. Home energy performance ratings could decrease information asymmetry about the residential building efficiency between builders or owners and users or buyers; in addition, home energy performance ratings could enable an array of policies to improve the energy performance of homes. For example, if home energy performance ratings were standard practice for compliance with energy codes, market risks to builders for complying with energy codes would be lowered.

\subsubsection{Stakeholders and Constituencies}

A home energy performance rating system has little benefit as a standalone policy; if policies to use ratings are not developed and ratings become required, there is likely to be disagreement on economic grounds.

Opposition to policies incorporating home energy performance ratings will be dependent upon the policies proposed. However, likely opposition will come from groups who disagree with the validity of the rating, or who stand to lose money. For example, construction companies may lose money in the short run if ratings become required to validate their compliance with energy codes - especially if they were previously getting by with non-compliance; however, compliant construction companies may not lose money and support such a policy that reduces their market risks.

As technologies and practices change, it will be important for the rating system (HERS or otherwise) to be flexible enough to adapt. Similarly, States and localities would benefit from making every effort to ensure that raters in place are familiar with the specific conditions of their climate and consider the type and use of dwellings when rating. This consideration is important because HERS estimates have been shown to be inconsistent, on an individual house basis, and dependent upon assumptions (like that the space is conditioned) that may be erroneous in some cases (Stein and Meier, 2000; Kordjamshidi and King, 2009). This is a note of caution when moving to a National system, not an expression that the HERS ratings are unreliable. Further, it supports the idea that ratings are appropriate for the building itself, irrespective of occupant (which could be public information), and for the building as occupied (private information). 
Caution on this front is necessary to ensure that private information is not made public, at the same time that information that would not violate privacy is available for public use.

\subsubsection{Policy Evaluation}

Appropriateness of the Federal Role. Providing guidance, training, funding, and model legislation to States is already part of the Federal role in environmental and energy policy. Existing channels, including existing Federal programs could be used to help States develop policies that incorporate home energy performance ratings.

EPA uses HERS to qualify homes for its ENERGY STAR homes program. In addition, EPA developed Home Performance with ENERGY STAR, a public-private effort sponsored by States, local governments, and utilities. This is a fairly new program, with existing programs in a handful of States and several metro areas, but more than a dozen States are considering such a program (NASEO, 2008). Home Performance with ENERGY STAR strives to provide comprehensive, whole-house, energy audits as well as recommendations for cost-effective upgrades - much like a traditional HERS rating but with a focus on ENERGY STAR specifications. Additional efforts at the Federal level could coordinate State and local action by providing training or guidance to NASEO or specific jurisdictions as they consider adopting such a program.

The Federal Housing Administration has offered energy-efficient mortgages nationwide, based on home energy performance ratings, since October 1995. Fannie Mae, Freddie Mac, and the Veteran's Administration also offer energy efficiency loan products. Efforts to promote these existing financing mechanisms combine well with broader efforts to help consumers purchase homes that they can afford.

Seed funding for revolving loan programs for improvements that follow Home Performance with ENERGY STAR inspections or other home energy performance ratings could be implemented through existing State Energy Program or environmental funding mechanisms.

Broad Applicability. Home energy performance ratings are applicable to all housing; more than 112 million housing units are currently in place in the United States (Table 2.2). ${ }^{17}$

\footnotetext{
${ }^{17}$ There are more than 127 million housing units, but about 12 percent are vacant (U.S. Bureau of the Census, 2006; 2007; 2008a).
} 
Table 2.2 Existing Occupied Housing Units by Census Region, 2005-2007

(U.S. Bureau of the Census, 2006; 2007; 2008a) ${ }^{18}$

\begin{tabular}{|l|c|c|c|}
\hline \multicolumn{1}{|c|}{ Area } & $\mathbf{2 0 0 5}$ & $\mathbf{2 0 0 6}$ & $\mathbf{2 0 0 7}$ \\
\hline Northeast & $20,582,523$ & $20,553,582$ & $20,593,754$ \\
\hline Midwest & $25,603,971$ & $25,688,303$ & $25,778,315$ \\
\hline South & $40,712,300$ & $40,963,290$ & $41,381,254$ \\
\hline West & $24,191,823$ & $24,412,227$ & $24,624,654$ \\
\hline U.S. & $111,090,617$ & $111,617,402$ & $112,377,977$ \\
\hline
\end{tabular}

The way that home energy performance ratings are used in policies will affect their applicability. An ideal situation would have each dwelling rated at construction (for building "potential" rating), with each occupant (for "occupant-specific" rating, which includes behavior), and upon any renovation a new "potential" rating could be developed without considering current occupant behavior. Thus, the home rating is specific to the home, but actual performance and associated cost-effective improvements will vary by occupant characteristics. However, current costs of ratings relative to costs of energy consumption do not support this level of information collection and provision. Depending on State and local policies, the applicability of ratings will fall somewhere between the current use and the ideal described above.

Significant Potential Benefits. Simply adopting a rating system or training and certifying raters does not have any independent benefits. However, a rating system can provide information that is a catalyst for other action. Home energy performance ratings can be applied for different policy purposes. For example, buyers of rated homes can qualify for Energy-Improvement Mortgages, if the home's performance is poor, or Energy-Efficient Mortgages, if the home's performance is exemplary. Both of these financing options are currently underused; buyers and lenders alike are not fully aware of these programs through the Federal Housing Administration. The EPA lists several benefits of Home Energy Rating Systems combined with Energy-Efficient Mortgages ${ }^{19}$ :

- More disposable income for homeowners.

- Higher property values for energy-efficient homes.

- Increased local employment opportunities in construction and retrofit projects.

- Greater use of energy-efficient technologies and practices.

- Larger loans for lenders.

- Reduced need for electricity generation.

\footnotetext{
${ }^{18}$ About 70 percent of U.S. Housing units are single family structures; about 25 percent are multifamily units; the remainder are mobile or manufactured homes (EIA, 2008a).

${ }^{19} \mathrm{http}$ ://yosemite.epa.gov/OAR/globalwarming.nsf/UniqueKeyLookup/SHSU5BUK22/\$File/energyandthehome.pdf
} 
- Reduced emissions of greenhouse gases and other pollutants such as nitrogen oxides.

In general, it is assumed that the benefits of home energy performance ratings would increase awareness of the homes' energy expense, much like EPA fuel efficiency stickers did for cars. Increased awareness along with recommendations for improvement, as provided with an energy performance rating, can help consumers make cost-effective investments that improve home energy efficiency. Getting existing homes down to a score of 100 could be a goal of energy efficiency retrofit programs. Table 2.3 shows what the HERS numbers mean; each one percent increase in energy efficiency corresponds to a one point decrease in the HERS index.

Table 2.3 What Does the HERS Number Mean? ${ }^{20}$

\begin{tabular}{|c|c|c|}
\hline & HERS Score & HERS Index \\
\hline Reference Home Score & $\begin{array}{l}\text { Reference Home is assigned a } \\
\text { HERS Score of } 80\end{array}$ & $\begin{array}{l}\text { Reference Home is assigned a } \\
\text { HERS Index of } 100, \text { while a } \\
\text { net zero energy home is } \\
\text { assigned a HERS Index of } 0\end{array}$ \\
\hline Reference Home Basis & $\begin{array}{l}1993 \text { Model Energy Code } \\
\text { (MEC) }\end{array}$ & $\begin{array}{l}2006 \text { International Energy } \\
\text { Conservation Code (IECC) }\end{array}$ \\
\hline Scale & $\begin{array}{l}\text { Each } 5 \text { percent increase in } \\
\text { energy efficiency corresponds } \\
\text { to a 1-point increase in HERS } \\
\text { Score }\end{array}$ & $\begin{array}{l}\text { Each one percent increase in } \\
\text { energy efficiency corresponds } \\
\text { to a 1-point decrease in HERS } \\
\text { Index }\end{array}$ \\
\hline Energy Use Considered & $\begin{array}{l}\text { Heating, cooling, and water } \\
\text { heating }\end{array}$ & $\begin{array}{l}\text { Heating, cooling, water } \\
\text { heating, lighting, appliances, } \\
\text { and onsite power generation }\end{array}$ \\
\hline ENERGY STAR Requirement & HERS Score 86 & $\begin{array}{l}\text { HERS Index of } 85 \text { in climate } \\
\text { zones } 1-5 \\
\text { HERS Index of } 80 \text { in climate } \\
\text { zones } 6-8\end{array}$ \\
\hline Status & $\begin{array}{l}\text { Phasing out; used for homes } \\
\text { rated before July 1, } 2006\end{array}$ & $\begin{array}{l}\text { Approved by the RESNET } \\
\text { Board of Directors. To be } \\
\text { implemented as of July 1, } \\
2006 .\end{array}$ \\
\hline
\end{tabular}

If 100,000 (about 0.1 percent) average existing homes are retrofit each year to meet a score of at least 100 (from an assumed score of 120) this would represent a 20 percent decrease in energy

${ }^{20}$ http://www.energystar.gov/index.cfm?c=bldrs_lenders_raters.nh_HERS 
consumption for those homes), annual incremental energy savings could be up to $230 \mathrm{GWh}$ or 13,400 million cubic feet of natural gas, but is likely to be a combination of the two. ${ }^{21}$

While it is beyond the scope of this proposed policy, data collected through home energy performance ratings could allow for detailed energy analysis and comparison by region and vintage, such data could help future research. ${ }^{22}$ Current rating systems do not require systematic collection of data, nor is there funding for analysis of ratings in many areas.

Solutions not Dependent on Future R\&D. The current barrier is a lack of skilled raters and workers who can build new structures requiring advanced framing and can install new equipment and technologies in homes required to meet the established HERS rating. This is not only true of new construction but is even more acute in existing buildings. Non-profit organizations have established a niche of training and certifying home energy performance raters; these organizations have more history and experience in States where pilot programs provided funding for their development.

Widespread use of home energy performance ratings will require a ramp up of efforts to train enough raters. Some areas may have many qualified raters, but they may not be prepared to complete the ratings necessary to support any larger effort. "In discussions with interviewees, it became apparent that energy auditing was not a primary profession for many certified energy auditors but an ancillary qualification.” (MEEA, 2006 p. 20)

Cost Effectiveness. Assuming that a rating costs between $\$ 300$ and $\$ 700$, retrofits would need to lead to savings shown in Table 2.4. While saving 20 percent of average household electricity use almost pays back the lower estimate cost of rating in one year, nearly five years are needed to payback the higher rating cost using natural gas alone. This table illustrates the need to include the cost of rating in financing for retrofits and the need to achieve sufficient retrofit savings to cover the cost of rating in addition to the cost of the retrofit.

\footnotetext{
${ }^{21}$ This assumed savings is intentionally conservative - except with regard to the number of houses. 100,000 homes nationwide represents about 2,000 per state. There are not sufficient raters in some states to cover enough homes to achieve this number of homes that follow the rating with energy improving retrofits. Energy savings presented are based on saving 2,300 kwh or 13.4 thousand cubic feet per home based on average home energy use from 2005 Residential Energy Consumption Survey (RECS) Table US8. Average consumption by fuels used http://www.eia.doe.gov/emeu/recs/recs2005/c\&e/detailed tables $2005 \mathrm{c} \& \mathrm{e} . \mathrm{html}$ 22 http://www.meteo.noa.gr/datamine/
} 
Table 2.4 Energy Savings Required to Recover the Cost of Rating

(further savings would be necessary to cover the cost of retrofits)

\begin{tabular}{|c|c|c|c|c|c|c|}
\hline & \multirow[b]{2}{*}{ Price $^{a}$} & \multirow[b]{2}{*}{ Unit } & \multirow{2}{*}{$\begin{array}{c}\text { Average } \\
\text { Household } \\
\text { Annual } \\
\text { Use }^{b}\end{array}$} & \multirow{2}{*}{$\begin{array}{c}20 \text { Percent of } \\
\text { Average Household } \\
\text { Energy Use (assumed } \\
\text { saved) }\end{array}$} & \multicolumn{2}{|c|}{ Rating Cost } \\
\hline & & & & & $\$ 300.00$ & $\$ 700.00$ \\
\hline Natural gas & $\$ 13.00$ & $\begin{array}{l}\text { thousand } \\
\text { cubic feet }\end{array}$ & 67 & 13.4 & 23.1 & 53.8 \\
\hline Electricity & $\$ 0.11$ & kilowatthour & 11,480 & 2,300 & 2,727 & 6,364 \\
\hline \multicolumn{7}{|c|}{ 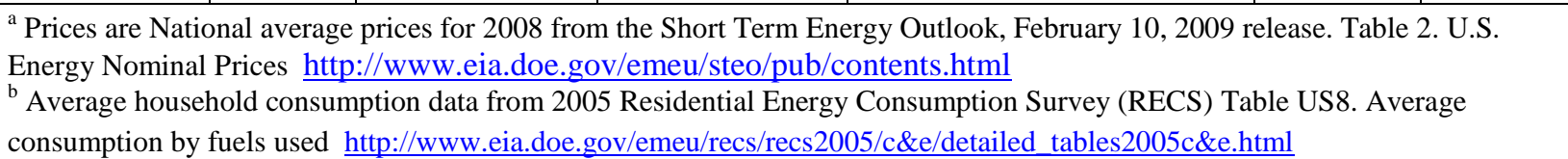 } \\
\hline
\end{tabular}

Cost-effectiveness is in the eye of the beholder; energy performance ratings that lead to energyefficiency improvements can be seen as an additional "cost" of $\$ 300$ to $\$ 700$ on top of incremental improvement costs. While the average payback for retrofits is less than seven years, the payback for retrofits + rating will depend upon the retrofits that are undertaken. A home energy performance rating will seem very cost-effective when making expensive retrofits, but it may negate savings for less costly improvements, such as installing a programmable thermostat or upgrading lighting fixtures.

In New York, the average Home Performance with ENERGY STAR project house spent \$8,369 in 2008 on retrofits and this program's average per house savings are $804 \mathrm{kWh} /$ year and 420 Therms/year. New York's model is impressive because the contractors only charge what the market will bear for the rating and analysis; in competitive markets, this means that the energy performance rating is provided at no cost. Massachusetts's program completed 8,435 Home Performance with ENERGY STAR ratings, leading to $\$ 30$ million in customer retrofits and 243,000 MMBtu annual savings over four years from 2003 to 2007. Maryland and the MidAtlantic Home Performance Collaborative demonstrate how States can work together to reduce administrative and program costs and share information. ${ }^{23}$ These efforts show that consumers will undertake investments to improve the energy performance of their homes when they are provided with information on how to do it. Reaching more consumers this way could lead to significant private investment in energy efficiency.

In addition to supporting broader use of home energy performance ratings, Federal policy could include a robust monitoring, verification, and evaluation program. Evaluating the performance of existing home energy performance ratings and programs that use them will be necessary to ensure that the methods keep pace with the changing needs of consumers and the housing

\footnotetext{
${ }^{23}$ Reported information from states on Home Performance with ENERGYSTAR is based on a webinar from NASEO (2008)
} 
market. Evaluations should also consider improvements in home stock over time and make adjustments to policy if goals are not being met. Surveys of consumers could provide useful evaluative material on awareness, understanding, and value of home energy performance ratings. The costs of the program requirements to the public should be weighed against the energy benefits; however, driving energy benefits through such a program will take time. If the cost of home energy performance ratings is subsidized by Federal, State, or local government, benefits would accrue faster to consumers but costs would accrue to the government. Because widespread home energy performance ratings will require a large certification workforce, labor benefits will be immediately recognizable while benefits from energy savings will take time.

Administrative Practicality. This Federal action requires additional funding to existing training efforts; it also requires coordination for development of a common system of reporting. As such, the Federal administrative burden for this recommended program is low.

At the State and local level, ordinances may need to be amended to allow for home energy performance ratings to qualify for certain State and local building permits or programs. In addition, certification or acceptance of a rating method may require some legislation for those States that do not currently have rating systems in place or endorse home energy performance ratings.

Additionality. Because a rating system is an enabling policy, it is difficult to directly attribute benefits. However, ratings provide standardized information that consumers and policy makers alike can use. Other policies to improve information communication in the residential market will make the benefit of a rating system even harder to differentiate, but a suite of information efforts would be more effective than just a rating system.

\subsubsection{Summary}

It is recommended that the Federal government provide technical and financial assistance to States to develop policies that incorporate home energy performance ratings and ensure a qualified home energy performance rating workforce. Expanded use of home energy performance ratings can support a number of policies to reduce energy consumption in homes. In addition, as ratings become commonplace, homeowners will be able to judge homes by their energy performance as they do other obvious measures, like how many bathrooms it has. While home energy performance ratings do have a cost, they can be of value to policy makers and individuals. Their ultimate value will depend on the policies developed to interact with them. 


\section{Policies to Promote Energy-Efficient Improvements to Existing Residences}

Energy efficiency improvements in older homes are often found to be highly cost-effective investment opportunities. Among the numerous strategies for cutting energy costs and carbon emissions, they are often seen as some of the most "profitable" approaches (McKinsey \& Company, 2007). However, numerous market failures and barriers impede these investments; foremost among them are the problems of misplaced incentives and imperfect and asymmetric information.

Labeled the principal/agent problem by economists, this problem occurs when one party (the agent) makes decisions in a given market, and a different party (the principal) bears the consequences of those decisions. Such market failures were found by Prindle (2007) to be significant and widespread in many end-use markets in both the U.S. and other IEA countries. In many market situations, buyers purchase equipment on behalf of consumers without taking into account their best interests. Two types of misplaced incentives inhibit energy-efficient investments in the buildings industry:

- Architects, engineers, and builders select equipment, duct systems, windows, and lighting for future building occupants who will be responsible for paying the energy bills; and

- Landlords purchase appliances and equipment for tenants who then pay the energy bills.

The involvement of intermediaries in the purchase of energy technologies limits the ultimate consumer's role in decision making and leads to an under-emphasis on life-cycle costs. The problem is particularly difficult in rented dwellings, which constitute a large fraction of the U.S. housing market. Nearly one-third (32 percent) of U.S. households rent their homes. For this segment of the market, landlords have a powerful influence over the energy efficiency of the building structures and their equipment (Brown, Southworth, and Stovall, 2005).

The landlord-tenant relationship is a classic example of misplaced incentives (Murtishaw and Sathaye, 2006). If a landlord buys the energy-using equipment while the tenants pay the energy bills, the landlord is not incentivized to invest in efficient equipment unless the tenants are aware of and express their self-interest. Thus, the circumstance that favors the efficient use of equipment (when the tenants pay the utility bills) leads to a disincentive for the purchase of energy-efficient equipment. The case that favors the purchase of efficient equipment (when the landlord pays the utility bills) leads to a disincentive for the tenants to use energy efficiently (Ottinger and Williams, 2002). About 90 percent of all households in multifamily buildings are renters, which makes misplaced incentives a major obstacle to energy efficiency in urban housing markets. 
Information barriers occur when consumers do not possess enough usable information to make decisions that are in their own best interest. These barriers are sometimes actually problems of asymmetry where one party (usually the seller) has information applicable to the transaction that the other party (usually the buyer) does not have. Sometimes information barriers are compounded by a lack of trusted, actionable information. While a vast array of facts and data is available to consumers, the information is often presented in terms that are not specific enough to the consumer to be useful or to drive change. In addition, the degree to which consumers act on information depends on the type of decision and the type of consumer; households report habitual energy savings more than purchasing efficient products, and pro-environment households tend to report more energy saving lifestyle choices than non-environmentalist households (Barr, Gilg, and Ford, 2005). These differences suggest that consumer education efforts should take into account the general perspectives of the target population.

The result of these market barriers and obstacles is a large backlog of energy retrofit opportunities. The following policy options would help to address these barriers to energy efficiency in the existing homes and in rental housing markets.

\subsection{Mandated Disclosure of Energy Performance Information}

Policy Option: Require disclosure of home energy consumption or home energy performance at the point of sale or lease of a residential unit.

\subsubsection{Synopsis of Policy Option}

Federal legislation could require that information regarding the energy consumption or energy performance for a home be disclosed at the time the home is listed for sale. States may need to modify existing disclosure laws to match this new Federal requirement.

Common reporting methods should be established concurrently to ensure potential buyers have access to the information before making a significant commitment to purchase or rent a home (Stern, S., 2005). In addition, measurement and verification methods should be agreed upon or allowed to be established by the States. Experience in Denmark shows that program effectiveness, and hence overall benefits, is tied to the degree of monitoring, verification, and evaluation to drive dollars where they are most effective. In older homes where efficiency upgrades will provide the most savings per dollar, audits should be more comprehensive (Ea Energianalyse, 2008). In newer homes, comprehensive, and relatively expensive, audits may not drive the level of investment required to recover costs in the near term. This is not to claim that newer homes do not face cost-effective improvements; rather, there is more low-hanging fruit in the least efficient homes, and this should be considered in implementation. In addition to vintage 
effects, there are likely regional effects that will also benefit from monitoring, verification, and evaluation.

The success of disclosure will require that the public understands and is comfortable with the material presented to them. Simple reporting methods as well as public information or education campaigns can help consumers interpret energy consumption and energy performance information disclosed to them. Consumers should be educated not only about the specific rating scheme, if one is created, but also on average consumption data, the benefits of greater efficiency, and the cost of retrofits. A case study in California demonstrated that consumer understanding of the meaning and usefulness of home energy performance data was a necessary prerequisite in most cases for consumer interest in home energy performance (Robert Mowris and Associates, 2004).

\subsubsection{Policy Experience}

Mandated disclosure policies are in place or under consideration in several jurisdictions both in the United States and abroad. Denmark and the Australian Capital Territory have had the most experience.

The policy form of mandated disclosure varies with two general types of information required at point of sale alone or in combination: energy usage history or energy performance rating. A more aggressive form of this policy - requiring a certain level of energy performance or level of expenditure on energy efficiency at the time of sale of a property - is in place in Berkeley and San Francisco, California, but its diffusion to other jurisdictions who have considered this policy form has been limited due to high associated costs, potential impact on home sales, local opposition, and income effects. ${ }^{24}$ This document will consider mandatory disclosure as one policy, with discussion on areas where the two policy forms differ; final policy form is left to debate.

- Energy usage history. This policy form requires provision of energy consumption data to the buyer at the time of sale.

Montgomery County, MD, adopted an ordinance in April 2008 requiring that sellers, beginning in January 2009, provide an energy-efficient retrofit guidebook and 12 months of energy usage information, where available, to buyers (Montgomery County, 2008). ${ }^{25}$ The council had initially considered requiring energy inspections at time of sale, but amended the bill because of the

\footnotetext{
${ }^{24}$ Requiring that homes meet a standard or are subject to a certain level of efficiency investment is not considered further in this document.

${ }^{25}$ Bill 31-07, Real Property - Energy Performance Audits; http://www.montgomerycountymd.gov/content/council/pdf/bill/2008/20080804_31-07.pdf
} 
prospective costs and objection on the part of local home inspectors, who were anticipated to be allies; the bill sponsor claims that local realtors support the bill (Montgomery County, 2008).

Disclosure of energy usage history will be most useful in comparison with the range and average consumption for similar dwellings. In regards to appliances, consumers were found to interpret energy labels (like EnergyGuide stickers) as certification of good energy performance (like ENERGY STAR) (Egan and Brown, 2001). Newer labels for appliances combine these information forms.

- Energy performance rating. An energy performance rating requires completing an assessment or audit of a home's energy performance and translating the results into an understandable rating system. There are varying degrees of complexity in audits and inspections used to create a rating.

Conducting a standardized inspection is much faster than providing a full energy audit. The report provided at the conclusion of an EnergyCheckup includes rating, comparison of current and after retrofit energy bill costs, and a list of recommended retrofits. ${ }^{26}$ This method will be less accurate than a full audit, but offers reduced time and cost.

Australian Capital Territory (ACT) has required disclosure of home energy efficiency in all sales information since 1999; the ACT scheme is a star rating with more stars indicating greater thermal efficiency. ${ }^{27}$ Australia is considering mandatory disclosure in all territories based on the experience in other areas, notably ACT and Denmark (Australian Greenhouse Office, 2005).

Following the European Union Performance in Buildings Directive (EPBD), all member countries are required to establish standard energy performance audits for existing homes. Directive 2002/91/EC of the European Parliament and of the Council of 16 December 2002 on the energy performance of buildings required European member States to develop common rating schemes and put them into place by 2006 with a grace period for implementation until $2009 .^{28}$ This grace period is expected to be necessary to train inspectors (Wouters and van Dijk, 2007). The most popular form of compliance with the directive is the Energy Performance Assessment of Existing Dwellings (EPA-ED). EPA-ED is standardized to the point that assessors can follow a set of steps for data collection and then utilize EPA-ED software to provide location specific performance assessments; much freedom is allowed for local policy,

\footnotetext{
${ }^{26}$ http://www.energycheckup.com/content/MyRep_New.asp?Rid=2

${ }^{27}$ The original requirement for rating and disclosure was made in the Energy Efficiency Ratings (Sale of Premises) Act 1997; this act was repealed when the Civil Law (Sale of Residential Property) Act 2003 was passed since the newer law included energy efficiency rating disclosure as Part 3 of the Act. The current version, including amendments, can be found at http://www.legislation.act.gov.au/a/2003-40/current/pdf/2003-40.pdf. A description of the rating scheme is available from the Australian Capital Territory Planning and Land Authority: http://www.actpla.act.gov.au/topics/property purchases/sales/energy efficiency.

${ }^{28}$ http://europa.eu/scadplus/leg/en/lvb/127042.htm
} 
technical specifications, and climate (Poel, van Cruchten, and Balaras, 2007). While it is beyond the scope of this proposed policy, uniform data collection in the rating or assessment could allow for detailed energy analysis and comparison by region and vintage. ${ }^{29}$

In Austin, Texas, the city council was considering requiring sellers to upgrade homes to meet efficiency standards prior to listing. The Austin Board of Realtors argued that performance disclosure protects the real estate agent and seller from legal action for poor performing homes; uniform performance disclosure also allows for market transformation (Chenevert, 2008). The final form of the ordinance, passed November 6, 2008, requires energy audits before selling homes with a voluntary program for implementing cost effective upgrades; it also sets targets for audits of multifamily units. ${ }^{30}$ The voluntary upgrade program will be run by Austin Energy with a spending cap of one percent of the home's value for upgrades with a simple payback of not more than seven years. ${ }^{31}$ The council's task force anticipates 85 percent of audited homes will participate in this voluntary program over the first four years.

Combined forms. Denmark has required energy disclosure on new and resale residential and commercial buildings since 1997; buildings are divided into three groups for rating purposes: Large, small, and industrial. ${ }^{32}$ The Danish rating scheme includes a rating, plan for savings, and direct consumption information; ratings are required annually for large buildings and upon construction or point of sale for small buildings (Laustsen and Lorenzen, 2003). The Danish model used a combined building rating scheme that included electricity, heating, and water consumption histories, ratings, and combined environmental impact levels (Figure 3.1). With the passage of the EPBD, Denmark redesigned the policy to match EU goals (Law No. 585 of June 2005 "On the Promotion of Energy Saving in Buildings" and Decree No. 228 of April 2008 "On the Energy of Buildings"), and the associated label may have had to change as well. The new energy rating is longer, with recommendations for improvements included. ${ }^{33}$

\footnotetext{
${ }^{29}$ http://www.meteo.noa.gr/datamine/

${ }^{30}$ Only single family homes more than 10 years old require an audit; there are exemptions to the audit requirements for homes in foreclosure, those with recent efficiency upgrades, for low-income homeowners, and for historical and other types of structures (Ordinance No. 20081106-047). This ordinance can be found at http://www.cityofaustin.org/edims/document.cfm?id=123737

${ }^{31}$ These goals were established by the task force and formally adopted by the Austin City Council as Resolution No. 20081106048 (http://www.cityofaustin.org/edims/document.cfm?id=123402).

${ }^{32}$ Act to Promote Energy and Water Savings in Buildings No. 485 of 12 June 1996. Denmark. http://soeg.ekn.dk/Afgorelser/L_585_Act_to_promote_energy_savings.pdf

${ }^{33}$ The example energy rating is available (in Dutch) at http://ens.dk/graphics/Energibesparelser/Ny_energimaerkningsordning_og_ny_kedelordning_PDF_filer/Eksempel_Enfamilieshu s.pdf; no similar one-page label to the one published by Miguez et al. (2006) was found on the Danish Energy Agency website.
} 


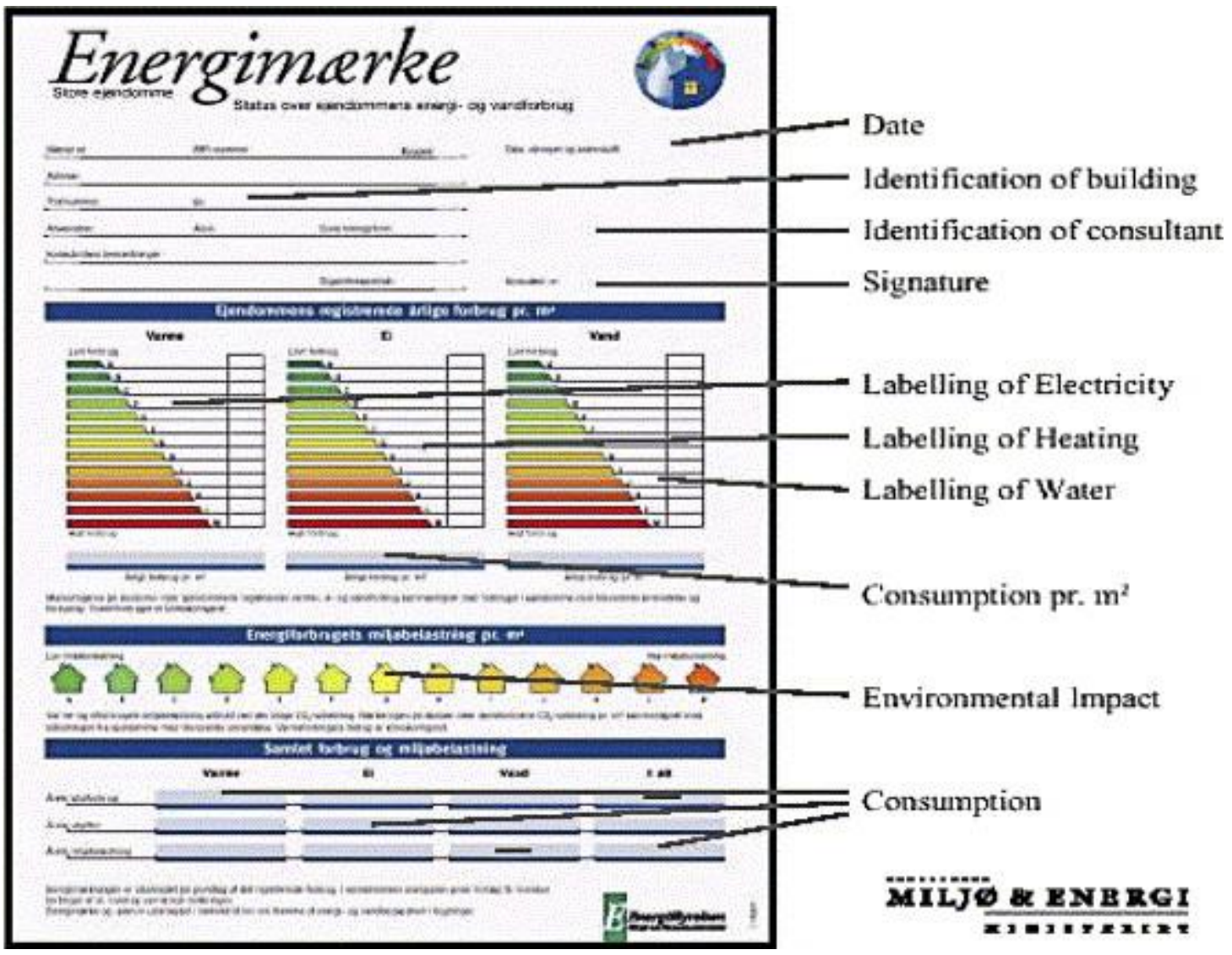

Figure 3.1 Energy Rating Form in use in Denmark

(Miguez et al, 2006, Fig. 3)

Denmark has shown sustained success with its consistent message. "Between 45,000 and 50,000 ratings per year are carried out, almost 70 percent of single-family dwellings are rated at the time of sale, and spending on energy in single-family dwellings has dropped by around 20 percent [since 1997]" (Miguez et al., 2006).

Several jurisdictions are considering combined form disclosure.

- Maine's SP 841 would require that new construction and significant renovations meet building energy code requirements and provide certification of energy performance to the first buyer; subsequent sales would require provision to the buyer of 24 months of consumption history and a report on thermal performance. ${ }^{34}$

- In Ontario, Canada, a bill has been introduced that would require disclosure of an energy efficiency audit for new homes followed by resale homes and those listed for rent (McNeely, 2008). Debate in the Ontario Legislative Assembly was supportive of the

\footnotetext{
${ }^{34}$ This bill has been postponed indefinitely. http://www.mainelegislature.org/legis/bills/bills_123rd/billtexts/SP084101.asp
} 
intent and measure of this bill (Bill 101-2008); the bill was referred to the Standing Committee on Finance and Economic Affairs. ${ }^{35}$

- Denver, Colorado's council has considered a hybrid point-of-sale star rating system. This policy form assigns stars via a prescriptive checklist to three stars and relies upon performance (in the form of HERS ratings) for four and five stars. The policy form does not rely on HERS entirely due to anticipated inspection cost, lack of qualified raters, and HERS focus on energy per square foot, rather than total consumption. ${ }^{36}$

\subsubsection{Policy Rationale}

Mandated disclosure of energy performance information for housing units advertised for resale could help address the information gaps and misplaced incentives that pervade the existing housing market, leading to a backlog of energy retrofit opportunities. In the rental market, knowledge of a dwelling's efficiency can reduce the misplaced incentives on both the owner and tenant while helping renters ensure that the rent + utilities will remain in their budget.

Consumer's decisions to retrofit or upgrade homes to increase their energy efficiency are based on many factors including rising energy costs (and the expectation is they will not fall again), the ability to estimate a short term return on investment, sufficient income or financing options, and credible information on cost-effective improvements (Russell, 2006). In addition, consumers may upgrade windows and insulation for comfort reasons, even though the investments will not pay back during their residency and may not be reflected in the home's resale value. Comfort and amenities can be drivers, and energy efficiency an ancillary benefit. Mandated disclosure will provide credible information and should make identification of return on investment simpler; however, this research suggests that availability of loans to make improvements could drive greater retrofits. While this policy does not intend to provide financing or financial incentives, demand for efficient improvement of houses could lead to development of a private market for micro-loans, or consumers may make greater efforts to uncover other creative financing mechanisms.

Federal guidance can ensure consistency in definitions and presentation across States; consistency is important so that consumers can understand what is being disclosed and those who are conducting rating and assessments are doing so with a common technique and perspective.

The degree of variability across the nation for real estate disclosure is striking; there are more than 400 separate multiple listing services (MLS) in operation. MLS are not operated by realtor associations, but they do respond to realtor association input to determine their format. Alaska

\footnotetext{
${ }^{35}$ Text of bill discussion can be found at http://www.ontla.on.ca/web/house-proceedings/house_detail.do?Date=2008-10$16 \&$ Parl $=39 \&$ Sess $=1 \&$ locale $=$ en\#P951 316869

${ }^{36}$ www.recaonline.com/docs/arc/arc2008/PointofSale_DenverCO.doc
} 
and Washington have a field for energy-efficiency ratings (Combs, 2008). Colorado and Wyoming have a field for energy consumption history and Utah has fields for yearly highs and lows; these fields are not used due to laws or guidelines declaring the information private, high potential for mistakes in entries, and a lack of support among real estate agents (Combs, 2008). Portland's Regional MLS has added several additional searchable fields, including certifications like ENERGY STAR, and products, like solar tubes (Hawkins \& Shepherd, 2008). Other MLS may be following suit, but for realtors and consumers, the patchwork can be confusing.

While the United States does not have to deal with the same language and governance barriers of the European Union, we can learn the value of a priori definitions and consistency for home energy performance disclosure (Casals, 2006). To the extent that information on energy consumption or performance is disclosed to buyers, standard methods of disclosing such information should be developed at the same time as the type of information is determined.

\subsubsection{Stakeholders and Constituencies}

Mandatory disclosure laws affect the day-to-day operations of MLS organizations and realtors; these two private actors will need to agree that the form of disclosure does not present an unnecessary burden to them. On the National level, the U.S. Green Building Council (USGBC) and the National Association of Home Builders are competing to make their standards "the standard," further adding to the confusion, there are over 80 State and local green building councils (Alsever, 2007).

States may have existing laws that conflict with mandatory disclosure of home energy performance.

Private actors who engage in home energy rating will be eager to drive the reporting requirements in a way that benefits them. Similarly, utilities may support or oppose mandatory disclosure depending on how the ruling relates to them.

\subsubsection{Policy Evaluation}

Appropriateness of the Federal Role. "As a general matter, government remedies are most suited to overcoming genuine market failures or government failures" (CCCSTI, 2009, p. 5). In the case of homes, the buyer (or leasee) must make a decision to purchase (rent) without knowing the energy consumption likely to be required to keep the home's interior within a healthy temperature range, operate a range of appliances, and provide sufficient lighting. Because the seller (leasor) is likely to be aware of their own prior consumption needs, the transaction occurs under asymmetric information, a classic market failure. OMB guidance 
suggests that policies or measures explicitly designed to alleviate asymmetric information should be given preference over other measures (OMB Circular A-4). ${ }^{37}$

Federal action to require disclosure of potential energy consumption information has precedent for appliances and automobiles; yet these objects have less of an impact on an individual's or family's energy consumption than their home.

Federal action to require disclosure of information pertinent to the sale of a home has precedent in the lead-paint disclosure. The Housing and Community Development Act of 1992, Title X (Residential Lead-Based Paint Hazard Reduction Act of 1992) requires that sellers disclose presence of lead-based paint to the extent of their knowledge; buyers are also provided with a brochure on the potential hazards of lead-based paint. ${ }^{38}$ While it can be broadly argued that home energy performance is not a potential health hazard of the magnitude of lead-based paint, there are health benefits from better performing homes (Schweitzer \& Tonn, 2002). To the extent that energy performance does contribute to improved health, especially among vulnerable populations, it may be sensible to establish authority for the program under the Office of Healthy Homes and Lead Hazard Control.

As such, Federal action to require disclosure of home energy consumption or home energy performance at the point of sale (lease) can be considered appropriate. Because real-estate transactions are generally a local matter, alternative Federal action to require or aid local governments in adoption of similar measures could be warranted. If this alternative action is taken, development of a model rule could reduce local promulgation delay while saving aggregate promulgation time and associated costs (Kaplow, 1992). Local governance is preferred over Federal action in most cases; the only concern is that fragmented local action can confuse buyers who often move between, rather than within, jurisdictions. This concern is highlighted in the cost-effectiveness section (2.1.5) of this document where the need for understanding and acceptance of the disclosure system, among buyers, is a necessary precondition to success of the program; varying methods for disclosure could significantly limit the capacity of buyers to use the information provided. Variation would also inhibit economies of scale in (1) the training and certification of auditors and home energy raters and (2) the provision of utility billing information from energy services companies doing business across multiple States.

Specifically pertaining to leases, the Federal government is already involved in promoting green leases in its own lease transactions. Also, the Federal government, through both the DOE and the EPA, provides extensive information on energy efficient practices. Offering useful information

\footnotetext{
37 "A regulatory measure to improve the availability of information, particularly about the concealed characteristics of products, provides consumers a greater choice than a mandatory product standard or ban" (Circular A-4 p.9)

3842 U.S.C. $4852 \mathrm{~d}$
} 
to promote the use of green leases, such as a Green Lease Toolkit, could easily be included in with current initiatives. This effort is currently focused on commercial space, but it could be translated to the residential sector.

Broad Applicability. The point of influence of this policy mechanism is when a housing unit is being sold. ${ }^{39}$ Approximately five percent of the housing stock is sold each year, with turnover varying slightly by region (Table 3.1). Thus, while the program is applicable to all existing homes; it will reach about one-quarter of the housing stock over five years. Individual housing unit turnover rates vary, and some housing units may never turn over; despite these limitations, a sustained disclosure program will reach most housing units by 20 years. ${ }^{40}$

\footnotetext{
${ }^{39}$ The potential for savings in the rental market is less clear (leasees still have no incentive to improve their leasor's property); therefore, savings estimates from green leases are not included here. However, renters could demand more efficient properties and drive investments by owners.

${ }^{40}$ The U.S. Real estate market has experienced a downturn since 2005; if the market becomes more active, housing turnover could be accelerated or vacant homes may become occupied.
} 
Table 3.1 Existing Occupied Housing Units and Home Sales by Census Region, 2005-2007 (NAR, 2008; U.S. Bureau of the Census, 2006; 2007; 2008a) ${ }^{41}$

\begin{tabular}{|l|c|c|c|}
\hline & $\mathbf{2 0 0 5}$ & $\mathbf{2 0 0 6}$ & $\mathbf{2 0 0 7}$ \\
\hline \multicolumn{4}{|c|}{ Northeast } \\
\hline Housing Units & $20,582,523$ & $20,553,582$ & $20,593,754$ \\
\hline Existing Home Sales & $1,169,000$ & $1,086,000$ & $1,006,000$ \\
\hline Percent Sold & 5.68 & 5.28 & 4.88 \\
\hline \multicolumn{4}{|c|}{ Midwest } \\
\hline Housing Units & $25,603,971$ & $25,688,303$ & $25,778,315$ \\
\hline Existing Home Sales & $1,588,000$ & $1,483,000$ & $1,327,000$ \\
\hline Percent Sold & 6.20 & 5.77 & 5.15 \\
\hline \multicolumn{5}{|c|}{ South } \\
\hline Housing Units & $40,712,300$ & $40,963,290$ & $41,381,254$ \\
\hline Existing Home Sales & $2,702,000$ & $2,563,000$ & $2,235,000$ \\
\hline Percent Sold & 6.64 & 6.26 & 5.40 \\
\hline \multicolumn{5}{|c|}{ West } \\
\hline Housing Units & $24,191,823$ & $24,412,227$ & $24,624,654$ \\
\hline Existing Home Sales & $1,617,000$ & $1,617,000$ & $1,084,000$ \\
\hline Percent Sold & 6.68 & 6.62 & 4.40 \\
\hline & $111,090,617$ & $111,617,402$ & $112,377,977$ \\
\hline Housing Units & $7,076,000$ & $6,478,000$ & $5,652,000$ \\
\hline Existing Home Sales & 6.37 & 5.80 & 5.03 \\
\hline Percent Sold & \multicolumn{5}{|c|}{ U.S. } \\
\hline
\end{tabular}

Significant Potential Benefits. Providing potential home buyers with consistent, understandable information on home energy consumption or performance provides several benefits that lead to the targeted benefit of improved efficiency of the existing housing stock: addresses key information barriers, internalizes value for energy performance in homes, and provides for development of uniform system of describing or assessing home energy performance to prevent 'greenwash'. The only quantified benefits are for reduced energy consumption, presented in terms of the energy costs avoided by consumers.

Address key information barriers. If properly informed, buyers could drive the market to greater efficiency. If an assessment is not made at the time a property changes hands, and home energy

\footnotetext{
${ }^{41}$ About 70 percent of U.S. Housing units are single family structures; about 25 percent are multifamily units; the remainder are mobile or manufactured homes (EIA, 2008b).
} 
performance remains unknown, the resident or owner will be even less likely to make improvements, even cost-effective ones. So long as the information about the home's energy performance is known to the buyer and the seller, they will be able to work from the same set of knowledge to agree on a fair selling price (Freeman and Kolstad, 2006). ${ }^{42}$ Providing information on the home's characteristics is not found to harm the seller; rather sellers offering State mandated disclosure forms before purchase increase buyer confidence and is correlated to higher home sale prices (Nanda and Ross, 2007).

Internalize value of home energy performance. Research shows that buyers shop around and compare homes based on their features. In 2008, the average buyer viewed 10 homes over 10 weeks before making a purchase (NAR, 2009). While it was not one of the most demanded features, energy efficiency was important to 92 percent of home buyers in 2006 and 2007 (NAR, 2007). Consumers likely did not demand energy efficiency with the same vigor as other features because energy performance is intangible; potential home buyers cannot look at it and compare homes. Efficiency features are "decidedly unsexy" compared to features like designer kitchen and bathroom counter tops and fixtures (Alsever, 2007). In addition to their being invisible, efficiency features may not appear as core attributes of a home; mandatory disclosure of energy performance can move these features from auxiliary to core attributes and thereby increase their value (Faiers, Cook, and Neame, 2007).

Uniform system of assessment. Federal disclosure rules allow for uniform presentation of information across the country. Today, consumers are provided with several potential metrics or products they must navigate. On top of disagreement and confusion for what should be considered efficient or green, finding a green or efficient home based on any of these standards is a challenge. For example, ListedGreen.com attempts to connect buyers and sellers of environmentally advanced properties, but buyers are likely to overlook this site in favor of more general listings. ${ }^{43}$

Improved efficiency of the existing housing stock. Only twelve percent of occupied housing units in the United States in 2007 were constructed in 2000 or later; Table 3.2 shows the distribution of vintage for occupied housing units in the United States (U.S. Bureau of the Census, 2008b). Almost three-quarters of occupied housing units were built prior to 1990; widespread adoption of building energy codes did not occur until required in the Energy Policy Act of 1992, which amended the Energy Policy and Conservation Act of 1975 (Public Law 102-486).

\footnotetext{
${ }^{42}$ Freeman and Kolstad (2006) argue for seller to buyer disclosure in reference to industrial sites; while they are concerned with environmental contamination rather than energy consumption, the point is the same.

${ }^{43}$ A search on January 23, 2009 found only 128 listed properties in the United States, so sellers may also overlook this option to avoid only reaching a niche-market. http://www.listedgreen.com
} 
Table 3.2 Vintage of Occupied Housing Units in the United States, 2007

(U.S. Bureau of the Census, 2008b)

\begin{tabular}{|l|c|c|}
\hline Year Structure Built & $\begin{array}{c}\text { Percent of Occupied } \\
\text { Housing Units }\end{array}$ & Margin of Error \\
\hline 2000 or later & 12.0 & \pm 0.1 \\
\hline 1990 to 1999 & 14.2 & \pm 0.1 \\
\hline 1980 to 1989 & 14.2 & \pm 0.1 \\
\hline 1960 to 1979 & 28.2 & \pm 0.1 \\
\hline 1940 to 1959 & 17.4 & \pm 0.1 \\
\hline 1939 or earlier & 14.0 & \pm 0.1 \\
\hline
\end{tabular}

Due to the lifetime of homes, efficiency not achieved at construction or during major renovations is essentially a lost opportunity. Home buyers who are aware of the home's energy performance will be better prepared to adopt more efficient technologies and materials when those are needed or upon desire to improve comfort or reduce energy expenditure.

A pilot program in northern California recruited and trained home inspectors to offer prospective home buyers the opportunity to purchase an additional inspection, an energy inspection called EnergyCheckup, at the time of routine home inspections before purchase. Those who did purchase the EnergyCheckup rated the inspection information as reasonable, applicable, and informative; these buyers later adopted 46 percent of the recommended measures to improve their home performance. This number supports the theory that consumers are willing to pay for improved energy efficiency when well informed (Robert Mowris and Associates, 2004). Evaluators find that the program demonstrated the net-present avoided costs of EnergyCheckup at time of sale to be $\$ 208$ per home (Robert Mowris and Associates, 2004).

Actual benefits will vary by home, with older homes having the greatest savings from efficiency upgrades. The value of benefits will vary by cost; where energy is most costly, efficiency upgrades will be most beneficial from a monetary perspective. Research also shows that savings, for the median home, in the most energy-consuming end-uses, space heating and space cooling, vary dramatically by region (Table 3.3). 


\section{Table 3.3 Estimated Utility Bill Savings after Switching to ENERGY STAR or Best Available Technology}

(Mills, 2007, Table 27 p. 55)

\begin{tabular}{|l|c|c|c|c|c|}
\hline \multirow{2}{*}{\begin{tabular}{c}
\multirow{2}{*}{$\begin{array}{c}\text { Census } \\
\text { Division }\end{array}$} \\
\cline { 2 - 6 }
\end{tabular}} & $\begin{array}{c}\text { Space } \\
\text { Heat }\end{array}$ & $\begin{array}{c}\text { Space } \\
\text { Cool }\end{array}$ & $\begin{array}{c}\text { Water } \\
\text { Heat }\end{array}$ & Appliances & Total Bill \\
\hline New England & 63 & 33 & 50 & 35 & 49 \\
\hline Mid Atlantic & 66 & 33 & 50 & 33 & 47 \\
\hline $\begin{array}{l}\text { East North } \\
\text { Central }\end{array}$ & 66 & 62 & 50 & 33 & 49 \\
\hline $\begin{array}{l}\text { West North } \\
\text { Central }\end{array}$ & 66 & 59 & 50 & 34 & 52 \\
\hline South Atlantic & 65 & 62 & 43 & 35 & 50 \\
\hline $\begin{array}{l}\text { East South } \\
\text { Central }\end{array}$ & 65 & 62 & 43 & 35 & 49 \\
\hline $\begin{array}{l}\text { West South } \\
\text { Central }\end{array}$ & 67 & 62 & 50 & 35 & 53 \\
\hline Mountain North & 66 & 62 & 50 & 35 & 48 \\
\hline Mountain South & 65 & 62 & 43 & 35 & 48 \\
\hline Pacific North & 65 & 62 & 43 & 35 & 63 \\
\hline Pacific South & 67 & 62 & 50 & 34 & 47 \\
\hline
\end{tabular}

The Home Energy Saver results shown in Table 3.3 are based on adoption of the best available technology, and may not be cost-competitive (Mills, 2007). For the purposes of this report, a more conservative estimate of savings is made based on the weatherization program, rather than assuming that retrofits will adopt all best available technology. Based on a meta-analysis of weatherization savings, electric-heated homes save 10.5 percent of pre-weatherization wholehouse electricity consumption and gas-heated homes save 21.9 percent of pre-weatherization whole-house gas consumption, with average annual site energy savings of 29.1 million Btu (Berry and Schweitzer, 2003). The weatherization program is targeted to low-income consumers who are also likely to live in older but smaller homes; thus, the savings and the retrofit costs may be higher or lower than in the general population.

To assume benefits for the disclosure program and not retrofit, in general, this study assumes that one-third of home buyers, an estimated two million homes per year (less than the 46 percent offered by Robert Mowris and Associates (2004), to be conservative) adopt sufficient retrofits to achieve savings of 29.1 million Btu. This translates into an annual incremental savings of 58.2 trillion Btu. Over time this level of annual savings will shrink as the same homes re-enter the resale market. It is estimated that over a 10-year period, perhaps 0.5 quadrillion Btu could be saved, or approximately 0.5 percent of total U.S. energy consumption. 
Solutions not Dependent on Future R\&D. Requiring the disclosure of energy consumption histories, energy features, or energy performance ratings when housing is advertised for sale could be implemented immediately. It does not rely on R\&D or future technologies. Energy performance rating systems already exist, as do audit and inspection protocols.

Cost Effectiveness. The cost-effectiveness of the program will depend upon its final form and future energy prices. The benefits of a successfully implemented home energy disclosure program have been described above. Because this policy is not directed at retrofits, rather providing information to allow the market to drive retrofits, costs of actual retrofits are excluded from the policy consideration.

In terms of cost, the least costly measure is to require provision of consumption history from sellers or utilities while the most costly form would require detailed assessment of home energy performance at the time of sale. Providing assessment through a checklist will cost less than requiring assessment of home energy performance through an audit system. For each policy form, cost-effectiveness is presented here based on previous experience or based on estimates of costs and benefits under the assumption of six million housing units sold per year. Assume that administration, marketing, monitoring, verification, and evaluation are fixed costs regardless of policy form. Assuming that these will cost about $\$ 50$ (\$25 per home estimate for provision of these, offered by Robert Mowris and Associates (2004) ignores the higher costs at the beginning of such an effort); fixed costs are estimated at $\$ 300$ million per year. These costs are expected to decline overtime as experience develops.

Energy usage history. Disclosure of energy consumption histories will require consumption history for a residence to be provided at the time of sale by sellers or energy providers. Provision by sellers is anticipated to be less costly than provision by utilities; however, sellers who are unprepared will likely rely upon the utility for provision of information. As consumers learn the requirements of the policy, they will be more likely to maintain bills in preparation for future sale of their homes. Reliance on individual consumers learning is not recommended because of time lags; rather, active consumer awareness programs should make consumers aware of their role.

Electricity and natural gas consumption data is maintained by utilities and is available to customers upon request; in some cases, usage history is available online to customers. As a result, complying with this policy would be relatively inexpensive for both the utility and the homeowner. Utilities are already reporting a vast amount of information about their operations with minimal reporting burden; for example, EEI estimates that it takes 1.2 hours to respond to file an EIA-825 form on monthly electric sales and revenue (Bartholomot, 2007). Reformatting consumption information already provided to consumers should take much less time. Reporting 
consumption history is more costly for the significant percent of U.S. homes using other fuels such as natural gas (62.5 percent) kerosene (1.5 percent), fuel oil (7.7 percent), or propane (11.3 percent), where different suppliers may have sold these fuels to a homeowner over the course of several years, potentially not under long term contracts (EIA, 2008c). Providing the same information for consumption of wood or other materials (13 percent) will likely not be feasible (EIA, 2008c).

While home sellers may only be expected to provide numbers taken from their bills, utility provided home energy usage information may be more detailed, depending on the utility. Arizona Public Service (APS) has made available average billing costs (rounded to \$5) for the last 12 months for any address serviced by them; interested parties simply enter a valid address in a web form. ${ }^{44}$ Similarly, Xcel Energy will provide high, low, and average gas and electricity consumption data for any address serviced by them. NorthWestern Energy allows real estate agents access to energy usage information for the properties they represent. ${ }^{45}$ Progress Energy allows customers to access energy usage information online, providing graphs (Figure 3.2).

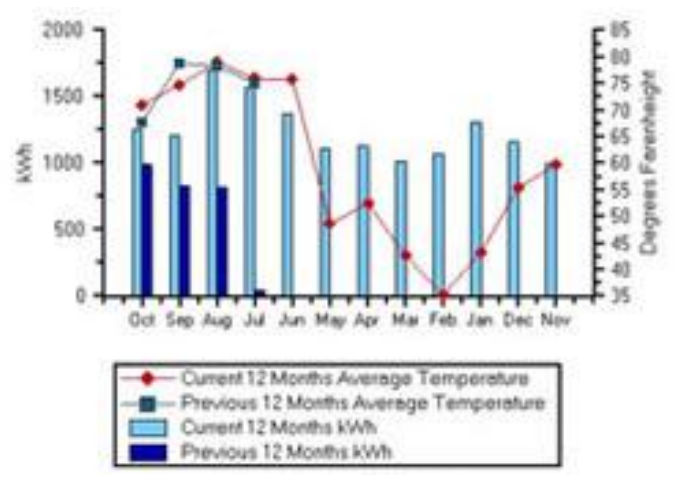

Figure 3.2 Progress Energy Example Energy Analysis Graph:
"Most Recent 12 Months Compared to Previous 12 Months""46

If data collection is conservatively estimated at one hour per home, and \$20 per hour - either a waged utility employee or a seller must spend their time on this activity rather than something else, this policy form (Energy usage history) would cost about $\$ 120$ million per year, in addition to fixed costs (total of $\$ 360$ million per year).

Energy performance rating. The city of Seattle's Green Building Task Force has considered mandatory disclosure through reporting of energy consumption history or performance

\footnotetext{
${ }^{44}$ http://www.aps.com/customer/addressSearch.asp

${ }^{45}$ http://www.northwesternenergy.com/display.aspx?Page=Real Estate Agent\%E2\%80\%99s Corner\&Item=103

${ }^{46}$ http://www.progress-energy.com/custservice/carres/myaccount/energyanalysisgraphdemo.asp
} 
audit/rating schemes; they concluded that an audit or rating would be more expensive than reporting consumption history but still administratively feasible (GBTF, 2008).

Energy rating in Denmark costs about 4500 Kroner for dwellings; this is about $\$ 770$ (Ea Energianalyse, 2008). ${ }^{47}$ An ordinance in Austin, Texas, requiring energy performance audits at time of sale doesn't go into effect until June 2009, so actual costs are still unknown; audits are expected to cost between $\$ 200$ and $\$ 300 .^{48}$ In Kansas, estimates for the cost of energy audits are higher, from $\$ 350$ to $\$ 500$ (Bell, 2008). Realtors in Kansas also argue that there are not enough raters to support point of sale audits in the State (Bell, 2008). Availability of trained inspectors or raters will ensure disclosure is based on technically proficient assessment and lead to reduced costs.

For the EnergyCheckup program described earlier, evaluators claim that a similar program could be designed to provide inspections at a cost of \$95 per home, broken down as follows: \$25 for administration, marketing, and verification, \$40 direct to inspector, \$25 in “free" energy efficiency kits for real estate agents to give to buyers at closing, and $\$ 5$ for training and technical support (Robert Mowris and Associates, 2004). For this particular study, benefits were estimated at \$208 per transaction, implying a Total Resource Cost measure of 2.1 (Robert Mowris and Associates, 2004). EnergyCheckup is proprietary software and inspection methodology, from GeoPraxis, that takes 30 minutes and claims to be as accurate as a three to four hour energy audit. $^{49}$

If a standardized inspection and rating can be provided at $\$ 70$ per home, the lowest cost end of this policy form would cost an additional $\$ 420$ million per year (total of $\$ 720$ million per year). If an individualized comprehensive rating can be developed from $\$ 200$ to $\$ 770$, this policy form would cost an additional $\$ 1.2$ billion to $\$ 4.6$ billion per year (total of $\$ 1.5$ billion to $\$ 4.9$ billion per year).

Evaluating the performance of a disclosure program will be necessary to ensure effectiveness and sustainability of providing home energy performance information. Evaluation should also consider the benefits to homeowners of having home energy performance information at the point of sale. Survey of consumers could provide useful evaluative material on awareness, understanding, and value of the program. The costs of the program requirements to the public should be weighed against the energy benefits; however, driving energy benefits through such a program will take time. Unless disclosure is through energy consumption history, costs will likely outweigh benefits for the first few years in all areas except labor. Because mandatory

\footnotetext{
${ }^{47}$ Currency converted on January 23, 2009 at http://www.x-rates.com/calculator.html

${ }^{48}$ Austin City Council Resolution No. 20081106-048 http://www.cityofaustin.org/edims/document.cfm?id=123402)

${ }^{49}$ http://www.geopraxis.com/content/pressrelease.asp?id=5
} 
disclosure of home energy performance will require a large rating workforce, labor benefits will be immediately recognizable while benefits from energy savings will take time.

Administrative Practicability. While there is limited experience with policies for disclosing home energy information, especially at the National level, the administrative burden is anticipated to be low.

The Office of Energy Efficiency and Renewable Energy already offers information on green leases for the commercial sector. ${ }^{50}$ Additional information on residential green leases could be added without creating a new program or incurring significantly greater expense.

A reporting burden will be created for those listing properties for sale or rent, and a monitoring and verification burden will fall on whichever agency is charged with ensuring that energy performance information is disclosed. Common reporting requirements and an informed public could ease identification of failure to disclose.

Additionality. Mandatory disclosure of home energy performance is a policy tool to address the policy issue of increasing efficiency in the existing stock of homes, many of which were built prior to widespread adoption of building energy codes. While this policy document has presented three different ways to implement disclosure, there are competing policy options to address energy use in the existing home stock. Almost all realistic policy options attempt to increase the efficiency and rate of turnover of built-in components of existing housing stock.

For example, consumer information campaigns tend to have limited direct value because consumers either do not to see the material as applicable to them or do not understand how to translate generalized information into actions. Even highly motivated consumers tend not to use this information productively (Desmedt, Vekemans, and Maes, 2009).

Related policies that appear to be effective at tackling the energy-efficiency gap in existing residential buildings are numerous, and therefore could capture some of the energy savings estimated for the mandatory information disclosure policy discussed in this paper. They include utility-operated demand-side management programs and on-bill financing of energy efficiency, decoupling of utility profits from energy sales, appliance and equipment standards, expansion of low-income weatherization, tax credits or refunds for efficient major purchases, consumer information campaigns on benefits of efficiency, and training programs for remodeling and repair professionals.

\footnotetext{
${ }^{50}$ http://www1.eere.energy.gov/buildings/commercial/leased.html
} 


\subsubsection{Summary}

Federally mandated disclosure of home energy performance before sale or rent of property is recommended in conjunction with common reporting methods, consumer education, and a robust monitoring, verification, and evaluation program. This policy will increase costs of purchasing or renting a home, and may create a reporting burden. However, providing potential home buyers with consistent, understandable information on home energy consumption or performance provides an opportunity for market transformation as efficiency becomes observable; this is in line with Federal regulatory goals of reducing information asymmetry. Over time, such a policy could drive substantial savings in home energy consumption.

\subsection{On-Bill Financing of Energy-Efficiency Improvements}

Policy Option: Provide financial assistance to State Energy Offices to establish revolving loan funds to enable on-bill utility financing of energy-efficiency improvements without upfront capital costs to the building owner.

\subsubsection{Synopsis of Policy Option}

The Federal government could encourage energy-efficiency investments in existing buildings by enabling State Energy Offices (SEOs) and utilities to offer on-bill financing to building owners. In the proposed financing scheme, the Federal government would provide seed money and program guidelines for revolving loans implemented through States. States would have the flexibility to determine their own program administrators and specific rules. However, State programs should include certified and bonded auditors and contractors competitively selected to promote quality and cost-competitiveness, and to ensure that monthly repayment obligations by consumers are less than the energy bill reductions from the energy savings.

In our recommended policy approach, supporting roles would be played by six organizations (Figure 3.3):

- The U. S. Department of Energy (DOE), which provides funding to SEOs to establish revolving loan funds to utilities that finance energy-efficiency improvements by their residential and small commercial customers.

- An SEO responsible for the successful implementation of the program in its State. The SEO would establish a revolving loan fund to finance the program and would competitively contract with companies to deliver energy audit and installation services. The SEO would also help market the program to potential participating customers 
(perhaps in collaboration with utilities) and would provide summary program performance statistics to DOE annually.

- One or more electric or natural gas utility that is willing to put a charge for energyefficiency services on their monthly bills to customers, and transfers these funds back to the SEO to replenish the revolving fund.

- Energy customers willing to pay for the retrofit work through their utility bills. Their willingness to pay is contingent on the monthly repayment obligation being less than the energy bill reductions from the energy savings. It is also important that any unpaid obligations transfer to subsequent building owners.

- A certified and bonded energy auditor to recommend proven retrofit measures and verify afterward that the work was done correctly. Completion of a Home Energy Rating (or comparable rating for a small commercial building) would be an integral part of the auditor's responsibility, as would an inspection of the building after the contractor has completed the energy-efficiency upgrade.

- A certified and bonded contractor to install the energy-efficiency improvements. The pool of certified contractors available to program participants would be competitively selected by the SEO.

A similar arrangement could be used to finance renewable energy installations on customer properties.

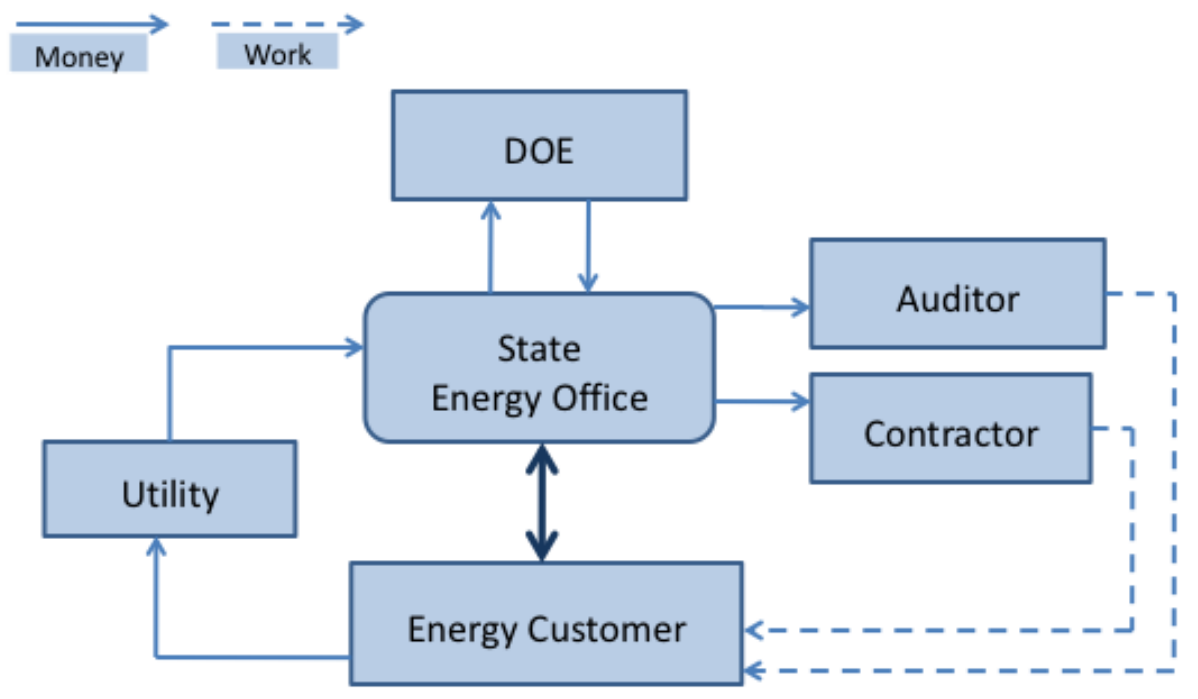

Figure 3.3 Conceptual Organization of an “On-Bill Financing” Program

(Source: Revised from Rogers, 2007) 
A nontraditional financing scheme could be designed in different ways by changing the funding source, the implementing authority, or the method by which repayment is collected. Potential funding sources include: Federal, State, or local government agencies, banks or other lending institutions (perhaps with a Federal guarantee), third parties (energy services companies, for example), or utility funds. Either the utility, the State, or a third-party firm could effectively serve to implement such a program. Determining the terms of repayment could be accomplished through forecasting savings via engineering calculations, audit-based estimates, or by comparing consumption before and after the improvements are made.

On-bill financing programs are designed to help customers pay for energy-efficiency upgrades through energy savings. The effectiveness of this type of program is greatly enhanced by partnering with utilities because they already have an established billing relationship their customers, and they have access to information about energy usage patterns and payment histories.

Joel Rogers (2007) has developed an organizational model of an on-bill financing approach called "Pay-As-You-Save" with features that address the issues identified as barriers in the past. PAYS $^{\mathrm{TM}}$ is comprised of six generic players - offering a type of mix-and-match approach with great flexibility. We have taken these six roles and defined specific types of organizations for each, thereby fitting the PAYS ${ }^{\text {TM }}$ approach to the opportunity presented by the 2009 American Recovery and Reinvestment Act. Matthew Brown (2009) also discusses two related financing mechanisms: on-bill financing through a utility tariff (tariff-based systems) and on-bill financing through loans from the utility company (on-bill loans). In both cases, the utility pays for the full installed cost of the efficiency measures and the consumers pay a monthly fee on their bills to compensate the utility.

The program design described here is unique in terms of the proposed role of Federal and State government agencies and the reliance on a revolving loan fund to promote the long-term success of the effort.

\subsubsection{Policy Experience}

On-bill loan programs currently exist in many states. Indeed, a review of residential efficiency financing programs in the U.S. and Canada by Fuller (2008) identified 18 programs in operation across the country. Capital for these programs came from a variety of sources including lender funds, internal utility funds, and public benefits charges. The most common financing mechanism was an unsecured consumer loan (Fuller, 2008, p. 37). This approach is quite distinct from the program design being proposed in this paper, which would rely principally on federal revenues passed through State Energy Offices and utilities to individuals. 
Most on-bill loan systems have focused on small business or government sectors, with large average loans (e.g., up to $\$ 250,000$ per project) and subsidized low-interest rates (Brown, M., 2009). The Alabama and Arkansas programs are the only ones that focus principally on the residential sector. Unfortunately, the results of these residential programs are not well documented. The program in Connecticut, operated by the United Illuminating Company has been very successful, with a focus on commercial and industrial customers. The program financed 310 projects in 2006 and saved 5.8 MWh (Brown, M., 2009). The Sempra Energy program in California also focuses on business and government customers uses state public benefits funds to buy down interest rates and subsidize the loan program's capita. The Sempra Energy program does not offer loans to residential customers because consumer finance laws in California impose restrictions and additional fees on companies offering residential financing (Brown, M., 2009)

There are two Federally-backed financing vehicles already in place that target existing residences for improvements: Fannie Mae's Energy Efficiency Loan (through utilities) and Energy Improvement Mortgages (through banks and other lending institutions). However, success with these programs has been limited.

Fannie Mae's Energy Efficiency Loan product allows for homeowners to enter into retrofit contracts without paying for them upfront. Contractors are paid directly from a loan administrator, and homeowners pay the unsecured loan. Figure 3.4 shows the loan process from ViewTech, a financial services company that specializes in energy efficiency financing from government and utility funds. ${ }^{51}$

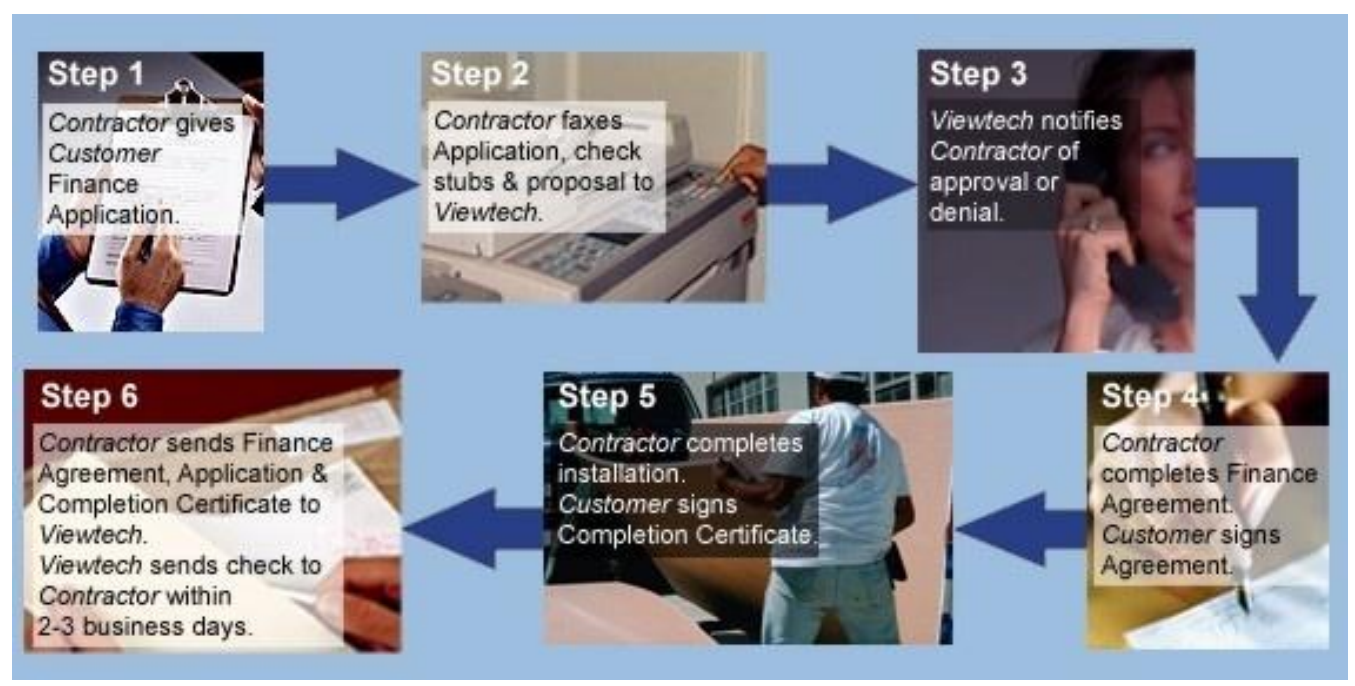

Figure 3.4 Fannie Mae Energy Loan Process

(Source: http://www.energyloans.org/body_process.html)

\footnotetext{
${ }^{51}$ The level of activity by consumers in these financing vehicles is largely dependent upon the state policy environment and the home owner's ability to qualify for FHA or VA loans (Farhar et al, 1997).
} 
While they generally do not perform the work or provide savings guarantees, several utilities offer on-bill financing for residential customers. The utilities offering these loans are using Fannie Mae funds in many cases, and they are self-funding in others. Utilities gain little in the way of risk protection from default, as Fannie Mae will cover only 1.5 percent of risk of loan losses for a fee.

An example of an existing on-bill financing program currently serving homeowners is the First Electric Cooperative of Arkansas' Home Improvement Loan program. This program grants loans to homeowners up to $\$ 15,000$ for heat pumps, efficient water heaters, and other electric service upgrades. Items purchased are applied to the electric bill and paid in installments, with term lengths varying depending on the size of the loan. ${ }^{52}$

While achieving energy-efficiency upgrades for many of its homeowners, this program has four important and interrelated weaknesses:

- the need to avoid losses significantly limits entry to "qualified debtors,"

- energy savings are not guaranteed,

- payments are made based on traditional loan terms rather than energy savings, and

- the loan contract is with the current homeowner without transfer.

In plain terms, these loans only partially address barriers to energy improvement for existing homes and small businesses, and then only for a subset of these markets.

In the case of Energy Improvement Mortgages, the design is based on energy savings (in dollars each month) being greater than the amortized improvement loan, as described by a home energy rating. This design should limit defaults, and it offsets the potential problem of not having payments based on savings. However, these mortgages must be requested by the homeowner upon financing or refinancing a home, and the homeowner must present the results of a home energy rating to the lender. Thus, the homeowner has had to pay a few hundred dollars for the rating and find themselves inconvenienced by the level of coordination and paperwork required to get into one of these mortgages. While Energy Improvement Mortgages can be considered a good idea, consumers do not often seek these because they either do not know about them or think it not worth it to pursue them.

Several programs exist or are in the process of being established that have many of the desirable attributes of utility on-bill financing.

${ }^{52}$ http://www.firstelectric.coop/content.cfm?id=2023 
In 2001, the New Hampshire Public Utilities Commission authorized pilot programs by the New Hampshire Electric Cooperative (NHEC) and the Public Service Company of New Hampshire (PSNH). Both pilots provided no-cash-upfront energy-efficiency improvements, with prepayment through electric bills. PSNH targeted municipal buildings, while NHEC targeted residential and small commercial buildings. A program evaluation performed 18 months after the start of each program found that the customers participating in these programs would not otherwise have invested in energy-efficiency upgrades.

In 2007, Midwest Energy Inc. (a customer-owned utility) sought permission from the Kansas State Corporation Commission to operate a program resembling the two on-bill financing programs operating in New Hampshire. In its filing, the utility expressed its desire to reduce customer energy bills, and not just control rates.

In 2008, the Massachusetts State Legislature passed an energy bill that included provisions for the establishment of a pilot on-bill financing program. ${ }^{53}$ Unlike the New Hampshire and Kansas examples, the motivation came from the State legislature and not the State utility commissions or individual utilities. The Massachusetts program will be administered by the State Energy Office in conjunction with public utilities. It specifically requires the payment to be structured so that the additions to the utility bill are less than the energy savings achieved, like the Energy Improvement Mortgages. It is tailored to smaller energy-efficiency purchases made by both businesses and residents.

The State of California requires utilities to reduce energy demand, and utilities have begun offering on-bill financing as one way to meet the requirement (Zwahlen, 2007).

\subsubsection{Policy Rationale}

On-bill financing provides a way for small businesses and homeowners to borrow money for the purchase of energy-efficient equipment. These groups often lack access to capital to insulate and weatherproof their buildings and to purchase high-efficiency equipment and appliances such as furnaces, water heaters, and heat pumps. Capital can be difficult to borrow, even though such improvements would save building owners money in the long term. Low-income customers often have special difficulties taking on debt, which makes on-bill financing especially applicable to these markets.

On-bill financing is a type of nontraditional financing mechanism that can overcome these barriers. With on-bill financing, the utility company loans money to businesses and/or homeowners to make such improvements; the loans are repaid (with or without interest) in installments applied to the monthly utility bill based on energy savings (rather than a traditional

${ }^{53}$ http://www.mass.gov/legis/laws/seslaw08/s1080169.htm, section 84 
loan-repayment schedule); the balance transfers with building ownership. Nontraditional financing is needed because the loans are relatively small, and without the ability to aggregate loans into an overall program, the transaction costs would be too large to manage.

Most performance contracting is directed at large or institutional customers; this is due, in large part, to State lead-by-example building improvement policies, as well as the relatively large savings and longer payback periods accepted by these customers (Goldman et al., 2005). Utilities experimented with performance contracting in the early 1980s as a means of financing home retrofits; however, the transaction costs were found to be high, and the energy services companies that conducted the retrofits for a share of the profit often invested in only a limited number of the most profitable upgrades, leaving significant opportunities behind (Brown and Reeves, 1986; Brown and White, 1988).

More than two decades later, designing a highly effective energy performance contracting program for residential and small commercial market seems highly feasible. Home Energy Rating Systems (HERS) have been matured, HERS training is available nationwide, and inspection protocols are available to verify that the recommended measures were installed. In a large portion of the residential market, energy-efficiency improvements can produce enough savings to completely pay for themselves with a short payback period, and there is enough experience with many types of retrofits to guarantee savings (HUD, 1992).

\subsubsection{Stakeholders and Constituencies}

By designing the program to deliver monthly energy bill savings that exceed the monthly financing costs for the energy-efficiency improvements, the participant benefits. The customers realize an economic benefit, and any future building owner would view the arrangement as a net benefit. Failure of a customer to repay the obligation could result in disconnection (just as failure to pay utility bills can cause services to be terminated). The utilities would benefit if their financial incentives are aligned with helping their customers use energy more efficiently. Regulatory reform may be required in States where utility profits are tied strictly to sales of electricity and/or natural gas.

\subsubsection{Policy Evaluation}

Appropriateness of the Federal Role. Most of these programs are administered by utility companies, often without assistance from a government source. However, there is plenty of room for the Federal government to encourage and assist utilities in offering on-bill financing. In the case of Massachusetts, the State provides funds to the utilities to cover the costs of the program. DOE could provide grants and funding to SEOs, which could in turn cover the costs of the 
program auditors and contractors. These costs would then be returned to the SEOs through the utility month bill repayments.

If the Federal government considers a National renewable and energy-efficiency portfolio (similar to those adopted recently in many States), then on-bill financing will likely be taken up by many more utilities. Supporting on-bill pilot programs now will give the Federal government and utilities a head start under such a scenario. Further, the use of a revolving loan fund mechanism would mean that the investments funded by the 2009 ARRA could be sustainable over many years. Such "sustainability" would mirror the success of the revolving loan funds established with Petroleum Violation Escrow accounts that provided for decades of energyefficiency financing in many States. ${ }^{54}$

To enable the creation of revolving loan funds in States using ARRArevenues, DOE must deem the funds as being spent as the energy-efficiency upgrades occur. Such a deeming is necessary because of the limited timeframe the Bill places on the expenditure of funds.

Broad Applicability. Utilities, particularly those with a large customer base, can easily offer onbill financing to their customers. Expanding services beyond the provision of gas or electricity to include energy-efficiency programs is a growing trend among utilities within the U.S. The use of DOE funds to enable on-bill financing is particularly important as a vehicle to allow municipal and rural cooperatives to participate, since they generally have less access to capital and would need more assistance in the initiation and design of such programs.

In the most general terms, such a financing program would be applicable to all existing dwellings and small businesses. Small businesses are those meeting the employee or receipts limits put forth by the Small Business Administration. ${ }^{55}$ Defining "small commercial" will require some consideration on the part of the administrating party based on the specific characteristics of each State; qualifying characteristics could conceivably be based on average annual receipts, number of full-time-equivalent employees, average annual utility bills, or floorspace.

Metropolitan areas could play a special role in delivering these energy savings through on-bill financing: urban areas are natural "aggregators" for reaching large markets in a cost-effective manner by capitalizing on market size and compactness. Lower income households may also be particularly well suited to participation in on-bill financing programs.

Significant Potential Benefits. The United Illuminating Company and its subsidiaries have been operating an on-bill financing program for small businesses since 2000. Since then it has

\footnotetext{
${ }^{54}$ Petroleum Violation Escrow funds came from fines paid by oil companies in violation of the Federal oil price caps in place from 1973-1981. http://www.afdc.energy.gov/afdc/progs/view_ind_fed.cgi?afdc/321/0

${ }^{55}$ Small Business Size Regulations specifying size standards and governing their use are set forth in Title 13, Code of Federal Regulations, part 121 (13 CFR §121).
} 
financed nearly 8,000 projects and estimates energy savings almost 200,000 MWh (worth \$20 million @ 10ф/kWh). In addition to financing, the utility offers a complete assessment of energy needs, use, and cost-effective measures to reduce energy consumption (Gandhi et al., 2008).

Spreading this type of program to utilities across the U.S. can result in tremendous energy savings, as demonstrated by the savings realized by the United Illuminating Company.

To estimate the potential benefits of on-bill financing programs, we assume that the annual participation rate is one percent of residences and small business floorspace, and the program begins in 2011, with new installations being financed for the following ten years, with the last of the energy savings occurring in 2030. ${ }^{56}$ This participation rate is achievable, based on the past experience of utility demand-side management programs across the country. For instance, the Energy Smart Design program, implemented by Bonneville Power Authority (BPA) through Northwestern utilities, had participation of 3.7 percent of eligible floorspace in its beginning years (Xenergy, 1996).

For residences, 113 million homes in 2006 is forecast to grow to 141 million homes in 2030; excluding the 23 percent of homes that are considered "multi-family", about 105 million homes would be eligible to receive financing under this program (EIA, 2008a). Based on a metaanalysis of weatherization savings, electric-heated homes save 10.9 percent of pre-weatherization consumption and gas-heated homes save 21.9 percent of pre-weatherization consumption, with average annual site energy savings of 29.1 million Btu (Berry \& Schweitzer, 2003). The weatherization program is targeted to low-income consumers who are also likely to live in older but smaller homes; thus, the savings and the retrofit costs could be higher or lower than in the general population. Based on the one percent assumption above, and a further assumption that each retrofit residence saved 29.1 MMBtu annually, annual incremental savings would range from about 27 trillion Btu in 2020 to 32 trillion Btu in 2030, excluding electricity related losses.

If average measure lifetime is assumed to be 10 years, cumulative annual savings would amount to about 280 trillion Btu in 2020 and 305 trillion Btu in 2030. Many of the most effective measures, such as insulation and better HVAC units have lifetimes longer than 10 years while some measures, like lighting, weatherstripping, and caulking have shorter lifetimes. Annual energy bill savings to residential participants could be between $\$ 316$ million and $\$ 966$ million $(2006 \$){ }^{57}$ Cumulative annual bill savings in 2030 could be between $\$ 3.9$ and $\$ 9.3$ billion (2006 $\$)$.

\footnotetext{
${ }^{56}$ If there were no duplicity, 19 percent of single family and manufactured homes would be retrofit if 1 percent of the stock were retrofit each year from 2011 to 2030, based on stock estimates from AEO 2008 (EIA, 2008a).

${ }^{57}$ Range given is low end of estimate in 2011 to high end of estimate in 2030. Low estimate based on AEO 2008 forecast of price for natural gas, and high estimate based on AEO 2008 forecast of price for electricity; these two fuels offer the lowest and highest per mmbtu price in the EIA forecast (about \$12 per MMBtu for natural gas and about \$30 per MMBtu for electricity, although the actual price forecasts vary from year to year) (EIA, 2008a, Supplemental Table 20).
} 
There was an estimated 77 billion square feet of commercial floorspace in 2006 that is estimated to grow to 104 billion square feet by 2030; this forecast demonstrates the importance of increasing the efficiency of existing buildings (EIA, 2009). In the quantification of benefits and costs in this report, small commercial benefits and costs are not defined; these are expected to be at least equal to those estimated here for residential dwellings.

Solutions not Dependent on Future R\&D. The main goal of on-bill financing is to overcome market barriers related to the costs of purchasing energy-efficient retrofits including insulation and other building shell improvements as well as high-efficiency equipment and appliances. It is not dependent on future research and development. However, improvements in materials, equipment, and retrofit will have an effect on costs and savings, and reductions in the cost of completing HERS ratings would help program economics.

Cost Effectiveness. On-bill financing has proved cost-effective enough that some utilities, such as First Electric Cooperative, have chosen to offer it even without government requirements or assistance. Smaller utilities without access to enough capital cannot do this without assistance, however. A Federal program providing assistance to them could be administered for relatively little cost. For the consumer, the program makes it possible for them to purchase energy equipment that results in energy savings at least as great as the cost of the equipment (and frequently more).

States that have enacted legislation enabling institutional performance contracting designate which sorts of institutions (State and local government buildings, universities, or K-12 schools) can take advantage of this type of financing. They also define a maximum payback period and set program guidelines and training to ensure all building managers entering into performance contracts understand what performance contracting is and how it affects them (Goldman et al, 2005). However, Goldman et al. (2005) caution that enabling legislation alone does not make for a successful performance contracting market; rules and procedures developed within States as well as the availability of energy-efficiency investment funds from ratepayer fees (also called system/public benefits charges) contribute to success. Consistent and simple rules and guidelines can reduce transaction costs while additional sources of money reduce total project costs from the perspective of the participant.

Due to short paybacks, seed monies for financing could be designed as a revolving loan fund where the paybacks refill the coffers over time. For the purposes of a rough estimate, all retrofits are assumed to have a five year payback (and a 10 year effective lifetime), although actual paybacks and lifetimes will vary considerably. A five year payback based on the low and high energy prices in the $A E O 2008$ forecast would support investment of $\$ 1,730$ to $\$ 4,480$, so an average of $\$ 3000$ is used as the cost per home. Thus, an investment of about $\$ 3$ billion per year 
is necessary and $\$ 15$ billion in seed funds would be required to have funds available in the revolving loan pool.

Costs for this program would be to DOE, SEOs, and energy customers; DOE and SEO costs include seed funds, administrative costs, and absorption of defaults while participant costs include any transaction cost associated with applying for funding and lost time or inconvenience during the audit, retrofit, and inspection phases. Although the design of the program is such that savings should be greater than or equal to loan payments and payments would be part of a regular utility billing cycle, there are still apt to be defaults; this study assumes the default rate is one percent (or about $\$ 30$ million, annually).

For participants, this policy is cost-effective with a total cost of $\$ 60.3$ billion from 2011 to 2030 and savings of $\$ 52.6$ (at lowest prices) to $\$ 135$ billion (at highest prices); considering investments made from 2011 to 2021 and savings to 2030 (assuming a 10 year lifetime and a one percent discount rate), the net present value of the benefit to cost ratio of the program for participants is 0.99 to 2.57 . The cost of borrowing money is excluded, but it will increase costs and decrease the benefit-to-cost ratio.

For illustration, consider a household or small business with an average monthly energy cost of $\$ 200$. Assume that a home audit approves an investment of $\$ 2,000$, which is estimated to cut the home's energy costs by 25 percent (i.e., saving $\$ 50$ in energy costs). Assume that the $\$ 2,000$ uses capital that is loaned at an eight percent rate of interest over a seven year amortization schedule, implying monthly payments of $\$ 32$. Assume that there is a modest program administration cost of $\$ 3$. The customer's utility bill could look like the following (based on Rogers, 2007):

\begin{tabular}{|lr|}
\hline & \\
Pre-participation monthly energy cost & $\$ 200$ \\
This month's energy savings & $(\$ 50)$ \\
Your consumption this month & $\$ 150$ \\
Your energy efficiency repayment & $\$ 35$ \\
\hline You owe this & $\$ 185$ \\
\hline
\end{tabular}

Funders need only set fees and interest rates higher than the default rate combined with inflation to realize a return. Such interest rates should be set to meet the required return on investment.

Administrative Practicability. The Federal government currently offers numerous funding assistance types of programs. It already administers the Low-Income Home Energy Assistance Program (LIHEAP) and Weatherization Assistance through State programs. These State 
administrators are well-connected to the utility providers and the energy needs of their communities and would be experienced and effective implementers of an on-bill financing program. In addition, the relationship between HERS raters and HUD offices for the distribution of EEMs offers an opportunity for effectively transferring remaining energy loan balances upon the sale of homes.

The development of funding and program guidelines should not create too large an administrative burden for the Federal government. Program guidelines for residential performance contracting have already been established by HUD in their program for Public and Indian Housing Authorities (HUD, 1992).

Administrative difficulty may arise in the beginning of the program as States or designated third parties work to establish procedures to effectively originate, monitor savings, and transfer loans. One point of difficulty for transfer of loans is the secondary market for equipment and appliances; contracts must be written in such a way to prevent the sale or transfer of equipment or appliances separately from the associated building until the loan and related fees have been completely repaid.

On-bill financing may also be difficult for some utilities to implement, given their current billing systems that may not be set up to have non-energy billing (Brown, M., 2009).

Additionality. This is a very specific policy addressing some of the market barriers to purchasing energy-efficient equipment. Other policies, such as Home Energy Rating Systems or mandated disclosure of energy use may also encourage the installation of more energy-efficient appliances and equipment, but only on-bill financing directly removes the upfront capital barrier. On-bill financing is also separate from weatherization programs, because assistance is being offered regardless of income and involves loans rather than direct government financial assistance for energy-efficiency upgrades.

It is important to note that this program is designed as a financing effort. Thus, savings attributable to this program may be counted by other programs that create awareness of energy consumption or savings potential. It will be difficult, in practice, to determine what energy and cost savings are directly attributable to this financing vehicle. Indeed, an effective communication outreach and marketing approach will be an important complement to enhance program effectiveness by achieving the levels of participation and economies of scale needed to produce program cost reductions.

At the same time, on-bill financing is particularly compatible with energy-efficiency performance standards, because the financing program offers a mechanism for meeting the EERS requirement. 


\subsubsection{Summary}

On-bill financing appears to offer significant potential to engage residential consumers in increasing energy efficiency. As a result, DOE could consider promoting this policy option by offering financial assistance to State Energy Offices to establish revolving loan funds to enable on-bill utility financing of energy-efficiency improvements without up-front capital costs to the building owner. This policy would address the capital constraints that often prevent homeowners and small businesses entrepreneurs from upgrading the energy integrity of their buildings. Establishing on-bill financing programs based on government-financed revolving loan funds could result in large-scale energy savings and could extend the positive impact of the 2009 American Recovery and Reinvestment Act by many years. 


\section{$4 \quad$ Utility Policies and Regulations to Promote Energy-Efficient Buildings}

While there are many barriers to the commercialization and deployment of clean energy technologies, those that are imposed by legislatures and regulators are particularly of interest as they operate at cross-purposes with the Federal government's commitment to GHG reductions. Government policies are designed to provide broad societal benefits that increase overall economic welfare, but they can inadvertently disfavor certain segments of the economy, including, in some cases, inhibiting the commercialization and deployment of energy-efficient technologies in buildings. When applied to the context of this report, these policies are referred to as "competing priorities" and are considered a barrier to deployment.

Many competing priorities result from policies established years ago for a public purpose that could be better addressed in other ways today. The utilities sector is replete with these. For example, electricity pricing policies set by State legislatures and regulatory commissions prevent markets from operating efficiently and create obstacles to low-carbon power choices. Ratemaking policies are supposed to ensure fair and efficient rates based on five, sometimes competing, goals:

- Capital attraction - making the regulated utility profitable enough to attract capital to maintain operations;

- Reasonably priced energy - ensuring rates are low enough that "everyone" can have access,

- Efficiency of production - ensuring rates are high enough that the utility can get a return on investment,

- Demand control - designing rates to avoid overconsumption, and

- Income transfer - designing rates that minimize the redistribution of wealth (Tomain and Cudahy, 2004).

Rates are traditionally set to reflect the average cost of maintaining a flow of electricity in a market designed to ensure capacity at peak. This means that the average rate will be slightly higher than the marginal cost of generation at all but peak periods. When the marginal cost of delivery is not equal to the marginal rate, consumers face inappropriate price signals. Not only do regulators resist rate increases for the utilities they regulate, legislatures repeatedly set artificially low price caps upon deregulation of the utilities. Rate regulation and downward pressure on rates is not isolated to electricity, but also occurs for natural gas (Hirst and Brown, 
1990). Because they face lower average prices, consumers under invest in energy-efficient systems.

The real-time costs of electricity production can vary by a factor of ten within a single day. Because peaking plants are more expensive to run than baseload plants, retail electricity rates are higher during peak times than during shoulder and off-peak times under dynamic pricing structures, such as: time-of-use or critical peak pricing. Yet most customers in traditionally regulated markets buy electricity under time-invariant prices that are set months or years ahead of actual use; as a result current market structures actually block price signals from reaching consumers (Cowart, 2001, p. vii).

The use of traditional rules-of-thumb for allocating tax dollars and regulated revenues can also create conflicting priorities that impede energy-efficient technologies. Utility company profits, even in traditionally regulated electricity markets, are a function of electricity sales to customers. As a result, energy efficiency and rooftop solar photovoltaics can reduce utility profits, thereby discouraging utilities from promoting these clean energy options in residential buildings. Under current rate designs, companies that own transmission lines also benefit from electricity throughput, and find their profits reduced by energy-efficiency programs (Brown and Chandler 2008).

As another example, consider the universal ban on private electric wires crossing public streets, which was established originally to maintain safety on roadways by preventing the introduction of low-hanging wires. By forcing would-be power entrepreneurs to use their competitors' wires often at a high cost - this ban penalizes local generation, which offers the potential for highefficiency power delivery that could be particularly suitable for high-rise apartment complexes (Casten and Ayres, 2007).

Such competing priorities contribute to the slow market uptake of energy-efficient technologies and practices in the buildings industry. The following policy options would help address these barriers.

\subsection{Performance Specifications for Smart Meters and Expanded Demand Response}

Policy Option: Define performance specifications for "smart meters" that limit use of the label to devices with customer read-outs. Provide technical and financial assistance to States and utilities to provide for expanded demand response of residential electric loads through smart metering technologies and pricing schemes. 


\subsubsection{Synopsis of Policy Option}

Enabling price responsive demand requires "smart meters," as an enabling device, in combination with time-dependent rates. The government could define and limit the use of the term "smart meter" to only be applied to those meters which: 1) Record (electricity, natural gas, water) consumption hourly or more frequently, or on demand and 2) can interface with an in-home device or on-line tool. ${ }^{58}$ Such a definition is already being called for and could be formalized to avoid confusion. Texas's Public Utility Commission reported to the legislature that, "[t]he components of a robust and scalable AMI include standards-based open architecture to create a network of smart meters that are fully integrated with demand-response capability" (TPUC, 2008, p.5). In the United Kingdom, the Energy Retail Association offers that "Smart metering must facilitate: Complex tariffs; Customer information display; Export capability for Microgeneration" (ERA, 2008, p.3). Smart meters are referred to as those that both "listen" and "talk." Google has taken the back-end of this effort and supplied it as open-source. ${ }^{59}$ Thus, utilities could provide information to consumers through Google's PowerMeter program, so long as the utility is receiving real-time consumption information.

In addition, Federal technical and financial assistance could help develop dynamic and interactive metering practices beyond utility pilot programs. Previous Federal efforts to offer somewhat varying prices demonstrated consistent consumer response via load shifting and energy savings, but the programs were not well known (Caves, Christensen, and Herriges, 1984). Fischer (2008) reviewed multiple consumption feedback studies and found that customers "approve feedback that is more detailed and more closely linked to consumption actions"; the most successful programs provided feedback through computerized (interactive) means, at least daily, and offered comparison to the users own historical consumption, rather than peers or average consumption. Dynamic and interactive feedback through in-home display meters or online consumption monitoring has been shown to drive both load management and energy savings (see reviews in Darby, 2006; Faruqui and Sergici, 2009).

Consumers will benefit from a concurrent information program. Information to consumers should increase understanding about how their energy is produced and delivered to them. Burr (2008) argues that consumers have been kept in the dark too long by the efforts of the government and utilities to ensure peak demand is met while keeping prices low and flat. Further, consumers may not trust utilities to provide them with technology and systems that actually help them, the consumers (Burr, 2008).

In addition, existing time variant pricing opt-in programs have low participation rates which drives utility regulators to conclude that consumers are not interested in smart metering or

\footnotetext{
${ }^{58}$ Water is not part of this policy discussion; however, water flows into a home, like energy, and can be measured with similar types of metering devices.

${ }^{59}$ http://www.google.org/powermeter/index.html
} 
demand response programs (Radford, 2008; FERC, 2008). If participation will remain on an opt-in basis, financial assistance to eliminate or reduce opt-in fees, (for example if consumers have to pay for the meter or other technology) could increase participation.

\subsubsection{Policy Experience}

Utilities have adopted advanced metering technologies already to reap the utility benefits of more detailed consumption information and reduced meter reading costs. However, more advanced meters with bidirectional communication and enabling rate policies, "smart meters" and advanced metering infrastructure (AMI) will be necessary to provide:

- more dynamic price information to consumers, [price responsive demand]

- alternative rate plans, [price responsive demand] and

- support load shedding programs [reliability responsive demand].

Of $6.1 \mathrm{GW}$ potential peak residential load reduction nationwide, $5.5 \mathrm{GW}$ is attributed to direct load control while pricing policies have had much smaller impacts (FERC, 2008, Table III-9). This is indicative of the state of current demand-side policies and not the future potential.

With time variant pricing and load management programs, like automatic operation, smart meters can drive more energy savings. More than 1.2 million residential customers (about one percent) were enrolled in some form of time variant rates in 2008 (FERC, 2008, Table III-5). Throughout this document, the term "time variant pricing" refers to any dynamic pricing scheme; these may be designed as peak and off-peak pricing, real time pricing, or critical peak pricing structures. ${ }^{60}$ Research suggests that critical peak pricing is the most effective (Faruqui and Sergici, 2009). Figure 4.1 shows the average, minimum and maximum savings from pricing pilots using Time of Use (TOU), Peak Time Rebates (PTR) and Critical Peak Pricing (CPP) with and without enabling technology; enabling technology, like smart meters, are clearly helpful.

${ }^{60}$ These pricing structures are laid out in the Energy Policy Act of 2005,Title XII, Subtitle E, Section 1252 


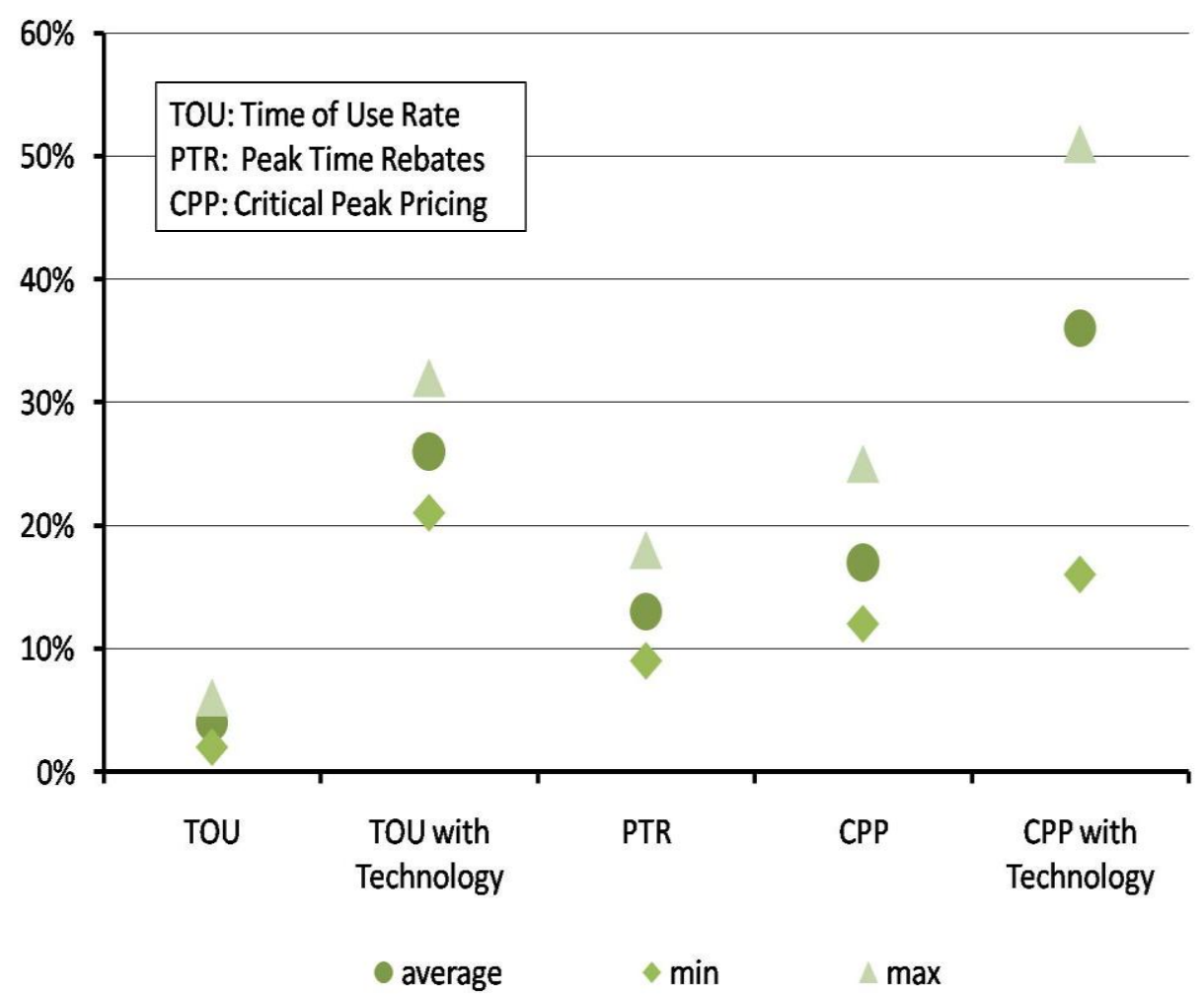

Figure 4.1 Summary of Pricing Pilot Savings

(Faruqui and Sergici, 2009 Table 31 p. 43)

The simplest form of time variant pricing is achieved by setting a higher "peak" rate and a lower "off-peak" rate; this does not exactly match the variability in the wholesale price, but it does provide a signal to customers that power is more expensive during peak periods, such as summer afternoons in most of the country. Rate design is an important part of success, and rates offered should be tailored to the region and customers. For example, New York's Con Edison offers a plan where customers opt-in to have lower "off-peak" rates; these customers have a higher base fee (at $\$ 18$, it is $\$ 5$ more than the base fee for regularly billed customers), but they can save money on their bills if they shed loads during peak periods (Belson, 2008). The program attracted only 2,500 of 2.7 million customers by July 2008, but mandatory time variant rates may be coming back for large customers - in 1992 they were put in place, but in 1997 they were no longer authorized. ${ }^{61}$

There are several pilots of various pricing schemes and display types ongoing across the United States. A large pilot program in Washington, DC, called Power Cents DC involves 1,200 customers over two years and is nearly halfway complete. ${ }^{62}$ Results of this study should answer some questions about the longevity of consumer response to direct feedback - as it is still

\footnotetext{
${ }^{61}$ New York Public Service Law § 66(27)(a), as amended by Laws of 1997, Chapter 307

${ }^{62}$ http://www.powercentsdc.org/aboutpcents.aspx
} 
unknown whether consumers will "learn to ignore" the in-home display or smart meter device (Faruqui and Sergici, 2009).

\subsubsection{Policy Rationale}

For most consumable products, people would find it difficult to imagine consuming blindly first and paying later: groceries and gas come to mind. If not provided with enough information before and during the transaction, consumers could be shocked at the end of the month when they received their bill. Further, they would not likely know where they could reduce their expenditure. However, with energy used in the home, this is exactly how consumers are treated. With the cost of household electricity consumption just over $\$ 100$ per month (and total residential energy consumption per household at \$167 per month), most families have little incentive to better understand their energy bills by collecting more detailed metered data (DOE/EERE, 2008). Consumers face two related lack of information barriers that can be overcome by smart meters and time-variant pricing - they lack usable information about their consumption and they lack price signals related to the production of the energy they consume (Brown et al, 2008).

FERC (2008, p. ii) claims that barriers to success of smart meters and demand response programs include:

- few customers on time-based rates,

- little customer access to consumption data,

- difficulty measuring success (actual savings) of existing demand side management programs, and

- limited variety in demand side management offerings.

Further resolution on barriers to successful demand response programs for both customers and utilities was developed by the Brattle Group through interviews, but they can be summarized as lack of technology and lack of availability of dynamic pricing structures (Pfannenstiel and Faruqui, 2008).

\subsubsection{Stakeholders and Constituencies}

Utilities, State regulators, and manufacturers of related products will be vocal stakeholders. Utilities will want to ensure they can meet their returns to investment. State regulators will want to avoid harming consumers and ensure compliance with other State laws. Manufacturers will look for their chance to expand their business. 
Consumers, especially those with low or fixed incomes are the most critical stakeholder in developing a dynamic pricing policy. There are concerns that the costs will be unfair and unbearable for low- or fixed-income consumers. Previous time variant pricing experiments have found this subpopulation to face a greater burden than the average consumer (Alexander, 2007). Alexander (2007) argues that low-income consumers are more likely to have an inelastic electricity demand; they may have inefficient appliances and live in uninsulated or leaky spaces, but they do not have the means - or always the authority, as the property may be owned by a landlord - to repair the situation. In California, "the elasticity of substitution for CARE customers is essentially zero" (Charles River Associates, 2005). ${ }^{63}$ Thus, low-income consumers would be unable to shift load or shed load to avoid a jump in prices that might be associated with time variant rates.

Any policy that drives dynamic rates, reducing stability and increasing real rates, should consider ways to avoid harming the most vulnerable consumers. Policy options include exempting certain customers, such as those who require life-support systems, setting a threshold of consumption below which dynamic rates do not apply, having a set bill that covers the peaks and valleys in a customer's real bill, and developing a fund to support a transition period for consumers not prepared for an increase in rates.

Alexander (2007) raises the question of the appropriateness of spot-prices and wholesale prices of electricity as the correct signal as they are not the producer's marginal cost, rather they are set on wholesale demand. These spot prices, and other auction style pricing structure, can be manipulated or inflated by those who wish to increase prices (Tierney, 2008). Borenstein (2002) showed that the incentive to capture gains in this market is high, and manipulation is bound to happen, as it did in California in 2000. When policies are developed to allow for widespread time variant rates, they should consider protections from market manipulation.

Policy design should also consider how much of the market is allowed to participate; if customer participation remains low, the aggregate demand market will not respond to changes in supply (Sioshansi and Vojdani, 2001). A market without a participating demand side, such as the current electricity "market", is not a market and cannot be expected to operate efficiently (King, King, and Rosenzweig, 2007). Figure 4.2A shows demand responding to price in a "perfect" normal market; Figure 4.2B shows a market similar to that for electricity. Even with great increases in cost of supply, demand is unresponsive; although demand is not perfectly inelastic, the figure is representative.

\footnotetext{
${ }^{63}$ CARE: California Alternative Rates for Energy; qualified customers get a 20 percent discount on energy prices http://www.cpuc.ca.gov/PUC/energy/Low+Income/care.htm
} 
A

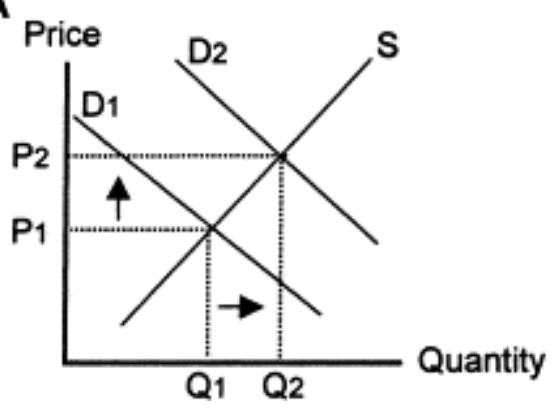

B

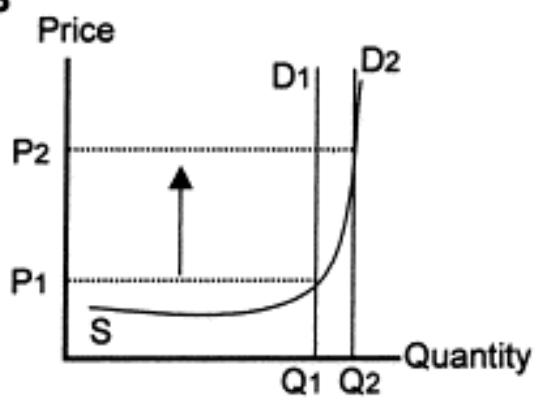

Figure 4.2 Supply and Demand Curves in (A) Normal Markets vs. (B) CapacityConstrained Markets with Perfectly Inelastic Demand

(Sioshansi and Vojdani, 2001, Fig. 4)

\subsubsection{Policy Evaluation}

Appropriateness of the Federal Role. For creating a requirement to bear the label "smart meter," the Federal government has many precedents for labeling and use requirements. Previous meter standards, which were not created by the government, were developed to address the physical connection of the meters and the electronic meter reading interfaces (Levy Associates, 2002).

Through the Federal Electricity Regulatory Commission (FERC), the Federal government applies National standards to utilities, especially electricity. FERC is already actively working in smart metering, time of use rates, and demand response. In the 2008 update to FERC's annual Demand Response Report, the recommendations are:

"(1) continue current coordination with NARUC on finding demand response solutions, with a focus on aligning retail demand response programs and timebased rates with wholesale market designs; (2) continue exploring how to remove barriers to the comparable treatment of demand response resources in wholesale markets; (3) coordinate the Commission's National Assessment of Demand Response and National Action Plan for Demand Response efforts required by Congress in the Energy Independence and Security Act of 2007 with the ongoing annual demand response reporting required by the Energy Policy Act of 2005 to ensure effective use of Commission resources; (4) support the efforts of organizations such as NERC, NAESB, and EIA to develop practical means to measure, verify, forecast, and track demand response; and (5) explore possible linkages among demand response, energy efficiency, and smart grid programs."

The 2009 update to the National Assessment of Demand Response, which will be prepared by FERC under statute, is supposed to have additional recommendations for achieving the nation's demand response potential. 
Broad Applicability. Smart meters are applicable to all residential customers of electricity and piped fuels. Residents who get fuel delivered to tanks face a different sort of demand response pressure, and they are faced with filling the tank. This is a similar situation to many prepayment options that have shown energy savings.

However, some customers will be able to respond more than others. Special populations could see real increases in their bills, and should be carefully identified to prevent harm. Renters who do not see or pay their bill separately from their rent may not have an incentive to respond. Lowincome or low-use consumers may not have any reductions to make. Homebound individuals especially those relying on "always on" equipment may be able to make reductions, especially involving comfort levels, but they could have health consequences.

Every building is metered; the main question is how well consumers will use the information and the extent to which it can change behavior. Research into feedback has shown that consumers will change their behavior with respect to energy consumption when provided with actionable information about their consumption and with economic motivation.

Significant Potential Benefits. Smart meters and their associated communication networks, also known as Advanced Metering Infrastructure (AMI) in the utility industry, have benefits outside of energy efficiency. These benefits can also be accomplished with a less "smart" technology, called an Automated Meter Reader (AMR), and include:

- reduced meter reading costs,

- improved meter reading accuracy,

- improved representation of outages and problems, and

- $\quad$ quicker move-out bills (Neenan and Hemphill, 2008).

However, these are only operational savings, and they accrue solely to the utility and ratepayers, insomuch as their cost of service may not increase as much as it would otherwise.

Societal savings are more difficult to quantify, but they include benefits from reducing market failures due mostly to flat, low rates that do not represent the true cost and time-dependence of electricity production and distribution. Neenan and Hemphill (2008) show that implementing demand response moves the efficiency frontier towards lower costs and lower risk; thus, smart metering with time variant rates and load management can drive such a move in the frontier. The energy-efficiency benefits of smart meters depend on the degree of support from regulating bodies and State policy that utilities have to capture gains from a demand side management point of view. 
It is important to consider benefits to all parties involved (utilities, taxpayers, participants, nonparticipants). Earle and Faruqui (2006) show that using bill savings as the measure of participant benefit does not reflect the differences in consumer gain and loss. Using a simplified model of a revenue-neutral two-period rate, consumer surplus was found to be half consumer bill savings under a variety of price elasticities and peak/off-peak consumption patterns (Earle \& Faruqui, 2006). This finding is important because the spread of demand response relies on California's Standard Practice Manual which uses consumer bill savings in its cost benefit tests (GOPR, 2002).

According to Neenan and Hemphill (2008), public information from utility business cases show that of total benefits, those considered societal, range from 15 to 65 percent with an average of 34 percent; the balance is operational benefits. Figure 4.3 shows how several societal benefits of smart metering might be quantified.

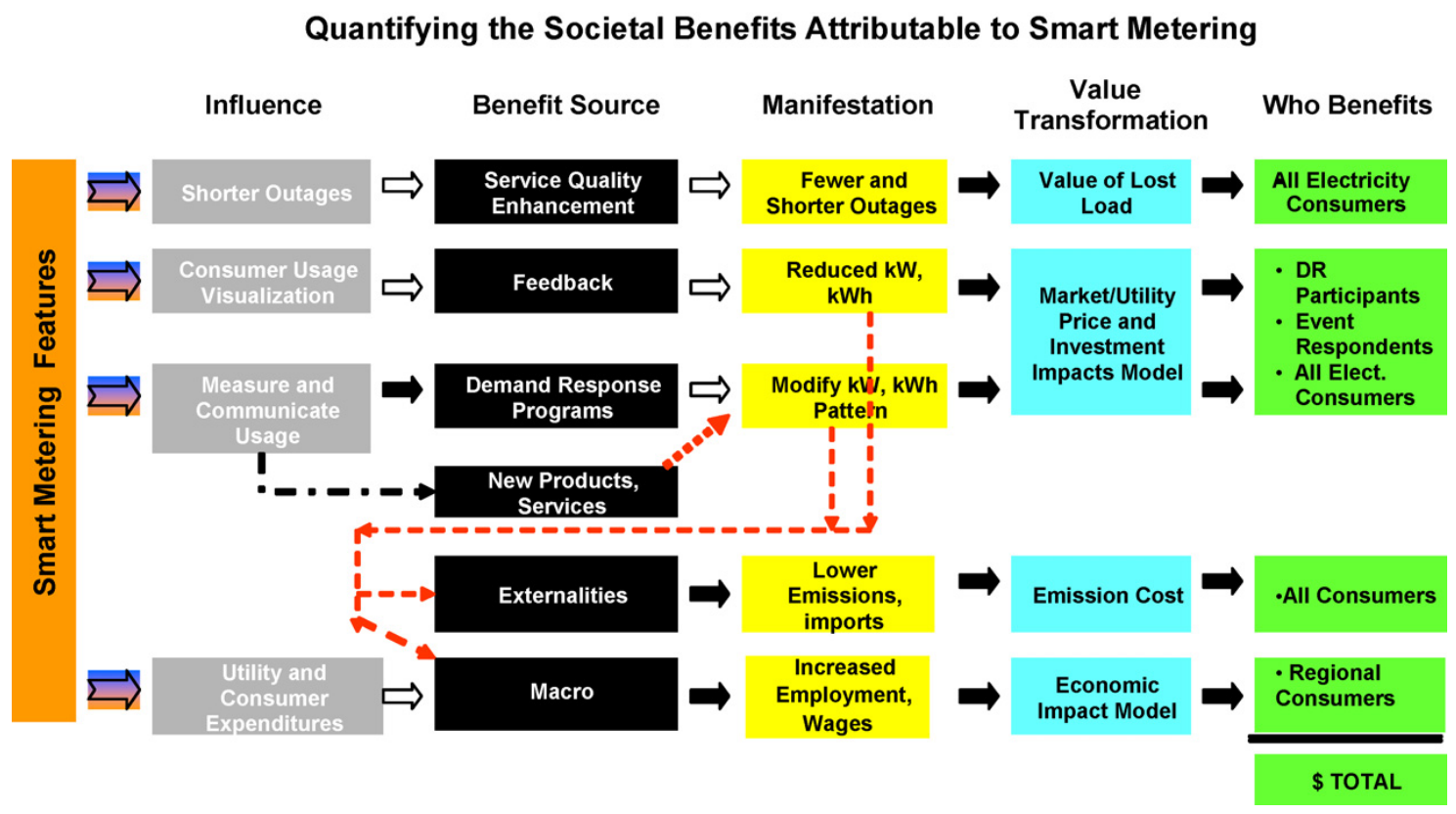

Figure 4.3 Example Flow Chart of How to Measure Societal Benefits (Neenan \& Hemphill, 2008, Fig.1 p.viii)

The potential for energy savings can be immense. Pfannenstiel and Faruqui (2008) estimate that technical potential for demand response is 25 percent of the peak while economic potential is 12 percent of the peak, and the current market achievable demand response potential is five percent. Of course, it is important to note that these estimates are for demand savings and not energy savings. While increasing demand response may have many benefits, it does not necessarily lead to significant KWh savings. Indeed, some demand techniques, like ice thermal storage, can actually use more energy. 
Energy savings from smart meter technologies alone or in combination with alternative pricing have occurred both as load shifting and as real energy savings. The impact of these energy savings on carbon dioxide emissions is less clear and depends on the carbon intensity of the base-load versus peak-load power production. If a significant amount of energy is shifted from relatively on-peak low-carbon sources such as natural gas combined cycle power plants to baseload high-carbon sources such as pulverized coal plants, the carbon impact of load shifting could be unfavorable. Across the country, fuel sources for peaking plants vary, but they can be significant producers of carbon dioxide and criteria pollutants. In New York, peaking has been identified as an environmental justice issue. "New York's dirtiest power plants, which burn oil and tend to be located in poorer neighborhoods and operate just about 100 hours a year during the summer's hottest periods, account for a significant portion of the city's greenhouse gas emissions because they release three to five times more pollution than gas-fueled units" (New York DPS, 2008).

Darby (2006) found that direct feedback from meters or in home displays averaged energy savings of five percent to 15 percent over several studies. Prepayment in addition to smart metering has saved an average of 12.8 percent annually for Salt River Project's M-Power program customers - more than 50,000 residential customers participate in this prepayment program (King, 2007). Having consumption meters within the home in a user-friendly way led to average savings from 2.7 percent in British Columbia to 18 percent in Newfoundland and Labrador (CEATI International, Inc., 2008). An analysis of pilot programs showed savings of three percent to six percent using TOU rates alone with savings of 13 percent to 20 percent if they were designed as critical peak rates; in addition, the use of enabling technologies, such as in-home displays increased savings using critical peak rates to 27 percent to 44 percent (Faruqui and Sergici, 2009).

Faruqui et al. (2007) claim that reducing the peak demand by five percent could lead to nationwide savings of \$31 billion with an updated figure by Faruqui and Sergici (2009) of \$66 billion. Faruqui (2008) argues that reducing just the peak isn't enough and offers that reconsideration and reorganization of inclining block rates could lead to overall energy savings in addition to dynamic price or other smart meter savings. Pricing policies in combination with easy access to consumption information can be an effective combination; especially if the policies remain in place and apply to all customers. Sustained meaningful pricing structures are important because the long-run price elasticity is estimated to have a mean of -0.9 , ranging from -0.7 to -1.4 , while the mean estimate of short-run price elasticity is -0.3 , ranging from -0.2 to -0.6 (EPRI, 2008). ${ }^{64}$

\footnotetext{
${ }^{64}$ Price elasticities are highly dependent on individual household, heating fuel, and regional characteristics (Bernstein and Griffin, 2005).
} 
Solutions not Dependent on Future R\&D. Effective smart meters have been developed and are already in place. 6.7 million smart meters were in place and being used in 2008, compared to just less than one million in place and being used in 2006; still more smart meters are installed and capable of being used (FERC, 2008). Still, 95 percent of meters are common technology old-style meters (FERC, 2008).

Further R\&D is ongoing and may bring costs of meters down and improve meter-human interaction and demand response; however, success of the program is not dependent on future research.

Examples of ongoing research include:

- Lawrence Berkeley National Laboratory is in the process of conducting a study to determine the most effective means of communicating more detailed consumption data to consumers.

- EPRI is working to develop a simplified method of accounting for all benefits and costs of smart meters.

- Similarly, FERC is researching the current practice and offering examples of demand response programs.

Cost Effectiveness. Faruqui and Sergici (2009) estimate that installing smart meters for the rest of the 95 percent of customers nationwide would cost about $\$ 40$ billion. However, several utilities have made business cases for installing smart meters without consideration for the savings, especially during the most expensive peaks, possible through demand response. With advanced meters and required component communication devices costing between $\$ 78$ and $\$ 181$, estimated payback (differs by vendor, not only by price) ranges from 6.5 to 10.1 years without demand response (Levy Associates, 2005).

Thus, smart meters with dynamic pricing and automatic load control should more than pay for themselves. Figure 4.4 shows that the low end of benefit projections exceeds anticipated costs. 


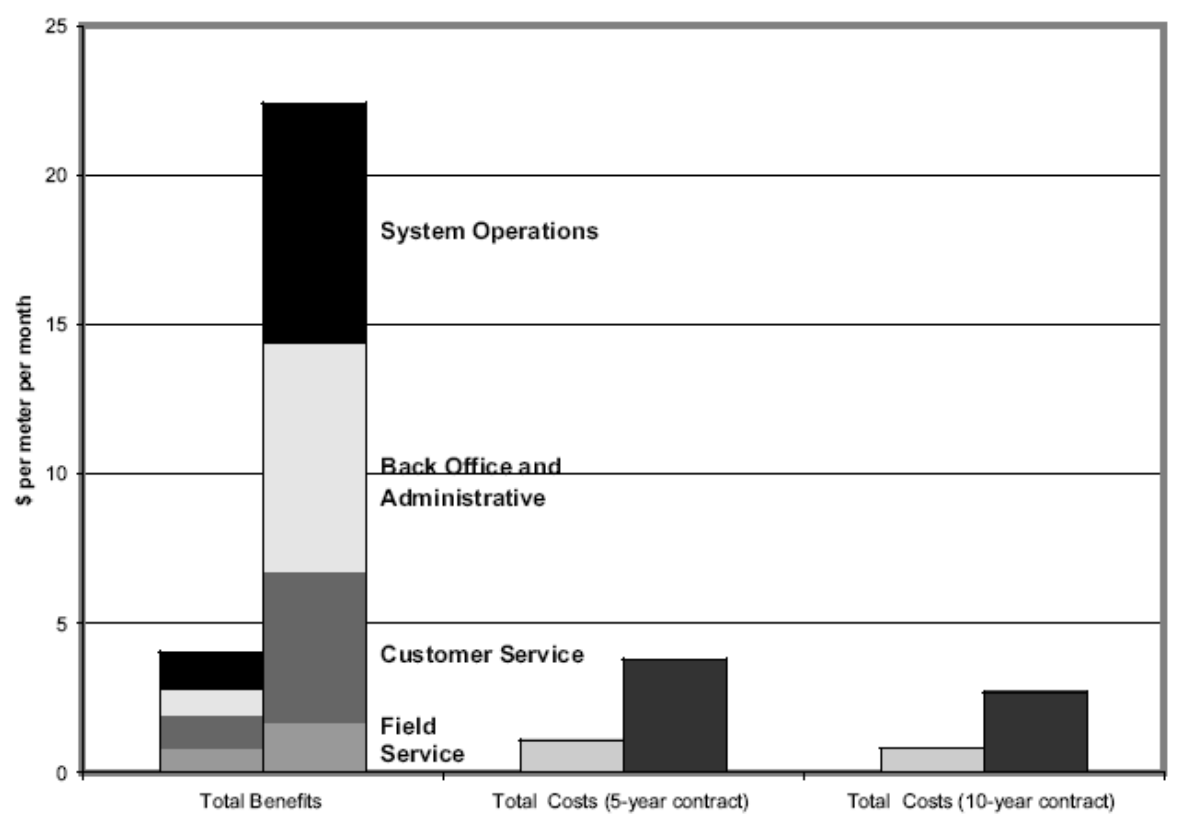

Figure 4.4 Comparison of Estimated Range of Benefits and Costs (Low on Left, High on Right) of Advanced Metering Systems

(Borenstein, Jaske, and Rosenfeld, 2002, Fig 2-a p.42)

Administrative Practicality. There are several ongoing avenues where administration of this program could be added with little or no change in administrative activity. Most fittingly, efforts to assist with development of smart meters, alternative or dynamic pricing, and automatic load control could be housed within existing smart grid efforts. For example, FERC is working with NARUC on the Smart Grid Collaborative; similarly, FERC is heading up efforts to define barriers and next steps in advancing the goals of the smart grid. DOE's Office of Electricity Delivery and Energy Reliability is working in the area of smart grid as well. While the Federal government cannot lobby State governments, they can provide the tools and analysis to aid PUC decisions.

At the State level, rolling out advance metering infrastructure and enabling time variant prices may require additional research and coordination efforts with utilities.

Additionality. Smart meters, together with time-of-use pricing and automatic load control, enable energy efficiency - especially by flattening peaks. Existing load management programs might offset some of the gains attributed to these meters and their associated load management policies. Policies to reduce total demand through energy efficiency may also interact with this policy; while savings will still accrue, they may not be completely additive. 


\subsubsection{Summary}

It is recommended that the Federal government define performance specifications for "smart meters" that limit use of the label to devices with customer read-outs, and provide technical and financial assistance to States and utilities to provide for expanded demand response of residential electric loads through smart metering technologies and pricing schemes. These two actions are dependent upon each other for success as the meter enables a wider variety of pricing policies than are broadly available. Costs may increase for some consumers, but the benefits of reduced peak load and energy savings can outweigh these costs.

\subsection{Alignment of Utility Financial Incentives with Customer Energy Efficiency}

Policy Option: Ensure DOE's strict enforcement of the 2009 American Recovery and Reinvestment Act requiring that disbursement of funds to States be contingent on Governor assurances that financial incentives will be established for utilities that help customers use energy more efficiently. Also, expand the Federal Regulatory Assistance Program to help States design appropriate financial incentives for energy-efficiency programs.

\subsubsection{Barriers Synopsis of Policy Option}

Traditional rate-of-return utility regulations discourage utilities from investing in programs that help customers use energy more efficiently. Two regulatory approaches are seen by many to be effective solutions for overcoming these disincentives:

- "financial incentives" to provide shareholders with a fair return on investment for achieving energy-efficiency program objectives, and

- "decoupling" of utility revenues and profits through periodic and frequent true-up of projected sales and other mechanisms to provide utilities with timely cost recovery and earnings opportunities for operating energy-efficiency programs.

The 2009 American Recovery and Reinvestment Act emphasizes the need for these regulatory reforms by limiting the disbursement of energy funds to States that have eliminated these disincentives. Specifically:

"Amounts appropriated under the heading "Department of Energy-Energy ProgramsEnergy Efficiency and Renewable Energy" in this title shall be available to the Secretary of Energy ... only if the governor of the recipient State notifies the Secretary of Energy in writing that the governor has obtained necessary assurances that each of 
the following will occur: (1) The applicable State regulatory authority will seek to implement, in appropriate proceedings for each electric and gas utility, with respect to which the State regulatory authority has ratemaking authority, a general policy that ensures that utility financial incentives are aligned with helping their customers use energy more efficiently and that provide timely cost recovery and a timely earnings opportunity for utilities associated with cost-effective measurable and verifiable efficiency savings, in a way that sustains or enhances utility customers' incentives to use energy more efficiently."

It is recommended that DOE strictly enforce this requirement. In addition, Federal assistance is needed to help encourage State utility commissions to reform their ratemaking practices and to assist them in their assessment of the many design options. This could be achieved by expanding the Federal Regulatory Assistance Program.

\subsubsection{Policy Experience}

Decoupling and performance incentives are not new regulatory solutions - they were tried in many States during the 1980s and 1990s in the era of "integrated resource planning" (Eto, Stoft, and Belden, 1997). With utility restructuring and the movement to competitive electric markets beginning in the mid 1990s, many of these regulatory approaches to promote efficiency came to an end. With the increased focus on energy efficiency resulting from higher electricity prices and the growing concern for global climate change, there is a resurgence of interest in regulatory reform.

Despite this resurgence of interest, few States have enacted regulatory decoupling, and there is a limited experience base because of the newness of these efforts since they were first tried 20-30 years ago. California and Oregon are the primary leading examples of decoupling since the movement to restructure the industry.

- In California, decoupling mechanisms are in place for all electric and natural gas utilities.

- In Oregon, a decoupling mechanism is in place for its two natural gas utilities.

Other States have recently implemented pilot programs including Maryland, New Jersey, North Carolina, Utah, and Ohio (Kushler, York, and Witte, 2006). Several additional States are considering such an approach.

In contrast, other States have concluded that decoupling is not needed. In Georgia and Florida, for instance, rate true-ups are seen as frequent enough to eliminate the problem of revenue erosion when energy-efficiency investments cut sales (Florida Public Service Commission, 
2008). ${ }^{65}$ Kushler, York, and Witte (2006) note that several States with relatively large utility ratepayer-funded energy efficiency programs do not have either performance incentives or decoupling mechanisms in place. ${ }^{66}$ Thus, other policy mechanisms and drivers are able to compensate for the absence of the two regulatory reforms described in this paper.

Under traditional rate-of-return regulation, utilities profits are based on the total amount of capital invested in selected asset categories (such as transmission lines and power plants) and the amount of electricity and natural gas sold. A utility's rates are set based on an estimation of costs of providing service over some period of time (including an allowed rate of return) divided by an assumed amount of electricity and/or natural gas sales over that period. If actual sales are less than projected, the utility will earn a smaller return on investment and in fact could fail to recover all of its fixed costs. Thus, financial incentives favor expanding energy sales and traditional utility-scale supply-side infrastructure.

Just as there are disincentives for end-use energy efficiency, there are also disincentives for distributed generation sold "off grid." Companies that own transmission lines also benefit from throughput and find their profits reduced by energy-efficiency programs. As Casten and Ayres (2007) explain: 'Regulators approve rates that are supposed to provide a 'reasonable' return on invested capital. This encourages capital investment, regardless of efficiency. With approved rates in place, the utility's profits hinge on throughput - how much electricity flows through their wires. More sales, more profits. Actions that lead to conservation, appliance efficiency gains, and local generation all penalize utility profits."

The fundamental question is how to provide utilities with an appropriate incentive for helping customers save natural gas and electricity, not just for selling energy. Both decoupling and performance incentives are generally seen as part of the solution. Decoupling is a way to make sure all of the utility's fixed costs are covered, but on its own, it does not provide a reward for programs that are successful at saving electricity. Both California and Oregon have combined decoupling with an additional reward to be sure the utility has an adequate incentive for investing in energy-saving technologies. Such performance incentives can take several forms, three of which are currently being used in one or more States (Kushler, York, and Witte, 2006):

- Allowing utilities to earn a rate of return on energy-efficiency investments equal to supply-side and other capital investments (Wisconsin).

\footnotetext{
${ }^{65}$ Rate true-ups are rate adjustments that reflect changes in utility company avoided costs associated with increases or decreases in the sale of electricity and natural gas.

${ }^{66}$ States with significant electric energy-efficiency investments that have not reformed their electric regulations include Washington, Oregon, New Jersey, Iowa, Montana, and Wisconsin (Kushler, York, and Witte, 2006).
} 
- Providing utilities with specific incentives or other financial rewards for meeting certain energy-efficiency program targets (Arizona, Connecticut, Massachusetts, New Hampshire, and Rhode Island).

- Allowing utilities to share the benefits of energy-efficiency programs in shared savings programs including on-bill financing programs (Minnesota).

\subsubsection{Policy Rationale}

In most States, utility regulations do not provide natural gas and electric utilities an economic incentive to operate programs that help their customers use energy more efficiently. In fact, traditional rate-of-return regulation typically results in disincentives for utilities to encourage their customers to be energy efficient because utility revenues and earnings shrink when utility sales decrease (Kushler, York, and Witte, 2006). It is becoming increasingly clear, that for utilities to embrace National goals of increased energy efficiency, utility regulations and policies need to be reformed (Leadership Group, 2006).

Fixing the problem of revenue erosion and decoupling profits from sales is critical to incentivizing the efficient use of electricity. Problems associated with utility ratemaking practices and their disincentives to energy efficiency were a major focus of the National Action Plan for Energy Efficiency (NAPEE). Developed by a Leadership Group composed of more than 50 leading organizations representing diverse stakeholder perspectives, the Action Plan was released on July 21, 2001. It focuses on these cost recovery problems, noting that regulatory policies governing utilities have more commonly compensated utilities for building power plants and selling energy, while discouraging energy efficiency even when saving energy costs less than generating energy. Ratemaking practices must be reformed for utilities to remain financially healthy while promoting the efficient use of energy by their ratepayers. Specifically, NAPEE recommends that stakeholders "Modify policies to align utility incentives with the delivery of cost-effective energy efficiency and modify ratemaking practices to promote energy efficiency investments (Leadership Group, 2006).”

\subsubsection{Stakeholders and Constituencies}

While the NAPEE Leadership Group included numerous utilities and utility organizations, many energy service providers have limited experience operating energy-efficiency programs for their consumers at the size and scope needed to transform the marketplace. Thus, utility industry resistance to the regulatory reforms proposed here exists in many regions of the country. On the other hand, there is increased recognition that the nation's growing demand for energy and increasing carbon emissions cannot be addressed without effectively tackling consumer end-use issues. Green and energy-efficient product vendors are becoming a more vocal force for 
government interventions, such as utility regulatory reforms, that expand the use of energyefficient equipment, appliances, and building practices.

\subsubsection{Policy Evaluation}

Appropriateness of the Federal Role The initiative proposed here is modeled after the Buildings Code Assistance Program (BCAP) operated by the Alliance to Save Energy, a nonprofit organization, for the U.S. Department of Energy's Building Technology Program. In this case, the initiative would support the activities of an existing but under-funded non-profit organization. The Regulatory Assistance Project (RAP), which was formed in 1992 by experienced utility regulators, provides research, analysis, and educational assistance to public officials on electric utility regulation. ${ }^{67}$ RAP workshops cover a wide range of topics including electric utility restructuring, power sector reform, renewable resource development, the development of efficient markets, performance-based regulation, demand-side management, and green pricing. RAP also provides regulators with technical assistance, training, and policy research and development. RAP has worked with public utility regulators and energy officials in 45 States and Washington, DC.

Broad Applicability. The sphere of influence of this policy mechanism could be quite broad, promoting energy efficiency in the residential and commercial buildings industry - both new and existing housing - and in industry, as well. In addition, decoupling is applicable to both natural gas and electric utilities. Currently decoupling legislation has been passed by 16 States for natural gas utilities and in six States for electric utilities.

Significant Potential Benefits. The NAPEE Leadership Group concluded that more than half of expected growth in demand for electricity and natural gas could be avoided over the next 15 years by extending energy efficiency "best practice" programs to the entire country, in conjunction with regulatory reform. They estimate that such an effort would save nearly \$20 billion annually on energy bills, avoid 60 new $500 \mathrm{MW}$ power plants, and reduce $\mathrm{CO}_{2}$ emissions annually by more than 400 million tons (Leadership Group, 2006).

Kushler, York, and Witte (2006) observe that five of the States with the largest portfolios of electricity efficiency spending as a percentage of total utility revenue in 2006 had either decoupling in place (i.e., California) or had performance incentives (i.e., Vermont, Massachusetts, Rhode Island, and New Hampshire). While the causality is not definitive, this finding suggests that these regulatory reforms are indeed powerful enablers and motivators of utility investment in energy efficiency.

\footnotetext{
${ }^{67}$ http://www.raponline.org/
} 
Since only 14 States have enacted decoupling in natural gas markets and only six in electricity markets, these findings underscore that regulatory reform of energy industries is only beginning in the U.S. Decoupling combined with performance incentives could transform utilities "from sellers of a least-cost energy commodity to providers of least-cost energy services" (Eto, Stoft, and Belden, 1997, p. 54).

\section{Gas and Electric Decoupling in the US}

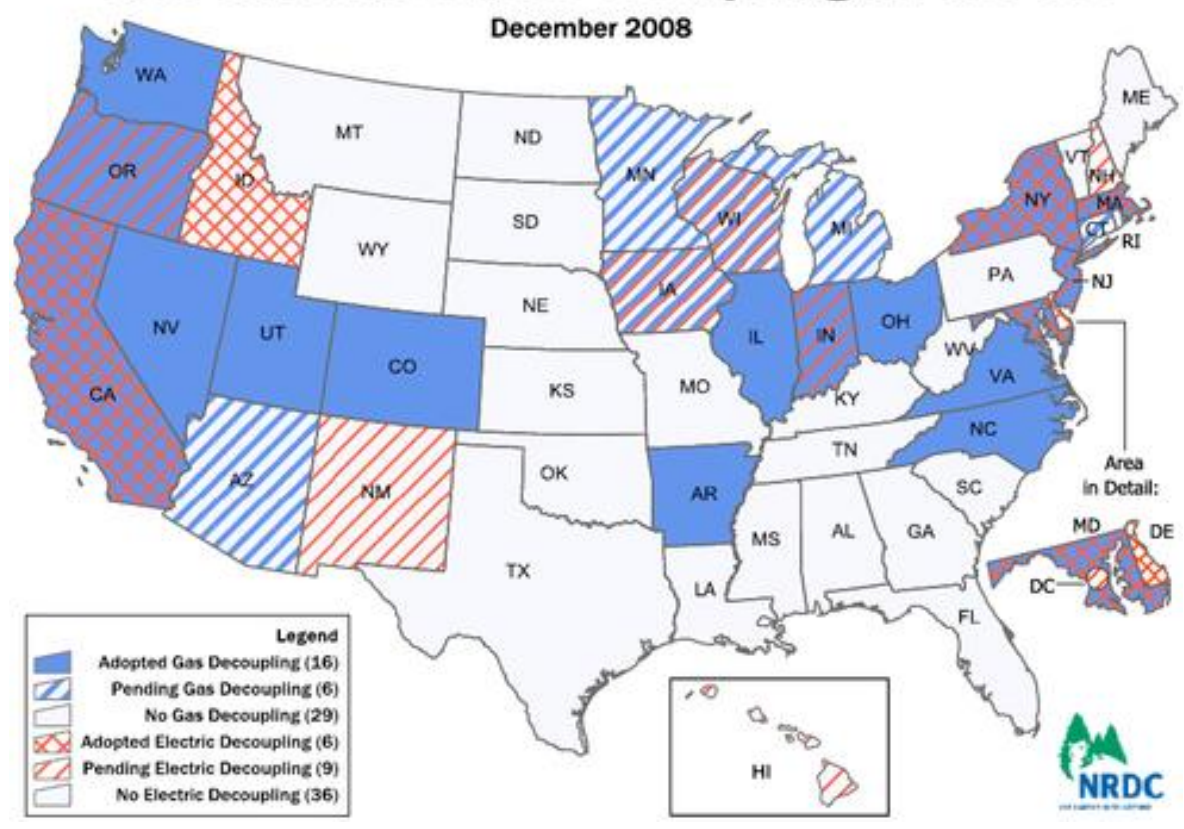

Figure 4.5 Status of Decoupling Requirements Across States in 2008 (Source: NRDC,

http://switchboard.nrdc.org/blogs/bcolander/decoupling_and_energy_efficien.html)

Solutions not Dependent on Future R\&D. Strict enforcement by DOE of the requirement that utility financial incentives align with customer energy efficiency could begin immediately. It does not rely on the successful completion of additional R\&D or the development of future technologies.

Cost Effectiveness. Duke Energy's recently announced "save-a-watt" initiative illustrates the type of promising new direction needed for utilities to promote energy efficiency. ${ }^{68}$ The initiative has been incorporated into the energy-efficiency plans filed over the last two years by Duke Energy in North Carolina, South Carolina, and Indiana. It entails the pursuit of all cost-effective energy efficiency savings with no company-imposed cap on its total energy-efficiency investment. The initiative's target calls for reducing electricity use by one percent or more each year, subject to the availability of cost-effective energy-efficiency programs to achieve the target.

${ }^{68}$ http://www.duke-energy.com/news/releases/2007050701.asp 
Administrative Practicability. To be successful, regulators in each State need to determine an appropriate and reasonable level of compensation to reward utility investments in customer energy efficiency. This is where an expanded Federal Regulatory Assistance Program (RAP) could be critical to unleashing these market forces for energy efficiency in metropolitan areas. RAP is a non-profit organization, formed in 1992 by experienced utility regulators, that provides research, analysis, and educational assistance to public officials on electric utility regulation. While an expanded RAP could help utilities reform their reward systems for energy efficiency, the ability of RAP to convince PUCs to change their ratemaking practices is somewhat uncertain.

Additionality. Many other approaches can promote energy efficiency, but reforming utility rateof-return regulation is seen by many to be a lynchpin.

\subsubsection{Summary}

DOE could strictly enforce the 2009 American Recovery and Reinvestment Act's requirements that utility financial incentives are aligned with helping their customer use energy more efficiently. It could also expand its technical assistance to help States design appropriate financial incentives for energy-efficiency programs. These Federal actions could reposition utilities as powerful enablers of a more efficient end-use energy infrastructure.

\subsection{National Energy Efficiency Resource Standard (EERS)}

Policy Option: Promulgate rules such that electric and natural gas distributors are required to meet an energy efficiency resource standard (EERS); concurrently establish a national market for trading energy savings credits.

\subsubsection{Synopsis of Policy Option}

The Federal government could establish a National Energy Efficiency Resource Standard that would require utilities to reduce electricity demand by at least 15 percent and natural gas demand by at least 10 percent by 2020. These goals are included in both House and Senate versions (H.R. 889 and S. 548) of the Save American Energy Act, introduced by Rep. Edward Markey (D-MA) and Sen. Charles E. Schumer (D-NY), and in Section 231 of the WaxmanMarkey Discussion Draft - The American Clean Energy and Security Act of 2009. EERS requires electric and natural gas distributors to meet customer needs in part through energy efficiency and load reduction programs thereby reducing greenhouse gas emissions and offsetting or postponing the construction of new power plants.

The Federal government could issue regulations on eligible measures accompanied by measurement and verification $(M \& V)$ methods. Enforcement could be at the Federal or State 
level. $\mathrm{M} \& \mathrm{~V}$ requirements should be clearly defined and present a reasonable burden so that the benefits of cost-effective energy efficiency projects outweigh the time and expense of $\mathrm{M} \& \mathrm{~V}$. Robust $\mathrm{M} \& \mathrm{~V}$ is essential to maintain a credible, transparent, and viable market trading system in which all parties have confidence. In addition, if parties agree to $M \& V$ methods, non-compliance can be dealt with swiftly rather than spending time in litigation over M\&V methods.

The EERS policy would benefit from being accompanied by a National market for trading energy savings. Such a market could be used to trade or bank energy savings between utilities across the nation. With a confident market - produced by reliable measurement and verification, energy savings can be traded to achieve savings at the least cost.

\subsubsection{Policy Experience}

Twenty-eight States currently have some form of EERS - either as a requirement or goal, with 18 including efficiency as a source for a Renewable Portfolio Standard (RPS). Figure 4.6 shows variation in State EERS adoptions and policy support for electric energy efficiency.

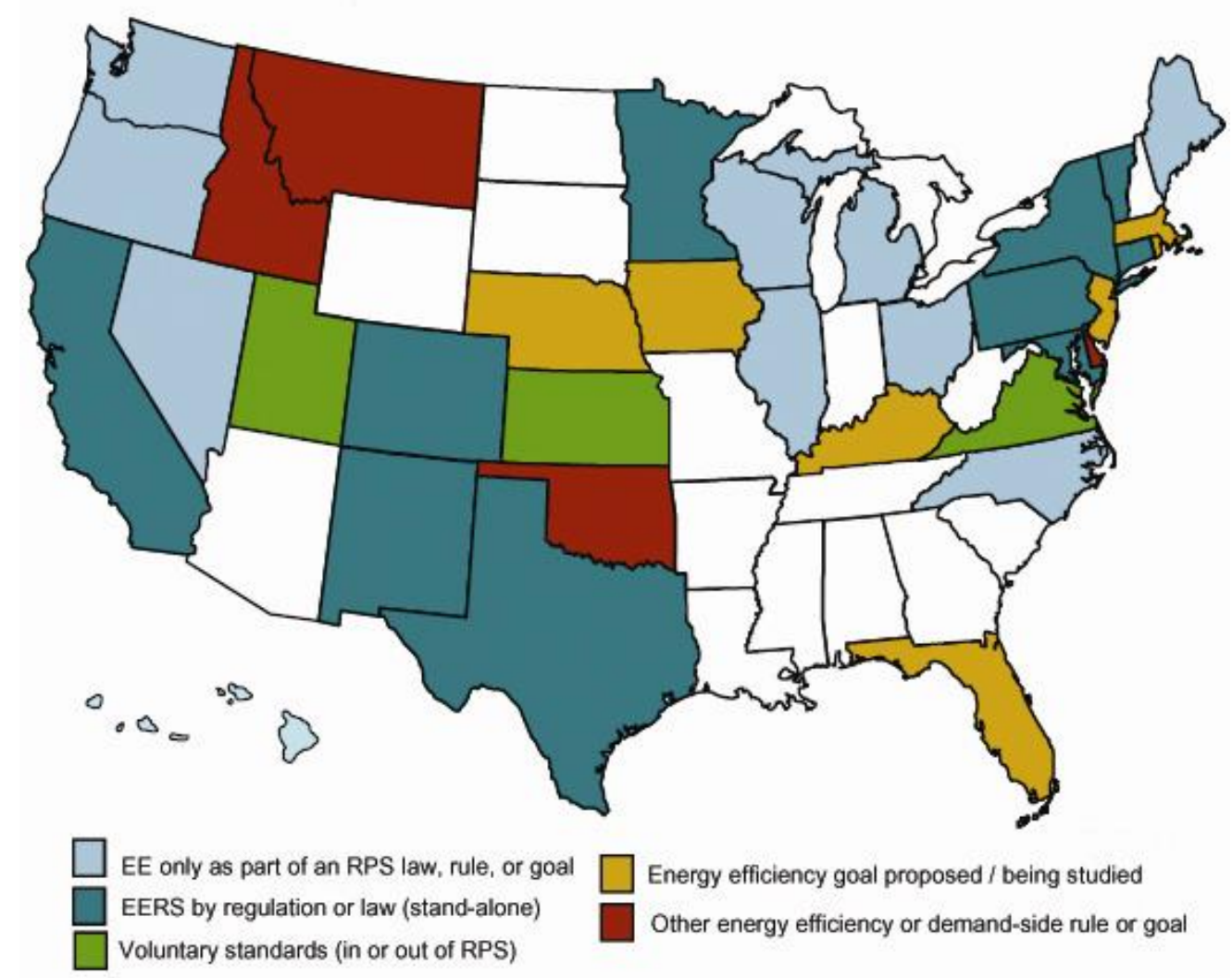

Figure 4.6 Energy Efficiency Resource Standards in the States

(Source: http://www.ferc.gov/market-oversight/mkt-electric/overview/elec-ovr-eeps.pdf, last updated March 10, 2009) 
While there are many similarities between EERS and RPS, the distinction between them is that the former requires a level of energy demand reduction through efficiency improvements, whereas the latter requires a level of renewable energy supply. In some States, energy efficiency is listed as an acceptable "source" of renewable energy supply for an RPS (Harmin, Vine, and Sharick, 2007). This extension of the RPS rules reflects the growing recognition of energy efficiency as a "resource" - on par with raw energy supplies - that can lower energy demand and provide economic and environmental benefits including the reduction of greenhouse gases and preservation of water quality.

Considering a few State case studies is helpful for evaluating the impacts at a National level (ACEEE, 2009).

- In 1999, Texas required utilities to offset 10 percent of load growth through end-use energy efficiency. After meeting this goal at low costs, the legislature increased the standard to 15 percent of load growth by 2009, 20 percent of load growth by 2010 and directed that higher targets be investigated. A recent report commissioned by the Public Utility Commission of Texas found that raising the goal to 50 percent of load growth is feasible.

- Efficiency Vermont (EV), created in 2000 as an independent "efficiency utility," delivers efficiency programs for the State. It is contractually required to achieve energy savings and demand reduction goals. By the end of 2007, EV had cumulatively met over seven percent of Vermont's electricity requirements, completely offsetting electric load growth (Furrey, Nadel and Laitner, 2009). New goals for 2009-2011 call for saving about two percent per year. In 2007, EV improved its productivity by streamlining and simplifying their processes, allowing them to reach more customers and making it easier for their customers to take advantage of savings opportunities. The number of participating businesses (those that replaced equipment or upgraded their processes) continued to grow, with 63 businesses added in 2007, a 10 percent increase from 2006.

- California set energy savings goals for investor-owned utilities for 2004-2013 and expected to save more than one percent of total forecast electricity sales per year. In the early years, savings were less than one percent per year, but in 2007, measures installed that year met 1.5 percent of the State's electricity needs. In July 2008, the California PUC established new targets for energy savings for the years 2012 through 2020 for its regulated utilities. The new goals are expected to provide approximately five percent energy savings over that period.

- Under Hawaii's Renewable Portfolio Standard (RPS) requirements (in place since 2004), energy efficiency qualifies as an eligible resource. Utilities must meet 20 percent of electricity sales with eligible resources by 2020 , with no limit on how much may be met 
by energy efficiency. In recent years, Hawaii has been achieving between $0.4-0.6$ percent energy savings per year through energy efficiency.

- In June 2005, the Connecticut legislature modified its RPS to include efficiency. Starting in 2007, the State's utilities must procure a minimum one percent of electricity sales from "Class III" resources such as energy efficiency and combined heating and power, with an additional one percent required in 2008, 2009, and 2010. Savings in 2007 were 1.04 percent of sales.

- In 2005, Nevada expanded its existing RPS from 15 percent to 20 percent of electricity sales by 2015, and was amended to allow energy efficiency to meet up to 25 percent of the total portfolio standard. The State's utilities are quickly ramping up efficiency programs to hit the maximum allowed efficiency threshold (Furrey, Nadel and Laitner, 2009).

- The New York Public Service Commission (PSC) adopted a RPS in September 2004 and issued implementation rules in April 2005. ${ }^{69}$ On May 16, 2007, the Public Service Commission initiated a proceeding to design an electric and natural gas EERS. ${ }^{70}$ In June 2008, the New York State Public Service Commission approved the Energy Efficiency Portfolio Standard (EEPS), which sets a goal to reduce electricity usage 15 percent by 2015, a goal initially announced by Governor Spitzer in 2007. The Commission currently has an open proceeding working with utilities and the New York State Energy Research and Development Authority (NYSERDA) to expand existing programs and develop new ones (Furrey, Nadel and Laitner, 2009).

- On August 28, 2007, the governor of Illinois signed Senate Bill 1592 into law which includes an EERS and a RPS that will require Illinois utilities to reduce overall electric usage by 0.2 percent of demand in 2008 , escalating to two percent by 2015 . The RPS requires utilities to supply two percent of their power from renewable energy sources by 2008 for certain "eligible customers", escalating to 25 percent by $2025 .^{71}$ Utilities such as ComEd and Ameren Illinois Utilities have developed innovative programs such as Smart Ideas Incentive Program ${ }^{72}$ and the ActOnEnergy ${ }^{\mathrm{TM}}$ programs $^{73}$ to meet the goals of the EERS.

California, Connecticut, Hawaii, Nevada, Texas and Vermont have had the most experience with implementation of an EERS and, as such, are considered some of the most successful States in operating energy-efficiency programs. All of these States have consistently increased their

\footnotetext{
${ }^{69}$ New York Incentives for Renewable Energy: .http://www.dps.state.ny.us/03e0188.htm

${ }^{70}$ Energy Efficiency Portfolio Standard: Case 07-M-0548: http://www.dps.state.ny.us/Case_07-M-0548.htm

${ }^{71}$ Illinois Energy Efficiency Portfolio Standard (EEPS): http://smartenergy.arch.uiuc.edu/html/EEPS.html

${ }^{72}$ ComEd Smart Ideas Programs: http://www.comed.com/search?Find=Smart\%20Ideas\%20Program

${ }^{73}$ Ameren Illinois Utilities ActONEnergy ${ }^{\mathrm{TM}}$ Business Program Enjoying Immediate Success: http://money.aol.com/news/articles/qp/pr/_a/ameren-illinois-utilities-actonenergytm/rfid137796170
} 
annual energy savings goals over time and have been achieving or are on track to achieving their stated energy savings goals.

The nineteen States that are implementing an EERS are positioned to achieve a little over five percent electricity savings by 2020 (Furrey, Nadel and Laitner, 2009). These States are, therefore, on track to achieve about one-third of the national goal of 15 percent electricity savings by 2020. A more concerted effort is required in these States and in the remaining 31 States and the District of Columbia if the full 15 percent reduction is to be met by energy efficiency.

There is considerable international experience as well; EERS programs have been working well in the United Kingdom and the Flemish region of Belgium. Italy has recently started a program, and another is about to start in France.

In addition to experience with EERS policies, there is some recent experience with trading energy savings. Trading energy savings via Energy Savings Certificates (ESC), Tradable White Certificates (TWC), or White Tags ${ }^{\mathrm{TM}^{74}}$ fits well within the EERS program by allowing crediting, banking, or trade of savings to keep aggregate costs low (WRI, 2008). In 2003, New South Wales adopted a trading scheme for energy savings (Friedman, Bird, and Barbose, 2008). Since then, Italy, France, and the United Kingdom, along with four States, have developed systems for trading energy savings certificates. Among the four States - Connecticut, Pennsylvania, Nevada, and Michigan - only Connecticut has a working program while the other three allow trading to meet requirements (Friedman, Bird, and Barbose, 2008). The European Union is considering developing a European market for trading energy savings. ${ }^{75}$

A voluntary National market for energy savings certificates could develop, like the market for Renewable Energy Credits (RECs), but it is not clear when this would happen under current policies; similarly, energy savings certificates might be used to comply with carbon restrictions, like in the Regional Greenhouse Gas Initiative (Friedman, Bird, and Barbose, 2008). After reviewing existing ESC programs, Vine and Hamrin (2008) offer the following elements of an effective energy savings trading program:

- Transparent rules and procedures throughout development

- Little or no proprietary information withheld from the public

- A flexible measurement and evaluation system that ensures real, measurable, verifiable, and additional energy savings

\footnotetext{
${ }^{74}$ Any of these names can be considered "an instrument representing a unit of energy savings that has been measured and verified" (Friedman, Bird, and Barbose, 2008)

${ }^{75}$ Directive 2006/32/EC of the European Parliament and of the Council of 5 April 2006 on energy end-use efficiency and energy services and repealing Council Directive 93/76/EEC (accessed from http://eur-lex.europa.eu)
} 
- Independent third-party auditing for verification and compliance

- A process for issuing and tracking certificates that avoids double counting (responsible parties should be identified a priori)

- A system for detecting and penalizing non-compliance

Some of the effort to create measurement and verification as well as tracking certificates may be reduced by private efforts already undertaken. For example, the North American Renewables Registry claims to be prepared to meet the need for energy efficiency trading markets, "APX is closely following the development of energy-efficiency standards and State programs and is prepared to provide a market infrastructure solution to ensure trust and transparency for these new environmental commodities". 76

\subsubsection{Policy Rationale}

On the one hand, State policies such as EERS foster diversity, which encourages innovation and experimentation. Decentralized environmental decision-making, in general, provides for interjurisdictional competition and creates "laboratories of democracy," a metaphor coined by Justice Brandeis in 1932. It encourages adaptation to local circumstances and needs, creating "ecologies of scale" that can maximize social welfare and minimize cost. State and local policies tend to be more representative, creating regulations and public services that better match local interests and preferences, in contrast to Federally imposed uniformity (Sovacool and Brown, 2009).

On the other hand, a National EERS could reduce the regulatory confusion and administrative burdens that have resulted from the patchwork of State-regulated EERS. A Federal EERS mandate would produce a standardized regulatory environment that would provide manufacturers and industry with consistent and predictable business rules that are important when attempting to create national markets for green technologies. In contrast, a multiplicity of State standards increases transaction costs, causes confusion in the marketplace, and prevents economies of scale. State EERS in lieu of a Federal policy also send distorted price signals. By lowering demand for energy-intensive products, State standards can reduce the regional (and even global) price for carbon-intensive fuels. Reduced prices, in turn, decrease the incentive to enact energy efficiency and conservation measures.

A patchwork of State policies allows stakeholders to manipulate the existing market to their advantage, using regulatory loopholes to waste energy and emit greenhouse gases wherever regulators are the most lax. A National EERS with standardized M\&V guidelines would likely be less costly to operate than having a variety of State-defined M\&V approaches. In addition, a nationwide policy could provide greater economic efficiency by allowing utilities to trade energy savings credits across the country.

\footnotetext{
${ }^{76}$ http://narenewables.apx.com/about/FAQ.asp
} 


\subsubsection{Stakeholder and Constituencies}

Important stakeholders include the States - particularly regulating bodies, electric utilities, natural gas utilities, and energy services companies. Support or objection from these groups is likely to depend on the aggressiveness of targets set in the EERS and the ease of trading energy savings certificates in the national market.

Consumer groups represent the interests of citizens, but from different perspectives. A National EERS with a trading mechanism may be attacked on environmental justice grounds - if energy savings accrue in some areas while others face new plant construction. Without a trading mechanism, a National EERS may be attacked on economic grounds as some utilities, and some regions, can support efficiency programs at lower costs than others.

One equity issue that may create opposition to a National EERS is "credit for early action." Current drafts of National EERS legislation do not provide credit to States that have already enacted EERS policies or other energy efficiency initiatives. Instead, States are required to realize annual savings based on averages of the previous two years' sales relative to business-asusual (BAU) projections; this benchmark will change every year and will include efficiency gains from previous years. Credit for early action could be awarded by allowing pre-existing EERS policies to be considered as part of the BAU. The resolution of this additionality issue will either favor or penalize States that have taken early action to promote energy efficiency.

Research has shown that Federal funding can crowd-out State funding of projects (Knight, 2002). Design of any incentive program to support EERS will need to take this phenomenon into account. Arguments against incentive programs may also call such funding "coercion". Incentive policies seem less benign when viewed as a form of power rather than a form of trade; purpose and impact on character of parties involved should be considered alongside the degree of voluntariness in the action of receiving an incentive (Grant, 2006). It may be just as effective for the Federal government to make clear statements of its preferences for State policy action regarding energy efficiency (Allen, Pettus, and Haider-Markel, 2004).

Federal funds might also be saved by allowing States greater flexibility in designing EERS programs, as governors have shown willingness to accept less grant funding for fewer restrictions (Volden, 2007). The cost structure of a Federal mandated program could be based on customary practices in the States that are leading in EEPS programs. Typically, the customer pays two-thirds of the cost; utilities pay one-third of the cost of investment in efficiency measures. It is estimated that by 2020, under the proposed National EERS, customers will have invested approximately $\$ 78.5$ billion in energy efficiency measures. This level of investment will yield almost $\$ 170$ billion in net benefits as a result of energy efficiency measures installed in 
2020. "Net benefits" are the total savings gained from energy-efficiency measures minus the program costs and investments associated with the measures. These benefits have been estimated to average about $\$ 1,280$ in savings per household from efficiency measures installed by 2020 (Furrey, Nadel and Laitner, 2009).

\subsubsection{Policy Evaluation}

Appropriateness of the Federal Role. The Energy Policy Act of 2005 did not include either an EERS or a Public Benefit Fund (PBF) although it did include provisions for a DOE study and authorization of State pilot projects to stimulate utility and State electricity and natural gas efficiency programs. PBFs play a complementary role by creating funding that can be used to support efficiency programs, but they are not essential for EERS to be successful. Because PBFs are generally designed as a surcharge on per unit pricing, they act as a fee.

Other examples of Federal involvement in reducing energy use, mitigating emissions, and improving energy efficiency are embodied in the Energy Independence and Security Act (EISA) of 2007. Signed into law on December 19, 2007, requires (a) use of 36 billion gallons of ethanol by 2022; (b) creates a minimum Corporate Aggregate Fuel efficiency (CAFE) standard of 35 mpg by 2020 for cars and trucks; (c) creates various appliance efficiency standards; (d) establishes a lighting efficiency standard started in 2012; (e) requires industrial electric motors to meet the premium motor efficiency standards of the National Electrical Manufacturers Association (NEMA); and (f) creates or enhances a number of other programs related to industrial waste heat or natural gas efficiency, energy use in Federal buildings, weatherization assistance, and manufactured housing (EIA, 2008a, p. 15).

Federal incentives to drive State policy are commonplace. For example, Federal grants fund highway projects in States, so long as States maintain speed limits and other laws; Federal grants for education require States to implement and report certain minimal testing requirements.

Alternatives to EERS are a valid policy consideration. Two alternatives are: 1) alternative policies to reduce consumption, or 2) alternative policies to reduce emissions.

EERS set a target, goal, or requirement for efficiency to meet compared to forecast consumption. Other policies designed to drive efficiency could be used to meet this target, goal, or requirement. Alternative policies to reduce consumption include: fiscal policies, market transformation policies, and demand-side management policies.

- Fiscal policies provide tax credits, tax rebates, grants, or loans to improve efficiency in a process, application, or building. These are subject to free-riding, a market externality that harms economic efficiency. 
- Market transformation policies fundamentally change the way that energy is considered in the market. These take more work to fully develop. We have little policy experience with them because of their transformational nature. Two possible examples are provided. 1) Decreasing information asymmetry by requiring greater information about home or building energy consumption or performance before sale or lease. 2) Aligning utility incentives with energy efficiency by decoupling profits from sales.

- Demand-side management policies: work at reducing consumer demand at peak periods throughout the day and seasons. These are usually operated by utilities, which have acquired a great deal of experience with them. EIA (2008e, Table 8.13) estimates that estimate that electric utility DSM programs in 2006 were responsible for $11 \mathrm{GW}$ of actual peakload reductions. Smart metering with dynamic pricing, such as critical peak pricing, has reduced peak consumption in pilot programs by up to 20 to 50 percent (Faruqui and Sergici, 2009). Pricing policies not based on peaks, such as increasing block prices, could also reduce consumption. Sustained meaningful pricing structures are important because the long-run price elasticity is estimated to have a mean of -0.9 , ranging from 0.7 to -1.4 , while the mean estimate of short-run price elasticity is -0.3 , ranging from -0.2 to -0.6 (EPRI, 2008).

Sufficient attention should also be paid to improve EERS policy implementation. While there is not enough policy experience to determine main drivers of success or failure of the policy, there should be sufficient information about initial hurdles or methods of implementation. A better appreciation of the distribution of the burden for EERS should be developed to indicate how this burden may change over time or could there be other policy options that could accomplish the goals more effectively.

Broad Applicability. EERS are generally applied only to large investor-owned electric utilities. However, perverse incentives could be avoided by applying them to any electricity or natural gas retailer. If the intention is to expand EERS to other fuels the same concept would apply. Successful EERS is also contingent on decoupling of profits from sales.

EERS allows states the flexibility to establish their own business models that maximize energy savings. EERS is not a prescriptive methodology, but would require a new business model that deviates from the existing practice of feeding demand by constructing new plants. Other barriers that EERS overcomes is the "tenant/landlord" split incentives, marginally higher upfront costs of efficient products with disregard for long term benefits of energy and environmental stewardship.

Significant Potential Benefits. EERS can be a driver for employment, manufacturing, and environmental quality. A National EERS (at 15 percent electric and 10 percent natural gas by 2020) could save enough energy to "power almost 48 million households in 2020, accounting for 
about 36 percent of the households in the United States. Moreover, this level of energy savings will save Americans almost $\$ 170$ billion, create over 220,000 jobs and reduce greenhouse gas pollution by 262 million metric tons while eliminating the need to build 390 power plants" (Furrey, Nadel, and Laitner, 2009).

Consumers will benefit from reduced costs if efficiency is cheaper to supply than other sources and the savings are passed through to them. For residential consumers, lighting and behavioraluse changes for HVAC could potentially yield benefits almost immediately, especially for public benefit funded projects, which are "pre-paid," and projects paid for with on-bill financing. Other measures, such as building renovations and the installation of networked meters, may take longer. Many of the benefits, such as energy security and climate change mitigation will accrue to society as a whole and will not necessarily have a direct monetary/cost-benefit effect on consumers.

ACEEE estimated a benefit-to-cost ratio of 2.6 for a National EERS of 0.75 percent per year (after a two year ramp-up period) over the period 2007-2020 (Nadel, 2006a). Although efficiency has been shown to have levelized costs equal or less than that of other supply options, new programs are often developed, with associated costs, to implement efficiency efforts. There is not enough State experience with EERS to be sure of consumer benefits or costs, or to understand the distribution of the costs and benefits in terms of who gains, who loses, and how this changes over time. In addition, previous national studies of efficiency potential for the U.S. show that goals of the current EERS under discussion (15 percent electricity and 10 percent natural gas by 2020) are not likely to occur unless under a very aggressive policy scenario such as a Federal EERS; see Table 4.1.

Climate change benefits depend on the supply option (emitting or non-emitting) that are offset by the EERS. Policies like EERS can reduce the carbon intensity of the energy supply which could reduce the carbon intensity of the economy in general. In 2007, converting fuels to electricity emitted 2,400 $\mathrm{MMTCO}_{2} \mathrm{e}$ of 7,300 $\mathrm{MMTCO}_{2} \mathrm{e}$ for the economy (EIA, 2008d). A reduction in forecast emissions from the electric power sector in 2020 by 15 percent [assuming that the EERS target is met by avoiding carbon based electricity generation] amounts to a reduction of 374 $\mathrm{MMTCO}_{2} \mathrm{e}$ (EIA, 2009). Similarly, a reduction in forecast emissions from natural gas direct fire in 2020 by 10 percent amounts to a reduction of about $91 \mathrm{MMTCO}_{2} \mathrm{e}$ (EIA, 2009). The total estimate, about $465 \mathrm{MMTCO}_{2} \mathrm{e}$ represents seven percent of forecast energy-related emissions in 2020.

Some utilities may be concerned that state or Federal mandates on energy efficiency may create a false impression that there is no need to build new supply-side generation. Another concern is that an overly simplistic and inadequately funded M\&V system may not accurately capture the impact of energy efficiency programs. M\&V should have a high degree of transparency and 
statistical rigor to ensure that efficiency measures are properly accounted for during economic excursion events (boom or bust cycles). Notwithstanding the variances in estimating the effect of consumer behavioral factors on energy consumption, $\mathrm{M} \& \mathrm{~V}$ methodology should include guidelines for states to baseline their energy use, estimate peak energy demand reduction and develop the metrics for deemed savings. Issues related to $\mathrm{M} \& \mathrm{~V}$ have been adequately and successfully addressed by the International Performance Measurement \& Verification Protocol (IPMVP) serving large commercial and ratepayers who benefit from net saving of energy efficiency measures. The IPMVP is sponsored by the Efficiency Valuation Organization (EVO), committed to "develop and promote standardized methods to quantify and manage the risks and benefits associated with business transactions on end-use energy efficiency, renewable energy and water efficiency." business practices for the measurement, verification and reporting of the net energy and capacity savings of utility energy efficiency programs. The Electric Consumers Resource Council recommends a protocol consisting of national standards that includes common definitions, minimum allowable methods, statistical rigor, compliance measures and training requirements. "The protocol should be vetted on an on-going basis by an organization such as the North American Energy Standards Board (NAESB) using procedures that have been accredited by the American National Standards Institute (ANSI). The role of a process that is ANSI certified is very important for ensuring near universal credibility." 78

\footnotetext{
${ }^{77}$ Efficiency Valuation Organization, International Performance Measurement and Verification Protocol: Concepts and Options for Determining Energy and Water Savings, Volume 1, April 2007

${ }^{78}$ Utility Energy Efficiency Programs: Too Cheap to Meter? A Policy Brief of the Electricity Consumers Resource Council, November 2008; www.elcon.org
} 
Table 4.1 Estimates of U.S. Efficiency Potential as a Percent of End-Year Forecast Consumption

\begin{tabular}{|c|c|c|c|c|c|c|}
\hline Study Ref & $\begin{array}{l}\text { IWG } \\
(1997)\end{array}$ & $\begin{array}{l}\text { IWG } \\
(2000)\end{array}$ & $\begin{array}{c}\text { Elliott \& } \\
\text { Shipley } \\
\text { (2005) }\end{array}$ & $\begin{array}{l}\text { McKinsey } \\
\text { Global } \\
\text { Institute } \\
\text { (2007) }\end{array}$ & $\begin{array}{l}\text { Brown et } \\
\text { al. (2008) }\end{array}$ & $\begin{array}{l}\text { EPRI } \\
(2009)\end{array}$ \\
\hline End Year & 2010 & 2020 & 2020 & 2020 & 2030 & 2030 \\
\hline $\begin{array}{l}\text { Length } \\
\text { (years) }\end{array}$ & 13 & 20 & 15 & 13 & 20 & 22 \\
\hline \multicolumn{7}{|c|}{ Technical } \\
\hline Residential & - & - & - & - & - & - \\
\hline Commercial & - & - & - & - & - & - \\
\hline Industrial & - & - & - & - & - & - \\
\hline Total & - & - & - & - & - & $-(29 /-)$ \\
\hline \multicolumn{7}{|c|}{ Economic } \\
\hline Residential & - & $-(37 / 12)$ & - & $38(-/-)$ & $-(30 / 28)$ & - \\
\hline Commercial & - & $-(26 / 26)$ & - & $17(-/-)$ & $-(34 / 35)$ & - \\
\hline Industrial & - & - & - & $\mathrm{a}$ & - & - \\
\hline Total & - & - & - & $20(-/-)$ & - & $-(14 /-)$ \\
\hline \multicolumn{7}{|c|}{ Maximum Achievable } \\
\hline Residential & $12(17 / 3)^{1}$ & $21(27 / 8)$ & - & - & - & - \\
\hline Commercial & $13(15 / 5)^{1}$ & $19(22 / 8)$ & - & - & - & - \\
\hline Industrial & $13(15 / 14)$ & $17(22 / 11)$ & - & - & - & - \\
\hline Total & $13(16 / 9)^{2}$ & $19(24 / 9)^{2}$ & - & - & - & $-(11 /-)$ \\
\hline \multicolumn{7}{|c|}{ Moderate Achievable } \\
\hline Residential & $5(7 / 1)^{1}$ & $9(13 / 2)$ & - & - & - & $-(8 /-)$ \\
\hline Commercial & $6(6 / 9)^{1}$ & $9(11 / 7)$ & - & - & - & $-(9 /-)$ \\
\hline Industrial & $7(8 / 7)$ & $7(7 / 5)$ & - & - & - & $-(8 /-)$ \\
\hline Total & $6(7 / 6)^{2}$ & $8(10 / 5)^{2}$ & $-(11 / 10)$ & - & - & $-(8 /-)$ \\
\hline \multicolumn{7}{|c|}{$\begin{array}{l}\text { Savings shown as percent of end year consumption for: 'all fuels (electricity/natural gas)'. } \\
\text { Combined, these studies account for } 18 \text { estimates for all fuels, } 22 \text { estimates for electricity, } \\
\text { and } 11 \text { estimates for natural gas that included (or allowed calculation of) a percentage of } \\
\text { end-year forecast savings. }\end{array}$} \\
\hline \multicolumn{7}{|c|}{$\begin{array}{l}\text { - Estimate not presented in report } \\
\text { a Estimate provided but percent not calculated } \\
{ }^{1} \text { Includes all fossil fuels } \\
{ }^{2} \text { Calculated by authors }\end{array}$} \\
\hline
\end{tabular}

Solutions not Dependent on Future R\&D. Consumers have the choice of energy-efficient products in lighting, appliances, transportation, building materials, energy monitoring, and on- 
site energy generation. Many additional products and improvements are slated to come on the market. The solutions to energy conservation is not dependent on R\&D, but can be implemented at the individual, community, city, State and Federal levels. A big driver in promulgating efficiency and conservation programs is through EERS involving the public, private entrepreneurs, utilities, local, and Federal government.

Cost Effectiveness. Energy efficiency is described as a proven, cost-effective energy resource and the only policy solution that could provide near-term relief, stretching available energy sources while providing price relief to consumers (Elloitt, 2006). ACEEE estimated a benefit-tocost ratio of 2.6 for a National EERS of 0.75 percent per year (after a two year ramp-up period) over the period 2007-2020 (Nadel, 2006b).

In the near term, energy efficiency and conservation measures offer the quickest, most costeffective methods to reduce growing demand and mitigate climate change. Approximately 25 percent of total electricity use can be saved at an average cost of $\$ .03 / \mathrm{kWh}$ whereas new generation sources cost \$.05/kWh (Laitner, Ehrhardt-Martinez, and Prindle, 2007).

The savings from energy efficiency are compounded over time as residential energy prices have trended up over the past several years (following an historic decline since the mid 1980s) (EIA, 2008e, Table 8.10). Dollar for dollar, energy efficiency is one of the best energy investments that the country can make. ESCOs can play a significant role in a Federal EERS program. For example, Energy Performance Services (EPS) Capital Corp. has been active in the performance contracting ESCO industry since 1981. They have formed ESCOs in 10 countries and developed EEPS in over 25 countries. Most recently EPS Capital Corp. has a \$100 million joint venture in Hong Kong to finance EERS for ESCOs in mainland China on a paid-from-savings basis. USAID has a project in Armenia to train ESCOs in structuring and securing financing for EERS and training and educating local financial institutions in the assessment of EERS. There are about 60 active ESCOs in the U.S with estimated revenues of $\$ 3.6$ billion (in 2006). Energy efficiency accounted for almost three-fourths of industry revenues ( $\$ 2.5$ billion).

Consumer-sited generation, including renewables, is a growth area for ESCOs, representing 16 percent of their revenues in 2006. Lawrence Berkeley National Laboratory (LBNL) has a database of nearly 1,500 case studies of energy-efficiency projects completed by ESCOs. The median benefit/cost ratio is 2.1 for 309 private sector projects and 1.6 for 771 institutional sector projects. School, government, and health care/hospital projects represent $\sim 74$ percent of market activity for ESCOs. Nearly half of the activity is focused in four States (New York, New Jersey, California, and Texas), where the median cost of projects is $\$ 0.7 \mathrm{M}$. Eighty-three percent of private sector projects pay back in six years or less versus 44 percent of Institutional Sector projects. ECSOs are active service providers to State and local governments. 
DOE has a list of 16 "Super ESCOs" for renovations to U.S government facilities funded by the ARRA of 2009. ESCOs use multiple business models for implementation of energy efficiency projects through ESCO route. Two popular models are: Guaranteed Savings Model and the Shared Savings Model. Some ESCOs have the resources that allow them to fund the customer's project. ESCO may receive money from a Public Benefit Fund (PBF). Sometimes the customer may have sufficient funds of its own to finance energy efficiency re-fits. Any lingering doubts it may have about using its own resources to fund the project is allayed by the energy savings guarantee built into the contract. The company's accountants do the math to determine whether the investment is worth it or not.

ESCOs constitute a thriving national industry: Between 1990 and 2006 alone, 20 percent average annual growth culminated in 2006 revenues totaling \$3.6 billion. Over this period, ESCOs served a majority institutional (Federal and $\mathrm{MUSH}^{79}$ ) client base - Federal, MUSH, and private sectors respectively accounting for 22 percent, 58 percent, and only 20 percent of project investments.

PI-50 conducted an extensive literature survey, interviews with industry experts, ${ }^{80}$ and independent analysis. The analysis also drew on the LBNL database of nearly 1,500 case studies of energy-efficiency projects completed by ESCOs (Hopper et al., 2007). The findings collectively highlight ESCOs' strong record and potential for enabling cost-effective GHG emissions reductions. In particular:

- ESCOs' main business line is defined by energy efficiency (primarily lighting and HVAC system retrofits) in large institutional buildings. For such projects, LBNL studies report median energy savings of 15-20 percent, mainly (80 percent) from reduced electricity consumption.

- Buildings account for over 40 percent of U.S. energy consumption (20.4 EJ and 570 $\mathrm{MtCO}_{2}$ associated emissions, in 2006 alone); ESCOs currently access Federal and MUSH, but not private, market segments; they therefore capture only a two percent share of the total buildings market and associated GHG mitigation potential.

- Prior to the current economic recession, capital costs for a typical Federal project were determined by the going market rate of about 5-6.5 percent. At a seven percent discount rate, over 70 percent of ESCO projects remain cost-effective.

- Assuming a seven percent discount rate, the average Federal ESCO project achieves energy and emissions reduction rates, per unit investment, of $1.24 \mathrm{GJ} / \mathrm{US} \$$ and 4.55 $\mathrm{tCO}_{2} / \mathrm{US} \$$ - exceeding $2500 \mathrm{GJ}$ and $9 \mathrm{MtCO}_{2}$, at a median benefit-cost ratio of 1.6, over a typical 14-year project lifetime.

- Thus ESCO projects already demonstrate high energy-saving potential and correspondingly deep $\mathrm{CO}_{2}$ emissions reduction opportunities.

\footnotetext{
${ }^{79}$ MUSH stands for municipal/state government, universities, schools, and hospitals.

${ }^{80}$ Interviewees included aurhors of two widely referenced studies (Goldman, Hopper and Osborn, 2005 and Hopper et al., 2007) and the President of the National Association of Energy Services Companies (NAESCO).
} 
- Policy measures such as subsidies, to lower capital costs, would further improve ESCOs' already positive cost-benefit characteristics - thereby expanding existing markets; enabling access to as-yet untapped markets; and cost-effectively amplifying energy and environmental benefits, both on a per-project and aggregate basis (specific projections available upon request).

Administrative Practicality. Because there is extensive policy experience with EERS, and EERS-like policies, they can be assumed to be administratively feasible. The Federal role is limited to developing and enforcing regulations, providing incentives, and establishing and monitoring an energy savings market. These actions have been taken for other areas, and are not expected to be significantly burdensome.

Funds to support administration and program costs of EERS could be captured in part through public benefits funds (PBFs). Over two dozen States and the District of Columbia have increased electricity surcharge ("wires charge") nominally to create a guaranteed stream of funds for energy efficiency. PBFs support projects to increase energy efficiency, renewable energy, low-income energy assistance, and energy R\&D. State PBFs spend almost $\$ 1$ billion per year just on energy-efficiency projects. A National "wires charge" could fund a Federal PBF. The Alliance to Save Energy estimates that a surcharge of a one tenth of one cent per kWh would provide $\$ 3.7$ billion per year, and would add less than $\$ 1$ to the average residential monthly bill. $^{81}$

Additionality. EERS set a target, goal, or requirement for efficiency to meet compared to forecast consumption. Other policies designed to drive efficiency could be used to meet this target, goal, or requirement.

\subsubsection{Summary}

It is recommended that the Federal government provide incentives and supporting policies (such as rules, measurement and verification protocols, and a market for trading energy savings), for States to develop EERS for electricity and natural gas. The benefits of energy-efficiency policies generally outweigh their costs, and with attention to measurement and verification of savings, EERS can support the lowest cost savings through trading of credits. Opposition to a National EERS may be due to equity, economic, environmental, or Federalist issues.

\footnotetext{
${ }^{81}$ Energy Efficiency in the Utility Sector Fact Sheet: http://www.ase.org/content/article/detail/2861
} 


\section{Conclusions}

The energy-efficiency gap in the U.S. residential sector is large; at the same time, homes are responsible for more than one-fifth of the nation's energy-related carbon dioxide emissions. If key barriers that impede investments in energy-efficient technologies and practices could be removed, homes could become a significant part of the solution to the global climate challenge.

Using a uniform set of policy evaluation criteria, this report has examined seven promising policy options that target residential energy efficiency. ${ }^{82}$ Two of these options promote energyefficient residential construction, two target energy-efficiency improvements to existing buildings, and three others focus on utility-based policy options to promote the efficient use of energy by residential customers. Table 5.1 summarizes our evaluation of these seven policy options.

In addition to the seven evaluation criteria, this table shows anticipated time to significant savings after adoption of a particular policy. Even for those policies that have medium or long time horizons, savings begin to accrue shortly after adoption and build up over time. For example, savings from the stronger enforcement of advanced building codes is constrained by the small increment of new construction each year relative to the existing building stock. In general, policies targeted at new construction offer longer term potential, while policies that target existing structures typically yield quicker impacts. Both are important for a balanced approach. Figure 5.1 offers a stylized example of temporal impacts of policies in the two subsectors; time $=0$ is assumed to be the point of policy implementation.

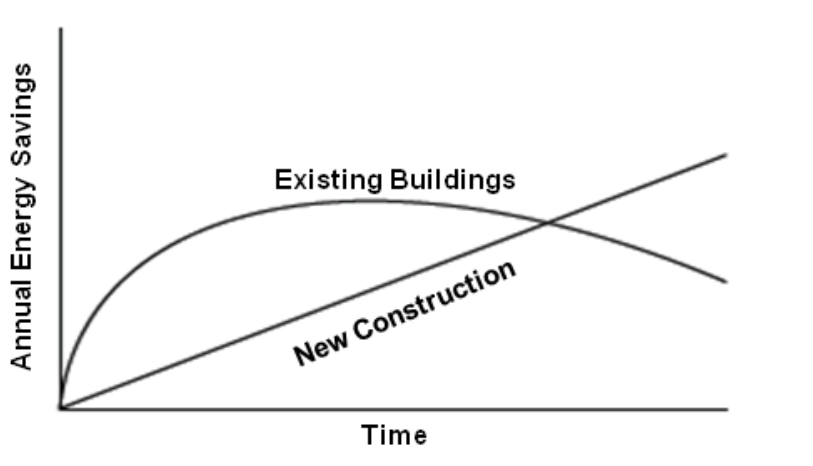

Figure 5.1 Timeline of Anticipated Energy Savings from Alternative Policy Targets

On the one hand, each of the seven policy options is judged to be cost effective. In addition, most of them have a strongly defensible Federal role, have broad applicability to the residential sector,

\footnotetext{
${ }^{82}$ As noted in the introduction (see Table 1.1), these policies are not necessarily limited to targeting the residential sector; however, this document was designed to focus on their implementation and effect in the residential sector.
} 
offer significant potential benefits, and are able to be implemented without further research and development. Most are also seen as strong in terms of "additionality" - that is, their impacts are not made redundant when other policies are implemented.

Table 5.1 Summary Assessment of Policy Options

\begin{tabular}{|c|c|c|c|}
\hline & Strengths & Weaknesses & Time Horizon* \\
\hline \multicolumn{4}{|c|}{ Policy Options to Promote Energy-Efficient Residential Construction } \\
\hline $\begin{array}{l}\text { Advancing and } \\
\text { Enforcing State } \\
\text { Building Energy } \\
\text { Codes }\end{array}$ & $\begin{array}{l}\text { Significant Potential } \\
\text { Benefits, Cost- } \\
\text { Effectiveness, } \\
\text { Additionality }\end{array}$ & $\begin{array}{l}\text { Administrative } \\
\text { Practicability, Stricter } \\
\text { Codes Require Improved } \\
\text { Technologies }\end{array}$ & Medium to Long \\
\hline $\begin{array}{l}\text { Expanded Use of } \\
\text { Home Energy } \\
\text { Performance Ratings }\end{array}$ & $\begin{array}{l}\text { Broad Applicability, } \\
\text { Potential Benefits, Cost- } \\
\text { Effectiveness }\end{array}$ & None & $\begin{array}{l}\text { Short to Long } \\
\text { (depends on policy } \\
\text { using them) }\end{array}$ \\
\hline \multicolumn{4}{|c|}{ Policy Options to Promote Energy-Efficient Improvements to Existing Residences } \\
\hline $\begin{array}{l}\text { Mandated Disclosure } \\
\text { of Energy } \\
\text { Performance } \\
\text { Information }\end{array}$ & $\begin{array}{l}\text { Appropriateness of the } \\
\text { Federal Role, Broad } \\
\text { Applicability, Technology } \\
\text { is Commercially Available } \\
\text { Today, Cost-Effectiveness }\end{array}$ & $\begin{array}{l}\text { Administrative } \\
\text { Practicability, } \\
\text { Additionality }\end{array}$ & Medium to Long \\
\hline $\begin{array}{l}\text { On-Bill Financing of } \\
\text { Energy-Efficiency } \\
\text { Improvements }\end{array}$ & $\begin{array}{l}\text { Appropriateness of the, } \\
\text { Broad Applicability, } \\
\text { Technology is } \\
\text { Commercially Available } \\
\text { Today, Significant } \\
\text { Potential Benefits, Cost- } \\
\text { Effectiveness }\end{array}$ & $\begin{array}{l}\text { Administrative } \\
\text { Practicability }\end{array}$ & Short to Medium \\
\hline \multicolumn{4}{|c|}{ Utility-Based Policy Options to Promote Energy-Efficient Buildings } \\
\hline $\begin{array}{l}\text { Performance } \\
\text { Specifications for } \\
\text { Smart Meters and } \\
\text { Demand Response }\end{array}$ & $\begin{array}{l}\text { Broad Applicability, } \\
\text { Significant Potential } \\
\text { Benefits, Cost- } \\
\text { Effectiveness, } \\
\text { Additionality }\end{array}$ & $\begin{array}{l}\text { Administrative } \\
\text { Practicability }\end{array}$ & $\begin{array}{l}\text { Short (for demand } \\
\text { response effect) to } \\
\text { Long (for savings } \\
\text { from performance } \\
\text { specifications) }\end{array}$ \\
\hline $\begin{array}{l}\text { Alignment of Utility } \\
\text { Financial Incentives } \\
\text { with Customer Energy } \\
\text { Efficiency }\end{array}$ & $\begin{array}{l}\text { Broad Applicability, } \\
\text { Technology is } \\
\text { Commercially Available } \\
\text { Today, Significant } \\
\text { Potential Benefits, Cost- } \\
\text { Effectiveness, } \\
\text { Additionality }\end{array}$ & $\begin{array}{l}\text { Administrative } \\
\text { Practicability }\end{array}$ & Medium \\
\hline $\begin{array}{l}\text { National Energy } \\
\text { Efficiency Resource } \\
\text { Standard }\end{array}$ & $\begin{array}{l}\text { Technology is } \\
\text { Commercially Available } \\
\text { Today, Significant } \\
\text { Potential Benefits, Cost- } \\
\text { Effectiveness }\end{array}$ & $\begin{array}{l}\text { Administrative } \\
\text { Practicability, } \\
\text { Additionality }\end{array}$ & Medium \\
\hline
\end{tabular}

*Time horizons when significant energy savings begin: short (5 years or less), medium (5 to 10 years), and long (more than 10 years). 
On the other hand, a majority of the policy options have issues of "administrative practicability." In several cases, new institutions or capabilities must be established, as is true with the creation of a third-party compliance system for building codes and the establishment of a revolving loan fund for on-bill financing. In other cases, new legislation is required (e.g., for mandating the disclosure of energy performance information), new utility commission rate-making rules must be established (e.g., to re-align utility financial incentives), or new Federal standards must be set (as with smart meters and a National energy-efficiency portfolio).

These same issues of administrative practicability could slow down the pace of energy savings, and therefore tend to be associated with more protracted time horizons for energy savings. The National energy-efficiency portfolio standard is an exception to this, since legislative proposals are already being debated. The concept of administrative practicability and its relationship to individual policies is not static. As legislation is passed and experience is gained with implementation, those policies that seem less practicable ex ante may be found to require little administrative effort ex post. This is especially the case for those policies that require an initial hurdle, such as development of standards or enabling of mechanisms not in practice today. Thus, having administrative practicability for a "weakness," as presented here should not be interpreted to mean that the policy is overly burdensome from an administrative standpoint.

Two policy options are judged to be weak in terms of "additionality:" mandated disclosure of energy performance information, because the gap it fills could also be addressed by other policies that increase the perceived value of efficiency; and a National energy-efficiency portfolio standard, because standards tend to be met with a diverse package of policy options to increase efficiency.

The only policy option that faces the need for ongoing technology R\&D is the advancement of state energy codes; here it is assumed that stronger codes in the future will require new and improved technologies. While the benefits of other policies typically would be enhanced by the availability of improved technologies, their cost-effectiveness is favorable based on best-practice technologies in the marketplace today.

While the success of most of the seven policies studied here does not depend on further technology R\&D, they would profit from greater social science research in the area of energy efficiency in homes. Energy efficiency policies repeatedly fall short of their potential impacts for lack of insights and information that could help policymakers and program implementers understand their target audiences. As a strategy for highlighting high-potential social science research, we consider the kind of knowledge and understanding that would help inform the design and implementation of each of the seven policies discussed in this report. 


\section{Box 5.1 Illustrative Social Science Research to Support Residential Energy Policy Design and Implementation}

\section{\#1: Advancing and Enforcing State Building Energy Codes}

- How can homeowners be made aware of residential building code features so that they can exert "demand pull" to ensure effective construction practices?

- How can homebuilders and inspectors become better informed about the mechanics and importance of building code compliance?

- What is the best way to train the workforce of building code enforcement officials?

\section{\#2: Expanded Use of Home Energy Performance Ratings}

- In what units should ratings be presented (abstract scales like the 1-100 HERS, energy units, dollars)?

- What rating information would be most credible and influential to each of the potential user groups (home buyers, home renters, rental property owners, architects, builders, mortgage lenders, real estate agents, etc.)?

- Should ratings take into account variations in building use due to household size, life cycle, behavioral differences, etc.? If so, how?

\section{\#3: Mandated Disclosure of Energy Performance Information}

- How, when, and by what media should information disclosure be mandated?

- What specific information should be disclosed?

- If peer pressure is as highly influential as research suggests, how can the disclosed information be most usefully packaged to provide homebuyers and sellers with useful comparative information?

\section{\#4: On-Bill Financing of Energy-Efficiency Improvements}

- What segments of the population would likely respond most favorably to on-bill financing as a means of retrofitting their homes?

- What are the sources of utility resistance to this policy and how can they be overcome?

- What are the possibilities for non-utilities to provide long-term funding of efficiency improvements? (e.g., appliance retailers, NGOs, state or local government agencies)

- What are the possibilities for financing of these improvements as part of mortgages and refinances? 


\section{Box 5.1 Illustrative Social Science Research to Support Residential Energy Policy Design and Implementation (cont.)}

\section{\#5: Performance Specifications for Smart Meters and Expanded Demand Response}

- How frequent should feedback be? In what units should it be given for greatest effectiveness with consumers?

- Do different types of consumers need different types of information (e.g., Internet, home thermostat, ...)

- How can meters be designed for convenient and meaningful use by home occupants who vary dramatically in levels of technological sophistication?

- What programs can be designed to maximize behavioral response to smart meters, with or without time-of-use pricing?

- What consumer education is necessary to maximize the impact of smart meters, and how can it most effectively be delivered?

- How can smart whole-home meters be combined effectively with technologies for measuring usage for particular outlets, switches, or pieces of equipment?

\section{\#6: Alignment of Utility Financial Incentives with Customer Energy Efficiency}

- What are the sources of utility resistance to this policy and how can they be overcome?

- If concerns about measurement and verification are as critical as they appear to be, how can utility program managers gain experience and become more confident with program evaluation practices?

- Who are the stakeholders that would benefit or suffer as a result of a major shift to utility-managed efficiency programs, and how can the concerns of the opposition be best addressed?

\section{\#7: National Energy Efficiency Resource Standard (EERS)}

- What are the sources of utility resistance to this policy and how can they be overcome?

- If concerns about measurement and verification are as critical as they appear to be, how can utility program managers gain experience and become more confident with program evaluation practices?

Further analysis of the interactions between the seven policies is presented in the Table 5.2. A "+" indicates that the row policy is expected to reinforce the column policy, perhaps by providing an enabling capacity or by addressing a common barrier. A "-." indicates that a row policy may duplicate some of the intended savings of the column policy, perhaps by targeting energy-efficiency investments in the same market segment or by eliminating a barrier that was a 
common focus of the two policies. Note that only one policy is seen as significantly duplicating or overlapping with the energy savings of another policy. In particular, if compliance with building codes is effectively enforced, then mandatory disclosure of home energy performance would become less important over time as performance information would be more readily known. In contrast, there are numerous examples of reinforcing policies:

Table 5.2 Complementariness of the Seven Policy Options (+ = driving or reinforcing, $-=$ duplication or overlap)

\begin{tabular}{|l|c|c|c|c|c|c|c|}
\hline & 1 & 2 & 3 & 4 & 5 & 6 & 7 \\
\hline [1] Advancing and Enforcing State Building Energy Codes & & & - & & & & \\
\hline [2] Expanded Use of Home Energy Performance Ratings & + & & + & + & & & + \\
\hline [3] Mandated Disclosure of Energy Performance Information & & + & & + & + & & \\
\hline [4] On-Bill Financing of Energy-Efficiency Improvements & & + & & & + & & \\
\hline $\begin{array}{l}\text { [5] Performance Specifications for Smart Meters and } \\
\text { Expanded Demand Response }\end{array}$ & & + & & + & & & + \\
\hline $\begin{array}{l}\text { [6] Alignment of Utility Incentives with Customer Energy } \\
\text { Efficiency }\end{array}$ & & & & & + & & \\
\hline [7] National Energy Efficiency Resource Standard (EERS) & & + & + & + & + & & \\
\hline
\end{tabular}

- Home energy performance ratings can be used to verify compliance with building codes [1] and provide input to mandatory disclosure [3], on-bill financing of retrofits [4], and EERS [7].

- Mandatory disclosure of energy performance information could drive demand for greater information about home energy use through performance ratings [2] (to determine cost-effective improvements) and smart meters [5], and could enable greater use of creative retrofit funding sources such as on-bill financing [4].

- On-bill financing may also drive greater demand for information about home energy use through performance rating $\mathrm{s}$ [2] (to determine cost-effective improvements).

- Smart meters and demand response efforts could drive demand for greater information about home energy use through performance ratings [2] (to determine cost-effective improvements) and greater use of creative retrofit funding sources such as on-bill financing [4].

- $\quad$ Aligning utility incentives with efficiency is likely to increase the priority for demand response [5] efforts on the part of utilities and will motivate utilities to help meet and possibly exceed EERS goals [7].

- A Federal EERS will increase the value of efficiency, thus it will likely drive utility interest in demand response [5] and on-bill financing. Similarly, it could drive demand 
for greater information about home energy use through performance ratings [2] (to determine cost-effective improvements) and greater use of creative retrofit funding sources such as on-bill financing [4].

Adaptation and flexibility are important to ensure that reinforcing policies do not become competing policies (Boonekamp, 2006; CCCSTI, 2009).

In totality, these policy options suggest an array of complementary cost-effective Federal actions that could enable homes to become strong contributors to global climate solutions. Without such policy initiatives, it will be difficult to shrink the energy-efficiency gap in the U.S. housing market. 


\section{References}

Alexander, Barbara. 2007. "Smart meters, real-time pricing, and demand response programs: Implications for low-income electric customers." http://www.pulp.tc/Smart_Meters_Real_Time.pdf

Allen, Mahalley D., Carrie Pettus, and Donald P. Haider-Markel. 2004. "Making the National Local: Specifying the Conditions for National Government Influence on State Policymaking." State Politics and Policy Quarterly 4(3): 318-44

Alliance to Save Energy. 2005. "Blueprint for Energy-Efficiency Acceleration Strategies for Buildings in the Western Hemisphere.” Washington, DC: Alliance to Save Energy.

Alsever, Jennifer. 2007. "Want a green house? Prepare to be confused.” MSNBC, May 7. http://www.msnbc.msn.com/id/18472719/

American Council for an Energy-Efficient Economy (ACEEE). 2009. "Success with energy Efficiency Resource Standards.” http://www.aceee.org/energy/state/EERS_statesuccess0109.pdf

Australian Greenhouse Office. 2005. International Directions For The Mandatory Disclosure Of The Energy Performance Of Buildings. http://www.nfee.gov.au/public/download.jsp?id=199

Barr, S., A. Gilg, and N. Ford. 2005. "The household energy gap: examining the divide between habitual- and purchase-related conservation behaviors." Energy Policy 33: 1425-1444.

Bartholomot, Henri. 2007. "EEI Views on the EIA Electric Survey Forms.” Presented at: EIA Energy Outlook, Modeling, and Data Conference, March 28, Washington, DC. Http://www.eia.doe.gov/oiaf/aeo/conf/bartholomot/bartholomot.ppt

Bell, Luke. 2008. "Energy Efficiency Issues in Residential Housing.” Presented at: National Association of Realtors 2008 Government Affairs Directors Institute, July 23-26, Jackson Hole, Wyoming. http://www.realtor.org/gadConf.nsf/files/gad_institute_08_luke.pdf/\$FILE/gad_institute_08_gree nbldg_luke.pdf

Belson, Ken. 2008. "Rewarding those who wait to flip the switch," New York Times: July 21, 2008. http://www.nytimes.com/2008/07/21/nyregion/21peak.html 
Bernstein, Mark and James Griffin. 2005. "Regional Differences in the Price-Elasticity of Demand for Energy." The RAND Corporation; prepared for the National Renewable Energy Laboratory. http://www.rand.org/pubs/technical_reports/2005/RAND_TR292.sum.pdf

Berry, Linda and Martin Schweitzer. (2003). "Metaevaluation of National Weatherization Assistance Program Based on State Studies, 1993-2002.” Oak Ridge, TN: Oak Ridge National Laboratory, Report No. ORNL-CON/488. http://weatherization.ornl.gov/pdf/CON_488.pdf

Boonekamp, Piet. 2006. "Actual interaction effects between policy measures for energy efficiency - A qualitative matrix method and quantitative simulation results for households." Energy 31: 2848-2873.

Borenstein, Severin. 2002. “The Trouble with Electricity Markets: Understanding California's Restructuring Disaster.” Journal of Economic Perspectives, 16(1): 191-211.

Borenstein, Severin, Michael Jaske, and Arthur Rosenfeld. 2002. "Dynamic Pricing, Advanced Metering, and Demand Response in Electricity Markets. Center for the Study of Energy Markets." http://repositories.cdlib.org/cgi/viewcontent.cgi?article=1005\&context=ucei/csem

Boulin, Jean. 2009. Personal communication, May 14.

Brown, Marilyn A. and Sharon (Jess) Chandler, 2008. "Governing Confusion: How Statutes, Fiscal Policy, and Regulations Impede Clean Energy Technologies," Stanford Law and Policy Review (19) 3: 472-509. http://slpr.stanford.edu/previous/Volume19.html\#Issue3

Brown, Marilyn A., Sharon (Jess) Chandler, Melissa V. Lapsa, and Benjamin K. Sovacool. 2008. "Carbon Lock-In: Barriers to the Deployment of Climate Change Mitigation Technologies." Oak Ridge, TN: Oak Ridge National Laboratory, ORNL/TM-2007/124, http://www.ornl.gov/sci/eere/PDFs/Carbon_Lock_In_Report.pdf

Brown, Marilyn A, John A. Laitner, Sharon Chandler, Elizabeth D. Kelly, Shruti Vaidyanathan, Vanessa McKinney, Cecelia Logan, and Therese Langer. 2009. Energy Efficiency in Appalachia, Prepared for the Appalachian Regional Commission.

http://www.seealliance.org/pdf/ARC_Final_March09.pdf

Brown, Marilyn A. and G. Reeves. 1986. “General Public Utilities: Buying Residential Energy Conservation" in Financing Energy Conservation, ed. M. Weedall, R. Weisenmiller, M.

Shepard, pp. 123-132. Washington, D.C.: American Council for an Energy Efficient Economy. 
Brown, Marilyn A. and Frank Southworth, 2008. "Mitigating Climate Change through Green Buildings and Smart Growth," Environment and Planning A (40): 653-675.

Brown, Marilyn A., Frank Southworth, and Therese Stovall. 2005. "Towards a Climate-Friendly Built Environment.” Arlington, VA: Pew Center on Global Climate Change. http://www.pewclimate.org/docUploads/Buildings_FINAL.pdf

Brown, Marilyn A. and D. L. White. 1988. "Stimulating Energy Conservation by Sharing the Savings: A Community-Based Approach.” Environment and Planning A 20(4), 517-534.

Brown, Matthew. 2009. Brief \#3: Paying for Energy Upgrades Through Utility Bills. Washington, DC: Alliance to Save Energy. http://ase.org/content/article/detail/5476

Brown, Rich, Sam Borgeson, Jon Koomey, and Peter Beirmayer. 2008. "U.S. Building Sector Energy Efficiency Potential.” Berkeley, CA: Lawrence Berkeley National Laboratory, LBNL1096E. http://www.osti.gov/bridge/servlets/purl/941430-cn2bC7/941430.pdf

Burr, Michael. 2008. "Snake oil and smart meters: customers deserve the straight truth about electricity costs," editorial. Public Utilities Fortnightly, 146(4):4-5.

Casals, Xavier. 2006. "Analysis of building energy regulation and certification in Europe: Their role, limitations and differences." Energy and Buildings 38:(5) 381-392.

Casten, Thomas R. and Robert U. Ayres. 2007. Energy Myth Eight - Worldwide Power Systems are Economically and Environmentally Optimal in Sovacool, B. K. and Brown, M. A. (eds.) Energy and American Society - Thirteen Myths (201-237). Dordrecht: Springer.

Caves, D. W., L. R. Christensen, and J. A. Herriges. 1984. "Consistency of Residential Customer Response in Time-of-Use Electricity Pricing Experiments." Journal of Econometrics 26:179-203.

CEATI International, Inc. 2008. "Results of Two-Year Study Demonstrates Residential Electricity Monitors Help Homeowners Conserve Electricity in a Big Way." http://www.bluelineinnovations.com/documents/pr-ceati.pdf

Charles River Associates. 2005. "Impact Evaluation of the California Statewide Pricing Pilot: Final Report." http://www.energetics.com/MADRI/toolbox/pdfs/pricing/cra_2005_impact_eval_ca_pricing_pil ot.pdf 
Chenevert, Emily. 2008. "Energy Efficiency Issues in Austin.” Presented at: National Association of Realtors 2008 Government Affairs Directors Institute, July 23-26, Jackson Hole, Wyoming.

http://www.realtor.org/gadConf.nsf/files/gad_institute_08_emily.pdf/\$FILE/gad_institute_08_gr eenbldg_emily.pdf

Combs, Susan. 2008. "The Home Energy Efficiency Report.” Texas Comptroller of Accounts. http://www.window.state.tx.us/specialrpt/hb3070/96-1350_Home_Energy_Eff_HB3070.pdf

Committee on Climate Change Science and Technology Integration (CCCSTI). 2009. "Strategies for the Commercialization and Deployment of Greenhouse Gas Intensity-Reducing Technologies and Practices." Washington, DC: U.S. Department of Energy, DOE/PI-0007. http://www.climatetechnology.gov/Strategy-Intensity-Reducing-Technologies.pdf

Cowart, Richard. 2001. "Efficient Reliability: The Critical Role of Demand-Side Resources in Power Systems and Markets.” Report to the National Association of Regulatory Utility Commissioners, Regulatory Assistance Project. http://www.raponline.org/Pubs/General/EffReli.pdf (accessed 11/9/06)

Darby, Sarah. 2006. "The effectiveness of feedback on energy consumption: A review for DEFRA of the literature on metering, billing, and direct displays." Environmental Change Institute http://www.defra.gov.uk/ENVIRONMENT/climatechange/uk/energy/research/pdf/energyconsu $\underline{\text { mp-feedback.pdf }}$

Department for Environment, Food and Rural Affairs (DEFRA). 2007. "Public Understanding of Sustainable Energy Consumption in the Home." http://randd.defra.gov.uk/Document.aspx?Document=EV02046_6701_FRP.pdf

Desmedt, Johan, Guy Vekemans, and Dries Maes. 2009. "Ensuring effectiveness of information to influence household behaviour." Journal of Cleaner Production, 17(4): 455-462.

Dirks, J.A., D.M. Anderson, D.J. Hostick, D.B. Belzer, and K.A. Cort. 2008. "Lost Opportunities in the Buildings Sector: Energy-Efficiency Analysis and Results." PNNL-17623. Richland WA: Pacific Northwest National Laboratory. http://www.pnl.gov/main/publications/external/technical_reports/PNNL-17623.pdf

Ea Energianalyse, Niras, RUC, and 4-Fact. 2008. "Evaluation of the Danish Energy-Saving Activities.” (in Dutch) Prepared for Danish Energy Agency. http://ens.dk/sw78247.asp [Bilagsrapport] 
Earle, Robert and Ahmad Faruqui. 2006. "Toward a new paradigm for valuing demand response.” The Electricity Journal 19(4): 21-31.

Egan, C. and E. Brown. 2001. "An analysis of public opinion and communication campaign research on energy efficiency and related topics." Washington, DC: American Council for an Energy-Efficient Economy. Report No. A013.

Electric Power Research Institute (EPRI). 2008. "Price Elasticity of Demand for Electricity: A Primer and Synthesis.” EPRI, Palo Alto, CA. 1016264. http://my.epri.com/portal/server.pt?Product_ID=000000000001016264

Electric Power Research Institute (EPRI). 2009. Assessment of Achievable Potential from Energy Efficiency and Demand Response Programs in the U.S.: (2010-2030). Palo Alto, CA: EPRI. Product \# 1016987. http://my.epri.com/portal/server.pt?Abstract_id=000000000001016987

Elliott, R.N. 2006. “America's Energy Straightjacket.” Washington, DC: Amercian Council for an Energy-Efficient Economy. http://www.aceee.org/pubs/e065.htm

Elliott, N. and A. Shipley. 2005. "Impacts of Energy Efficiency and Renewable Energy on Natural Gas Markets: Updated and Expanded Analysis.” Washington, DC: American Council for an Energy Efficient Economy, Report E052. http://www.aceee.org/pubs/e052.htm

Energy Information Administration (EIA). 2008a. Annual Energy Outlook 2008 with Projections to 2030, DOE/EIA-0383(2008). http://www.eia.doe.gov/oiaf/archive/aeo08/index.html

Energy Information Administration (EIA). 2008b. "Assumptions to the Annual Energy Outlook 2007," Table 7. http://www.eia.doe.gov/oiaf/archive/aeo07/assumption/pdf/residential_tables.pdf in 3.2

Energy Information Administration (EIA). 2008c. "2005 Residential Energy Consumption Survey; Table US2. Total Households by Fuels Used, 2005.” http://www.eia.doe.gov/emeu/recs/recs2005/hc2005_tables/detailed_tables2005.html

Energy Information Administration (EIA). 2008d. "Emissions of Greenhouse Gases Report." DOE/EIA-0573(2007). http://www.eia.doe.gov/oiaf/1605/ggrpt/index.html

Energy Information Administration (EIA). 2008e. Annual Energy Review DOE/EIA-0384(2007). http://www.eia.doe.gov/aer/elect.html 
Energy Information Administration (EIA). 2009. An Updated Annual Energy Outlook 2009 Reference Case Reflecting Provisions of the American Recovery and Reinvestment Act and Recent Changes in the Economic Outlook. SR/OIAF/2009-03. http://www.eia.doe.gov/oiaf/servicerpt/stimulus/excel/aeostimtab_18.xls

Energy Retail Association (ERA). 2008. "Principles and Requirements for Smart Metering." http://www.energy-retail.org.uk/documents/Principlesandrequirementsdocumentv11.pdf

ENERGY STAR. 2008. “ENERGY STAR Qualified New Homes Market Indices for States.” http://www.energystar.gov/index.cfm?fuseaction=qhmi.showHomesMarketIndex

Eto, Joseph, Steven Stoft, and Timothy Belden. 1997. "The theory and practice of decoupling utility revenues from sales.” Utilities Policy, 6(1), 43-55.

Faiers, Adam, Matt Cook, and Charles Neame. 2007. "Towards a contemporary approach for understanding consumer behaviour in the context of domestic energy use.” Energy Policy, 35(8) 4381-4390.

Farhar, B.C., N.E. Collins, and R.W. Walsh. 1997. "Case studies of energy efficiency financing in the original five pilot states, 1993-1996.” (No. NREL/TP--550-22355; Other: ON:

DE97000219; TRN: TRN: 97:004253). Golden, CO: National Renewable Energy Laboratory.

Faruqui, Ahmad. 2008. "Inclining toward efficiency: Is electricity price elastic enough for rate designs to matter?” Public Utilities Fortnightly, 146(8): 22-27

Faruqui, Ahmad, Ryan Hledik, Sam Newell, and Johannes Pfeifenberger. (2007). "The Value of Five Percent." The Electricity Journal, 20(8): 68-77.

Faruqui, Ahmad and Sanem Sergici. 2009. "Household Response to Dynamic Pricing of Electricity - A Survey of The Experimental Evidence." The Brattle Group.

http://www.hks.harvard.edu/hepg/

Federal Energy Regulatory Commission (FERC). 2008. “Assessment of Demand Response and Advanced Metering." Staff Report. Washington, DC.

Fischer, Corinna. 2008. "Feedback on Household Electricity Consumption: a tool for saving energy?" Energy Efficiency 1(1): 79-104.

Florida Public Service Commission. 2008. "Report to the legislature on utility revenue decoupling." 
http://www.psc.state.fl.us/publications/pdf/electricgas/DecouplingReport_To_Legislature.pdf (January 26, 2009)

Freeman, J. and C.D. Kolstad. 2006. Moving to markets in environmental regulation Lessons from twenty years of experience. New York: Oxford University Press.

Friedman, Barry, Lori Bird, and Galen Barbose. 2008. "Considerations for Emerging Markets for Energy Savings Certificates.” NREL Report NREL/TP-670-44072. www.nrel.gov/docs/fy09osti/44072.pdf

Fuller, Merrian. 2008. Enabling Investments in Energy Efficiency Oakland, CA: California Institute for Energy and Environment.

Furrey, Laura A., Steven Nadel, and John A. "Skip" Laitner. 2009. "Laying the Foundation for Implementing A Federal Energy Efficiency Resource Standard." ACEEE Report \#E091, Washington DC: American Council for an Energy Efficient Economy.

Gandhi, Nikhil, Paul Gray, Dennis O'Connor, Randall Vagnini, Kim Kiernan, Sharon Baggett. 2008. "On-Bill Financing of Small Business Energy-Efficiency: An Evolving Success Story." 2008 ACEEE Summer Study on Energy Efficiency in Buildings. Washington, DC: American Council for an Energy-Efficiency Economy.

Garrett, Vicki and Tomas M. Koontz. 2008. "Breaking the cycle: Producer and consumer perspectives on the non-adoption of passive solar housing in the US," Energy Policy, 36 (4): 1551-1566.

Goldman, Charles, Nicole Hopper, and Julie Osborn. 2005. "Review of US ESCO industry market trends: an empirical analysis of project data." Energy Policy, 33: 387-405

Governor's Office of Planning and Research (GORP). 2002. "California Standard Practice Manual: Economic Analysis of Demand-Side Programs and Projects." http://drrc.lbl.gov/pubs/CA-SPManual-7-02.pdf

Grant, Ruth. 2006. "Ethics and Incentives: A Political Approach." American Political Science Review, 100: 29-39

Green Building Task Force (GBTF). 2008. "Existing Building Committee Policy Review." Presentation, December 2.

http://www.seattle.gov/environment/Documents/GBTF_Policy_Synopsis_ExistBldgs.pdf 
Harmin, J., E. Vine, A. Sharick. 2007. "The Potential for Energy Savings Certificates (ECS) as a Major Tool in Greenhouse Gas Reduction Programs." San Francisco, CA: Center for Resource Solutions.

Hawkins, Julie and Scott T. Shepherd. 2008. "Enhancing listing data with MLS Green Fields." Realtor Association Executive, Summer. http://www.realtor.org/eomag.nsf/pages/GreenMLS

Hirst, Eric, and Marilyn A. Brown. 1990. "Closing the efficiency gap: barriers to the efficient use of energy." Resources, Conservation and Recycling, 3: 267-281.

Hopper, N., C. Goldman, D. Gilligam, T.E. Singer, D. Birr. 2007. A survey of the U.S. ESCO Industry: Market Growth and Development from 2000 to 2006. LBNL-62679.

http://www.ucop.edu/ciee/energyeff/financing.html

Howarth, R.B. and B Andersson. 1993. "Market barriers to energy efficiency." Energy Economics, 15(4): 262-272.

Interlaboratory Working Group (IWG). 1997. Scenarios of U.S. Carbon Reductions: Potential Impacts of Energy-Efficient and Low-Carbon Technologies by 2010 and Beyond. Oak Ridge, TN and Berkeley, CA: Oak Ridge National Laboratory and Lawrence Berkeley National Laboratory. ORNL-444 and LBNL-40533. http://enduse.lbl.gov/projects/5lab.html. Also published in Brown, Marilyn A.; Mark D. Levine; Joseph P. Romm; A.H. Rosenfeld; J.G. Koomey, 1998.

"Engineering-Economic Studies of Energy Technologies to Reduce Greenhouse Gas Emissions: Opportunities and Challenges," Annual Review of Energy and Environment, 23: 287-385.

Interlaboratory Working Group (IWG). 2000. Scenarios for a Clean Energy Future. (Oak Ridge, TN; Oak Ridge National Laboratory and Berkeley, CA; Lawrence Berkeley National Laboratory), ORNL/CON-476 and LBNL-44029. http://www.ornl.gov/sci/eere/cef/. Also published in a special Issue of Energy Policy devoted to the Scenarios for a Clean Energy Future, M. A. Brown, W. Short and M. D. Levine (eds.) Vol. 29, issue 14, 2001.

Jakob, Martin. 2006. "Marginal Costs and Co-Benefits of Energy Efficiency Investments: The Case of the Swiss Residential Sector." Energy Policy, 34.

Kaplow, Louis. 1992. "Rules versus Standards: An Economic Analysis.” Duke Law Journal, 42: 557.

Kempton, W. and M. Nieman. 1987. "Energy Efficiency: Perspectives on Individual Behavior." Washington DC: American Council for an Energy-Efficient Economy. 
King, Jennie. 2007. "M-Power: A Better Way to Keep Customers in Power." Energy Central, Energy Pulse ${ }^{\mathrm{TM}}$, http://www.energypulse.net/centers/article/article_display.cfm?a_id=1406

King, Michael, Kathleen King, and Michael Rosenzweig. 2007. "Customer Sovereignty: Why Customer Choice Trumps Administrative Capacity Mechanisms.” The Electricity Journal 20(1):38-52.

Kordjamshidi, M., and S. King. 2009. "Overcoming problems in house energy ratings in temperate climates: A proposed new rating framework." Energy and Buildings, 41(1): 125-132.

Knight, Brian. 2002. "Endogenous Federal Grants and Crowd-out of State Government Spending: Theory and Evidence from the Federal Highway Aid Program." American Economic Review 92(1): 71-91.

Kushler, Martin, Dan York, and Patti Witte. 2006. "Aligning utility interests with energy efficiency objectives: A review of recent efforts at decoupling and performance incentives." Washington, DC: American Council for an Energy-Efficient Economy.

Laitner, John A., K. Ehrhardt-Martinez, and W.R. Prindle, 2007. “A White Paper prepared for the Energy Efficiency Forum." Washington DC: American Council for an Energy-Efficient Economy. www.aceee.org/conf/07finance/financeforumwp.pdf

Lausten, Jens and Kristine Lorenzen. 2003. Danish Experience in Energy Labeling of Buildings. OPET network, http://www.opet-building.net

Leadership Group. 2006. National Action Plan for Energy Efficiency. http://www.epa.gov/solar/documents/napee/napee_report.pdf

Levy Associates. 2002. "Meter Scoping Study. Prepared for the California Energy Commission.” http://www.ucop.edu/ciee/dretd/references/documents/meterscope.pdf

Levy Associates. 2005. "Establishing the AMI Business Case Framework." Presentation. http://www.energetics.com/madri/pdfs/levy_050405.pdf

Linden, A.L., A. Carlsson-Kanyama, and B. Eriksson. 2006. "Efficient and Inefficient Aspects of Residential Energy Behaviour: What Are the Policy Instruments for Change?” Energy Policy, 34. 
Loper, Joe, Lowell Ungar, David Weitz and Harry Misuriello. 2005. "Building on Success: Policies to Reduce Energy Waste in Buildings." Report to the Alliance to Save Energy. http://www.ase.org/images/lib/buildings/Building\%20on\%20Success.pdf (accessed 11/9/06)

Lowe, R. and T. Oreszczyn. 2008. "Regulatory standards and barriers to improved performance for housing." Energy Policy, 36(12), 4475-4481.

Lucas, R.G. 2001. “Assessment of Impacts from Updating Kentucky's Residential Energy Code to Comply with the 2000 International Energy Conservation Code.” PNNL 13525. http://www.energycodes.gov/implement/pdfs/kentucky_res.pdf

Lucas, R.G. 2003. "Assessment of Impacts from Updating Iowa's Residential Energy Code to Comply with the 2003 International Energy Conservation Code.” PNNL 14431. http://www.energycodes.gov/implement/pdfs/iowa_2003_iecc_report.pdf

Lucas, R.G. 2006. "Energy Efficiency of the 2003 International Energy Conservation Code in West Virginia.” PNNL 16284. http://www.energycodes.gov/implement/pdfs/wv_res_2003_iecc.pdf

Lucas, R.G. 2007. “Assessment of Impacts from Adopting the 2006 International Energy Conservation Code for Residential Buildings in Illinois.” PNL 16266. http://www.energycodes.gov/implement/pdfs/il_2006_resfinal.pdf

Lutzenhiser, Loren. 2009. Behavioral Assumptions Underlying California Residential Sector Energy Efficiency Programs. Oakland, CA: California Institute for Energy and Environment. http://www.ucop.edu/ciee/energyeff/financing.html.

McKeown, Rosalyn. 2007. "Energy Myth Two - The Public is Well Informed About Energy." In B.K. Sovacool and M.A. Brown (Eds.), Energy and American society - Thirteen myths pp. 51-7. Dordrecht: Springer.

McKinsey \& Company. 2007. "Reducing Greenhouse Gas Emissions: How Much At What Cost?" http://www.mckinsey.com/clientservice/ccsi/greenhousegas.asp

McKinsey Global Institute. 2007. Wasted Energy: How the U.S. Can Reach its Energy Productivity Potential. http://www.mckinsey.com/mgi/reports/pdfs/wasted_energy/MGI_wasted_energy.pdf

McNeely, Phil. 2008. "Home Energy Rating Act, Bill 101 Introduced. Legislative Assembly of Ontario." 
http://www.ontla.on.ca/web/bills/bills_detail.do?locale=en $\&$ BillID=2059\&detailPage=bills_deta il_the_bill

Midwest Energy Efficiency Alliance (MEEA). 2006. "Midwest Residential Market Assessment and DSM Potential Study." http://www.mwalliance.org/image/docs/resources/MEEA-Resource$\underline{5 . p d f})$

Miguez, J.L., J. Porteiro, L.M. Lopez-Gonzalez, J.E. Vicuna, S. Murillo, J.C. Moran, E. Granada. 2006. "Review of the energy rating of dwellings in the European Union as a mechanism for sustainable energy." Renewable and Sustainable Energy Reviews, 10(1): 24-45.

Mills, E. 2007. "The Home Energy Saver: Documentation of Calculation Methodology, Input Data, and Infrastructure.” Lawrence Berkeley National Laboratory, Report No. LBNL- 51938 http://eetd.lbl.gov/emills/PUBS/PDF/Home-Energy-Saver.pdf

Montgomery County. 2008. Transcript of April 22, 2008 Montgomery County Council Meeting. http://www.montgomerycountymd.gov/content/council/pdf/transcripts/2008/04-22-08.pdf

Murtishaw, Scott and Jayant Sathaye. 2006. Quantifying the Effect of the Principal-Agent Problem on US Residential Energy Use, LBNL-59773 Rev, http://ies.lbl.gov/node/302

Nadel, S. 2006a. Energy Efficiency and Resource Standards: Experience and Recommendations. http://www.aceee.org/pubs/e063.htm

Nadel, S. 2006b. "Energy Efficiency Resource Standards: The New Kid on the Block." American Council for an Energy-Efficient Economy, NREL Seminar. http://www.docstoc.com/docs/528153/Energy-Efficiency-Resource-Standards---The-New-Kidon-the-Block

Nanda, Anupam and Stephen Ross. 2008. "The Impact of Property Condition Disclosure Laws on Housing Prices: Evidence from an Event Study using Propensity Scores." University of Connecticut Department of Economics Working Paper Series. http://www.econ.uconn.edu/working/2008-39.pdf

National Academies. 2001. "Energy Research at DOE: Was It Worth It? Energy Efficiency and Fossil Energy Research 1978 to 2000.” Committee on Benefits of DOE R\&D on Energy Efficiency and Fossil Energy, Commission on Engineering and Technical Systems, National Research Council. Washington, DC: The National Academies Press. 
National Association of Realtors (NAR). 2007. "What Buyers Want!" Highlights from the NATIONAL ASSOCIATION OF REALTORS® 2007 Profile of Buyers’ Home Features Preferences. http://www.realtor.org/Research.nsf/files/HBFeatures3.ppt/\$FILE/HBFeatures3.ppt

National Association of Realtors (NAR). 2008. "Existing Home Sales and Prices Overview." http://www.realtor.org/research/research/ehsdata

National Association of Realtors (NAR). 2009. "Profile of Home Buyers and Sellers, 2008." http://www.realtor.org/research/research/reportsbuysell

National Association of State Energy Offices (NASEO). 2008. "NASEO Home Performance with ENERGYSTAR Webinar" dated September 25, 2008.

http://www.naseo.org/taskforces/energystar/documents/Home_Peformance_with_ENERGY_ST AR_2008-09-25_Webinar.pdf

Neenan, Bernard and Ross Hemphill. 2008. "Societal benefits of smart metering investments." The Electricity Journal, 21(8): 32-45.

New York DPS. 2008. March 2008 DPS Staff Report on Recommendations for the EEPS Proceedings.

http://www.dps.state.ny.us/07M0548/07M0548_Staff_March2008_FastTrackUpdateReport.pdf

Office of Housing and Urban Development (HUD). 1992. "Energy PerformanceContracting forPublic and Indian Housing." http://www.huduser.org/Publications/pdf/energy.pdf

Ottinger, Richard L. and Rebecca Williams. 2002. "2002 Energy Law Symposium: Renewable Energy Sources for Development.” Environmental Law 32, 331-362.

Pacific Gas and Electric (PG\&E). 2008. "Residential New Construction Program." http://www.pge.com/mybusiness/energysavingsrebates/incentivesbyindustry/newconstruction/en ergystar/index.shtml

Parnell, R. and O.P. Larsen. 2005. "Informing the Development of Domestic Energy Efficiency Initiatives: An Everyday Householder-Centered Framework.” Environment and Behavior, 34.

Pfannenstiel, Jackalyne and Ahmad Faruqui. 2008. "Mandating Demand Response: California's load-management experience argues for formal DR standards." Public Utilities Fortnightly, 146(1): $48-54$ 
Poel, Bart, Gerelle van Cruchten, and Constantinos A. Balaras. 2007. "Energy performance assessment of existing dwellings." Energy and Buildings, 39(4):393-403.

Prindle, B. 2007. Quantifying the Effects of Market Failures in the End-Use of Energy. Washington, DC: American Council for an Energy-Efficient Economy, ACEEE Report Number E071, http://www.aceee.org/energy/IEAmarketbarriers.pdf accessed 8/5/07.

Prindle, W., N. Dietsch, R.N. Elliott, M. Kushler, T. Langer, and S. Nadel. 2003. Energy Efficiency's Next Generation: Innovation at the State Level. http://www.aceee.org/pubs/e031full.pdf

Radford, Bruce. 2008. "The policy: why many state regulators still have qualms about endorsing smart meters. (SELLING THE SMART GRID) (Florida. Public Service Commission)." Public Utilities Fortnightly, 146(4): 46-49.

Raven, R. P. J. M., R.M. Mourik, C.F.J. Feenstra, and E. Heiskanen. In Press. "Modulating societal acceptance in new energy projects: Towards a toolkit methodology for project managers." Energy, In Press, Corrected Proof.

Robert Mowris and Associates. 2004. "Evaluation Measurement and Verification Report for the Time-of-Sale (TOS) Home Inspection Program \#180-02.” Retrieved from http://www.calmac.org

Rogers, Joel. 2007. "Seizing the Opportunity (For Climate, Jobs, and Equity) in Building Energy Efficiency” November, Unpublished Manuscript.

Rosenquist, G., M. McNeil, M. Iyer, S. Meyers, and J. McMahon. 2004. "Energy Efficiency Standards for Buildings and Equipment: Additional Opportunities.” Prepared for the National Commission on Energy Policy, Washington, DC.

Russell, Becky. 2006. "The Relationship Between Home Energy Costs and Energy-Related Remodeling Activity.” Joint Center for Housing Studies, Harvard University. http://www.jchs.harvard.edu/publications/remodeling/n06-2_russell.pdf

Schweitzer, Martin and Bruce Tonn. 2002. "Nonenergy benefits from the Weatherization Assistance Program: A summary of findings from the recent literature.” ORNL/CON-484. Oak Ridge, TN: Oak Ridge National Laboratory. 
Scott, M.J., J.M. Roop, R.W. Schultz, D.M. Anderson, and K.A. Cort. 2008. "The impact of DOE building technology energy efficiency programs on US employment, income, and investment." Energy Economics, 30(5), 2283-2301.

Sioshansi, Fereidoon and Ali Vojdani. 2001. "What Could Possibly Be Better than Real-Time Pricing? Demand Response.” The Electricity Journal, 14(5): 39-50.

Smith, D.L. and J.J. McCullough. 2001. Alternative Code Implementation Strategies for States. Office of Building Technology, State, and Community Programs, Office of Energy Efficiency and Renewable Energy, U.S. Department of Energy.

http://www.energycodes.gov/implement/pdfs/strategies.pdf

Sovacool, Benjamin K. and Marilyn A. Brown. 2009. "Scaling the Policy Response to Climate Change," Policy and Society 27: 317-328.

Stein, Jeff Ross and Alan Meier. 2000. "Accuracy of home energy rating systems," Energy, 25(4): 339-354.

Stern, Stephanie. 2005. "Temporal Dynamics of Disclosure: The Example of Residential Real Estate Conveyancing." Utah Law Review, 57. http://ssrn.com/abstract=959726

Stern, Paul C. 2008a. "What the Research Literature Has Revealed," unpublished manuscript.

Stern, Paul C. 2008b. "Environmentally Significant Behavior in the Home," The Cambridge Handbook of Psychology and Economic Behavior, edited by A. Lewis (Cambridge, UK: Cambridge University Press), pp. 363-382.

Texas Public Utility Commission (TPUC). 2008. "Commission Report on Advanced Metering to the Legislature."

http://www.puc.state.tx.us/electric/projects/34610/Commission_Report_on_Advanced_Metering 2008.pdf

Tierney, Susan. 2008. "Pay-as-bid vs. uniform pricing: discriminatory auctions promote strategic bidding and market manipulation.” Public Utilities Fortnightly, 146(3): 40-48.

Tomain, J. and R. Cudahy. 2004. "Energy Law in a Nutshell.” St. Paul, MN: Thomson West.

U.S. Bureau of the Census. 2006. "2005 American Community Survey.” Table B25002. Housing Units by Occupancy Status. Http://www.factfinder.census.gov 
U.S. Bureau of the Census. 2007. "2006 American Community Survey." Table B25002. Housing Units by Occupancy Status. Http://www.factfinder.census.gov

U.S. Bureau of the Census. 2008a. "2007 American Community Survey." Table B25002. Housing Units by Occupancy Status. Http://www.factfinder.census.gov

U.S. Bureau of the Census. 2008b. "2007 American Community Survey 1-Year Estimates. S2504. Physical Housing Characteristics for Occupied Housing Units." Http://www.factfinder.census.gov

U.S. Department of Energy, Office of Energy Efficiency and Renewable Energy (DOE/EERE). 2003. Buildings Energy Data Book. Washington, DC, Table. 5.1.1. http://buildingsdatabook.eren.doe.gov/

U.S. Department of Energy, Office of Energy Efficiency and Renewable Energy (DOE/EERE). 2008. Buildings Energy Data Book. Washington, September, Tables 2.3.5 and 2.3.9, http://buildingsdatabook.eren.doe.gov/ChapterView.aspx?chap=2\#3

Vine, Edward. 1996. "Residential Building Code Compliance: Implications for Evaluating the Performance of Utility Residential New Construction Programs.” LBL 38382. http://www.osti.gov/bridge/servlets/purl/418459-Bsrs72/webviewable/418459.pdf

Vine, Edward and Jan Hamrin. 2008. "Energy savings certificates: A market-based tool for reducing greenhouse gas emissions.” Energy Policy 36(1) 467-476).

Volden, Craig. 2007. "Intergovernmental Grants: A Formal Model of Interrelated National and Subnational Political Decisions.” Publius, 37(2), 209-243.

World Resources Institute (WRI). 2008. "Bottom line on energy savings certificates." http://www.wri.org/publication/bottom-line-energy-savings-certificates

Wouters, Peter and Dick van Dijk. 2007. "EPBD Buildings Platform: Overall context and activities - Supersedes information paper P000. European Union, Buildings Platform.” http://www.buildingsplatform.eu/epbd_publication/doc/P039_EN_Overallcontext_p2748.pdf

Xenergy. 1996. Performance Measurement: Establishing Energy Impacts of Commercial New Construction Programs. Palo Alto, CA.: Electric Power Research Institute, Report EPRI TR106924s. 
Yang, Brian. 2005. "Residential Energy Code Evaluations: Review and Future Directions." (Building Code Assistance Program) A Joint Project of The Alliance to Save Energy, American Council for an Energy-Efficient Economy, Natural Resources Defense Council.

http://www.bcapenergy.org/files/BCAP_RESIDENTIAL_ENERGY_CODE_EVALUATION_STUDY_June200 $\underline{\text { 5.pdf }}$

Zing Communications, Inc. 2007. "2007 Commercial Energy Code Compliance Study.” http://www.aboutlightingcontrols.org/education/pdfs/2007\%20Commercial\%20Energy\%20Code \%20Compliance\%20Study.pdf

Zwahlen, Cynthia. 2007. "Loans Available for Saving Energy." Los Angeles Times.

http://articles.latimes.com/2007/may/02/business/fi-smallbiz2 
